\title{
Distributed Small-Scale Wind in New Zealand: Advantages, Barriers and Policy Support Instruments
}

A dissertation submitted in partial fulfilment of the requirements for the Degree of Master of Environmental Studies at Victoria University of Wellington

By Martin Barry

Victoria University of Wellington 


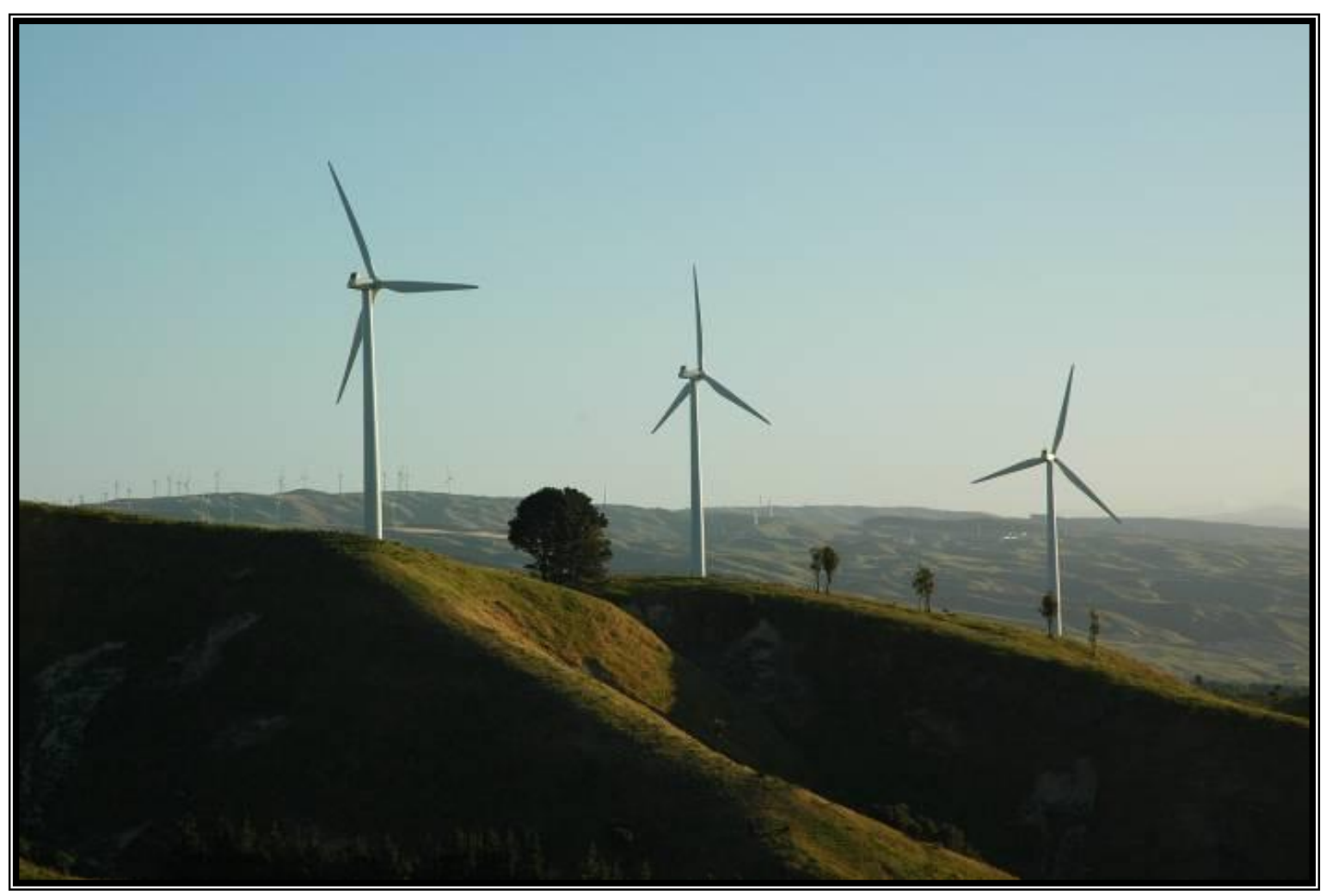

"If we want things to stay as they are, things will have to change"

Giuseppe di Lampedusa, 1896 - 1957 


\section{ACKNOWLEDGEMENTS}

I would like to extend warm thanks to the following people who made contributions to this paper. To my supervisor Associate Professor Ralph Chapman, who gave up considerable amounts of his time for consultation, and provided solid support and guidance on pulling this thing together. Jesse Nichols and Philippa Le Couteur who gladly assisted with proofreading and editing, Ben Gleisner, who helped conceptualise the structure and layout, and to Clive Anstey who provided the frontispiece photo.

Also, to those who helped with the rural survey. Ben Aicken, who created the photomontages and Colleen Kelly who helped with the statistical analysis. Finally, the School of Geography, Environment and Earth Sciences, and Greenpeace New Zealand, who provided the funding that made the survey possible. 
Despite having one of the best wind resources in the world, New Zealand's wind energy industry is growing at a slower rate than the OECD average. This is arguably due to a lack of appropriate government support, with industry development largely being left to the market. These conditions have created a wind industry with the following four characteristics: a trend toward large-scale wind farms (leading to increased local opposition), a small number of investors, a high geographic concentration of wind capacity and a limited local turbine manufacturing industry. These characteristics are arguably limiting the potential growth of New Zealand's wind industry.

This thesis investigates whether small-scale wind (SSW) farms can alleviate these limiting characteristics and thus provide for a higher rate of industry growth.

The approach is to investigate the advantages of, barriers to, and most effective policy instruments for SSW internationally, and apply these to the New Zealand context. Local research was conducted through interviews with 19 energy industry stakeholders and a rural mail survey questionnaire, to which 338 people responded.

Research found that SSW offers a number of advantages: significantly higher local public acceptance; facilitation of community ownership; the potential for distributed generation benefits and support for the local turbine manufacturing industry. Given these findings, it is argued that SSW can provide for a higher rate of industry growth in New Zealand.

The key barriers constraining SSW in New Zealand are its high cost, obtaining resource consent, a high degree of perceived investment risk, the electricity pricing system and the electricity market structure. The feed-in tariff appears to be the best policy instrument to overcome these barriers, along with the provision of investment subsidies and the classification of SSW as a controlled activity under the Resource Management Act 1991 (RMA). 


\section{TABLE OF CONTENTS}

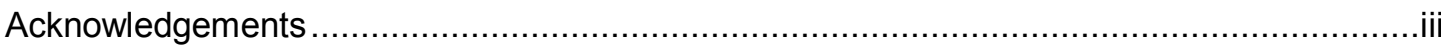

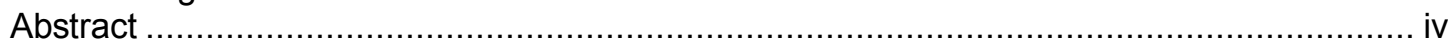

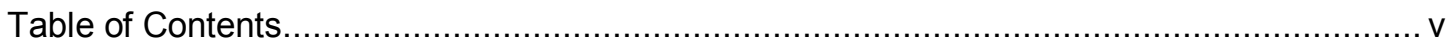

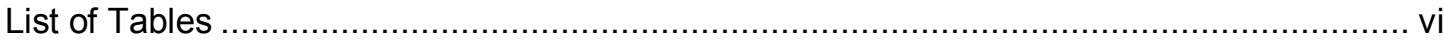

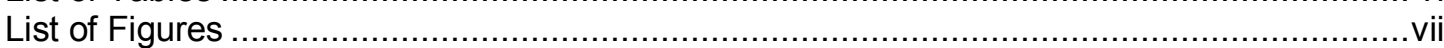

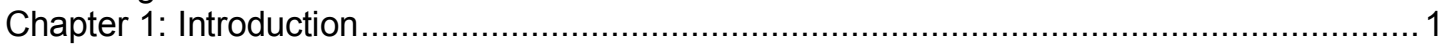

1.1 Aim

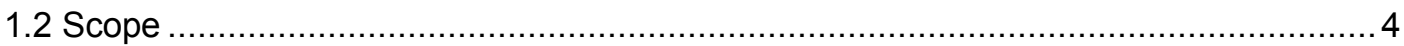

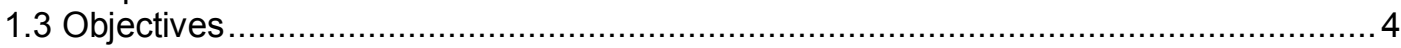

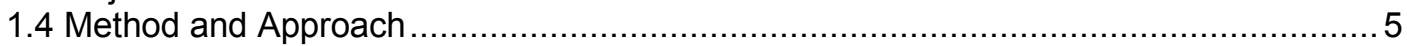

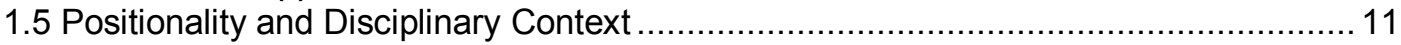

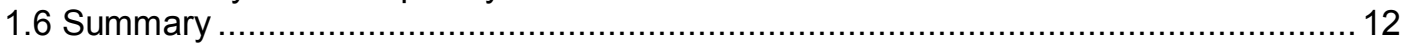

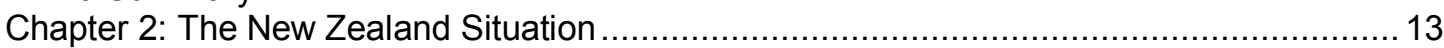

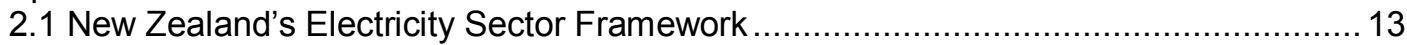

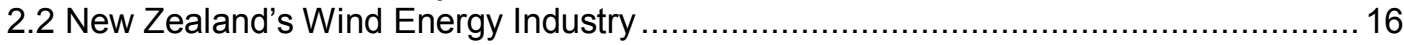

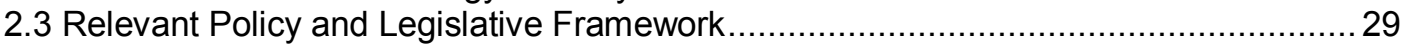

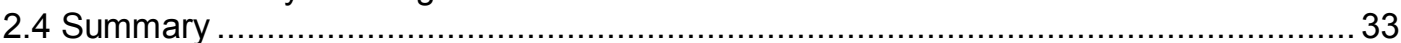

Chapter 3: The Advantages, Disadvantages and Barriers of Small-Scale Wind Internationally

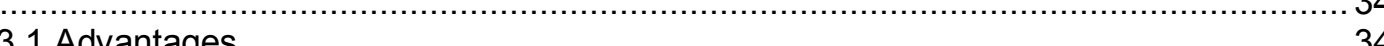

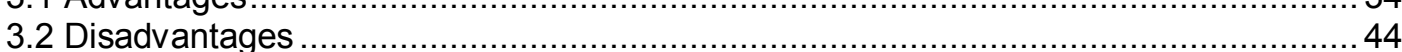

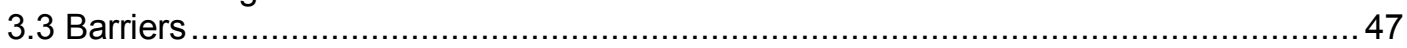

Chapter 4: Public Policy Options for Supporting Small-Scale Wind ....................................54

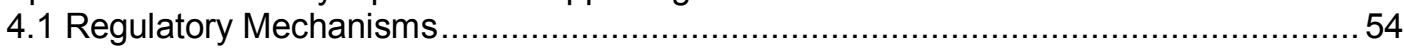

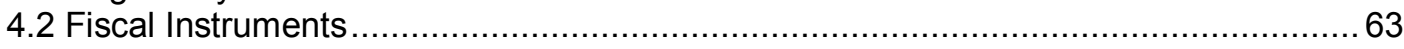

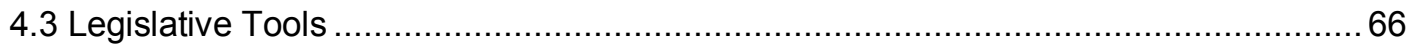

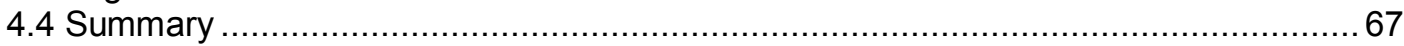

Chapter 5: Advantages and Disadvantages of SSW for New Zealand -...........................68

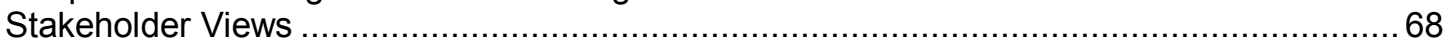

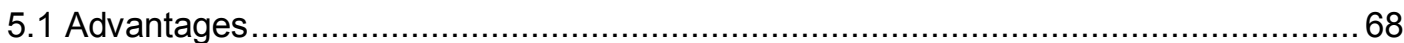

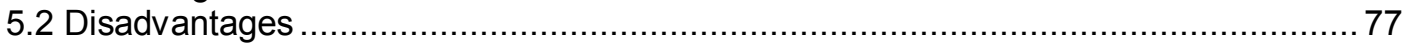

Chapter 6: Barriers to Small-Scale Wind in New Zealand -................................................. 79

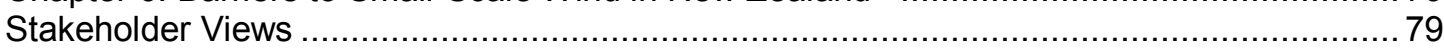

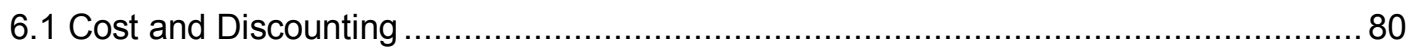

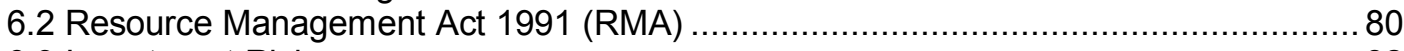

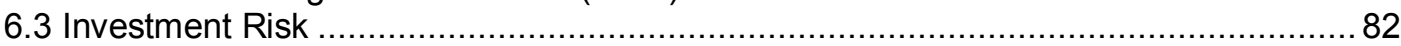

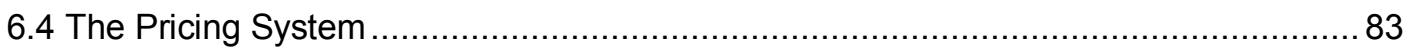

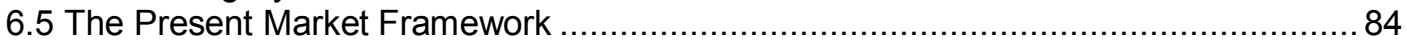

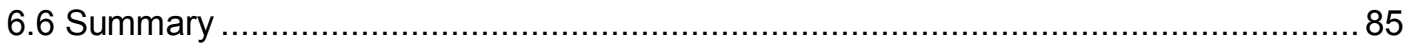

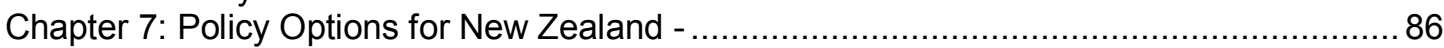

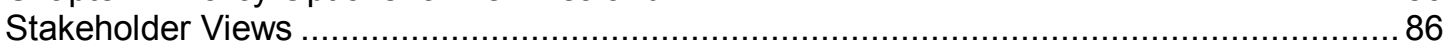

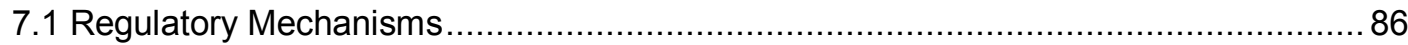

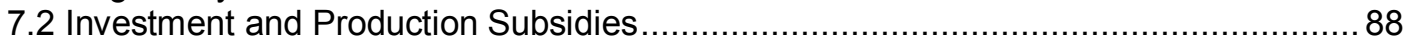

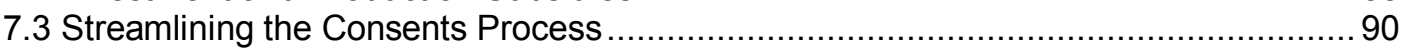

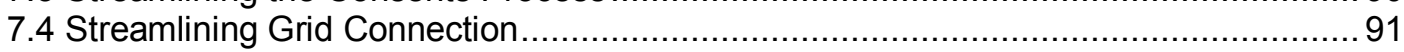

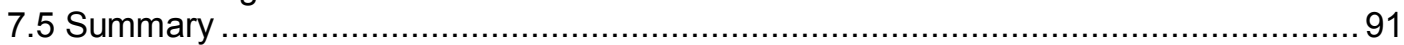

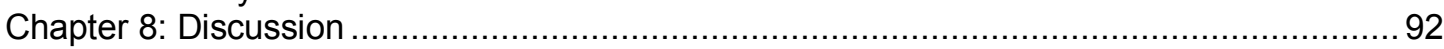

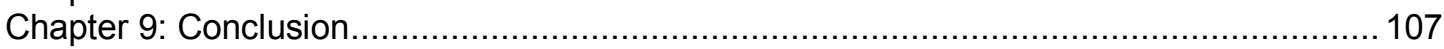

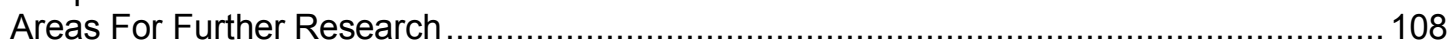

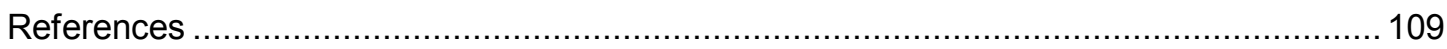

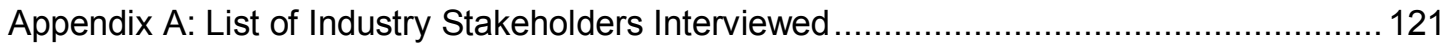

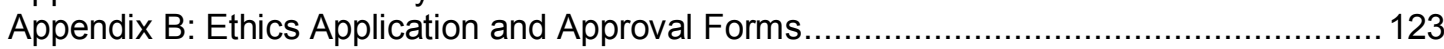

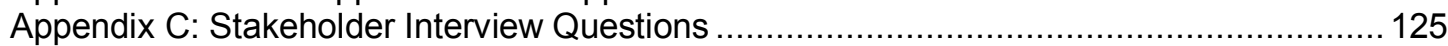

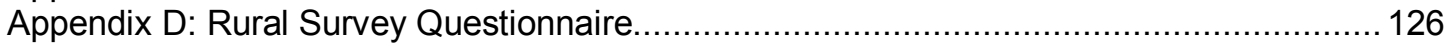




\section{LIST OF TABLES}

Table 1: The top ten countries in terms of installed wind capacity - December 2006 .1

Table 2: Sample size and response rate of the rural landowner survey ...........................

Table 3: Wind projects operating in New Zealand as at April 2007 ................................16

Table 4: Some proposed wind projects in New Zealand as at April 2007 .........................17

Table 5: Capacity factors for selected countries during 2004 and/or 2005.......................19

Table 6: A comparison of the economic benefits of community ownership with commercial

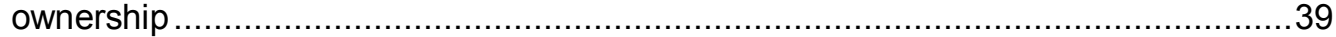

Table 7: The effect of the discount rate on generation costs .........................................48

Table 8: Applications of the various design elements of the feed-in tariff..........................56

Table 9: The world's 21 largest wind industries and the respective regulatory policy

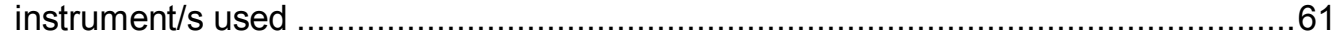

Table 10: An assessment of price- and quantity-based systems against four selected criteria.

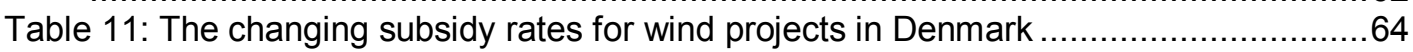

Table 12: International examples of countries where SSW developers are exempt from

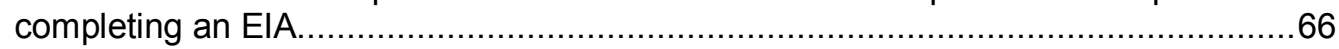

Table 13 Effects of regional variability of wholesale electricity pricing on wind project economics 


\section{LIST OF FIGURES}

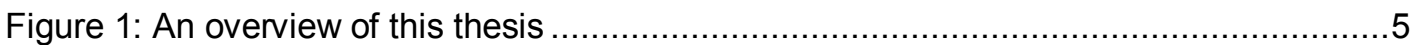

Figure 2: Investment in transmission in New Zealand along with electricity generation.......14

Figure 3: Average capacity factor of the Brooklyn turbine compared with 246 Danish turbines

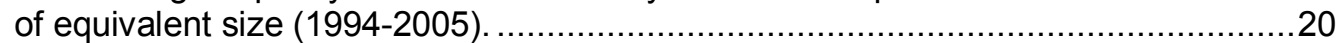

Figure 4: Number of turbines installed each year in New Zealand ...............................21

Figure 5: Cumulative wind industry growth rate in countries of similar population to New Zealand .21

Figure 6: Wind locations most suitable for wind energy development (left) and locations of projects currently operating in New Zealand (right).............................................22

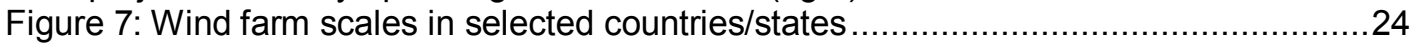

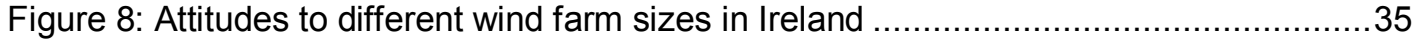

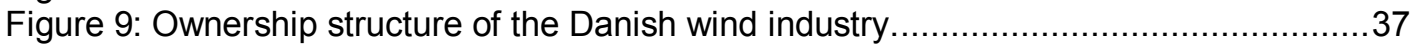

Figure 10: Location of wind projects in Denmark........................................................41

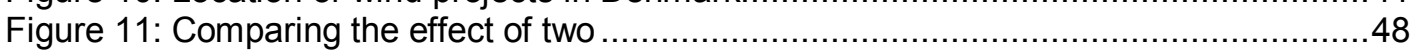

Figure 12: External costs of electricity generation in Europe ......................................5

Figure 13: Cumulative adoption of the feed-in tariff internationally ..............................55

Figure 14: Average bimonthly REC prices under MRET ...........................................58

Figure 15: Promotion models of renewable electricity in the EU .................................60

Figure 16: Rural landowners' views about small and large wind farms in their area...........69

Figure 17: Attitude towards wind farms of different sizes (among the 302 respondents who were supportive of wind power in general) .........................................................70

Figure 18: Rural landowners' level of interest towards investing in and owning a wind turbine on their land.............................................................................................. 72

Figure 19: Matching the advantages of SSW with issues in the wind and wider electricity

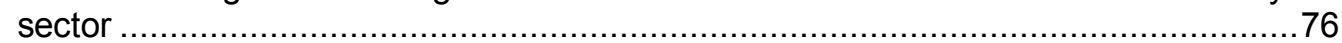

Figure 20: Number of times each barrier was ranked as being the most or second most important barrier by survey respondents ……..................................................... 79

Figure 21: New Zealand wholesale market spot prices ............................................ 82

Figure 22: Matching the barriers facing SSW in New Zealand with various policy instruments 101

Figure 23: A conceptualisation of the global trend of intervention in electricity markets .....98

Figure 24: Average monthly spot prices at selected nodes - 2005 .................................103 


\section{LIST OF ACRONYMS}

$\begin{array}{ll}\mathrm{CO}_{2} & \text { Carbon Dioxide } \\ \text { DG } & \text { Distributed Generation } \\ \text { EECA } & \text { Energy Efficiency and Conservation Authority } \\ \text { EIA } & \text { Environmental Impact Assessment } \\ \text { GPS } & \text { Government Policy Statement } \\ \text { IEA } & \text { International Energy Association } \\ \text { kWh } & \text { Kilowatt-hour } \\ \text { MED } & \text { Ministry of Economic Development } \\ \text { MfE } & \text { Ministry for the Environment } \\ \text { MOE } & \text { Minister of Energy } \\ \text { MW } & \text { Megawatts } \\ \text { NIMBY } & \text { The 'Not-In-My-Backyard' phenomenon } \\ \text { NPV } & \text { Net Present Value } \\ \text { PCE } & \text { Parliamentary Commissioner for the Environment } \\ \text { PRE } & \text { Projects to Reduce Emissions - A programme of MfE } \\ \text { RMA } & \text { Resource Management Act 1991 } \\ \text { SSW } & \text { Small-Scale Wind }\end{array}$




\section{CHAPTER 1: INTRODUCTION}

In recent years wind energy has moved from a marginal and relatively under-utilised technology to a widely recognised mainstream electricity generation source. The wind industry is one of the fastest growing energy industries in the world, employing over 235,000 people and with over US $\$ 30$ billion in global installations (IEA, 2006b). In the last ten years global wind capacity has grown from 7,575 MW in 1997 to $73,904 \mathrm{MW}$ by the end of 2006 , representing an average annual growth rate of $29 \%$ (WWEA, 2007). The leading ten countries in terms of installed wind capacity are shown in Table 1.

Table 1: The top ten countries in terms of installed wind capacity - December 2006

\begin{tabular}{|l|r|}
\hline Country & $\begin{array}{r}\text { Installed Wind } \\
\text { Capacity 2006 } \\
\text { (MW) }\end{array}$ \\
\hline Germany & 20,622 \\
\hline Spain & 11,615 \\
\hline US & 11,603 \\
\hline India & 6,270 \\
\hline Denmark & 3,136 \\
\hline China & 2,405 \\
\hline Italy & 2,123 \\
\hline UK & 1,963 \\
\hline Portugal & 1,650 \\
\hline France & 1,565 \\
\hline
\end{tabular}

Source: WWEA (2007)

The growth in the global wind industry has largely been in response to three major drivers: climate change; the decline of global fossil-fuel reserves; and the need for security of energy supply. As a result of these issues, many countries view wind as playing a key role in the transition to a more sustainable energy supply. New Zealand is one of these countries (EWEA, 2007).

In New Zealand there is currently $171 \mathrm{MW}$ of wind energy capacity installed, with 181 turbines, providing around $2 \%$ of New Zealand's total electricity requirement (NZWEA, 2007). 
Arguably, New Zealand's wind industry is failing to reach its full potential. Despite our excellent wind resource, the industry's growth rate is slower than the OECD average (EECA, 2006). According to Ashby (2004: 5) New Zealand is: "well behind other nations in the use of our wind resource". One commentator has observed that: "New Zealand's wind energy market, [is] long thought to be one of the world's most promising yet most moribund" (J. Hyde, 2006: 50).

This slow growth rate is arguably due to a lack of adequate support policy. The only policy used to date is the Projects to Reduce Emissions (PRE) programme, which ran between 2003 and 2004 (NZCCO, 2007). Many other countries have implemented more comprehensive policy schemes and have experienced considerably higher rates of growth as a result, despite having a far inferior wind resource. A review of the literature on wind industries overseas suggests that there is a higher rate of growth when the following factors are present:

- A diverse scale of developments from small-scale to large-scale wind

- High public acceptance of wind farms

- A diversity of investors from individuals to large corporations

- Wide geographic dispersal of turbines and wind farms

- A local turbine manufacturing industry.

The literature suggests that these factors are unlikely to be achieved through the market alone i.e. without government intervention, and that they have been achieved through a variety of policy instruments. The lack of adequate government support and the heavy reliance on the market in New Zealand has failed to achieve these factors, and has created a wind industry with the following characteristics:

- A tendency towards large-scale developments, leading to increased levels of public opposition

- Limited flow of investment

- High geographic concentration of wind capacity

- Limited local turbine manufacturing capacity.

It could be argued that these conditions are limiting the potential development of wind energy in New Zealand. Therefore, as a result of a lack of policy - which has led to 
an industry with the characteristics described above - the New Zealand wind industry has experienced a slow rate of growth.

This thesis asks whether developing small-scale wind (SSW) in New Zealand could alleviate these limiting characteristics and thus provide for a higher rate of growth of the wind industry in New Zealand. SSW is defined as "three or less utility-scale wind turbines that are connected to local distribution networks".

A review of the literature suggest that SSW has not yet been studied in any great detail in New Zealand. In November 2006 the Parliamentary Commissioner for the Environment (PCE) tabled a paper that relates to this area, entitled Wind Power, People and Place. This paper had a far broader approach, discussing the tensions between wind energy and its impacts on landscapes. However it did address some relevant themes such as wind farm scale and community ownership.

The report argued that New Zealand should develop wind farms of all scales, from SSW to large-scale wind farms. In doing so, the industry would more likely optimise the integration of wind energy into New Zealand's landscapes and communities (PCE, 2006).

A study by the Ministry of Economic Development (MED) and the Energy Efficiency and Conservation Authority (EECA) investigated the extent to which wind energy can be integrated into New Zealand's electricity supply system. This study highlighted the potential system benefits of having a high geographic dispersal of SSW projects throughout the country (MED/EECA, 2005).

Given the limited depth of relevant literature in New Zealand, the issues facing New Zealand's wind industry, the potential solutions offered by SSW, and the fact that wind policy is currently being developed under the New Zealand Energy Strategy, it seems timely to investigate this research topic. 


\subsection{Aim}

The aim of this thesis is to establish whether distributed, SSW generation in New Zealand is worthy of public policy support and, if so, determine the most effective policy instruments to promote its uptake.

\subsection{Scope}

SSW can be used in on-site power generation and in islanded generation, but these two uses are not covered in this research. This thesis focuses on distributed SSW projects that are connected to local lines networks. This is to enable a more thorough investigation of the research topic, leaving the other two more specialised uses to be explored in further research.

\subsection{Objectives}

The specific objectives of the thesis are to:

- Summarise the progress of New Zealand's wind energy industry to date and describe the current policy and legislative framework (Chapter 2).

- Identify the advantages and disadvantages of SSW internationally, along with the barriers limiting its uptake (Chapter 3).

- Identify the main public policy instruments used internationally to support SSW (Chapter 4).

- Identify the New Zealand industry perceptions of the advantages and disadvantages of SSW in New Zealand (Chapter 5).

- Identify the New Zealand industry perceptions of the barriers constraining the uptake of SSW in New Zealand (Chapter 6).

- Identify the most appropriate policy instruments for supporting SSW in New Zealand, as perceived by key industry stakeholders (Chapter 7).

- Summarise and discuss the key findings from international and local research and its application to the New Zealand wind energy industry (Chapter 8). 
Figure 1 below lays out the structure of this thesis:

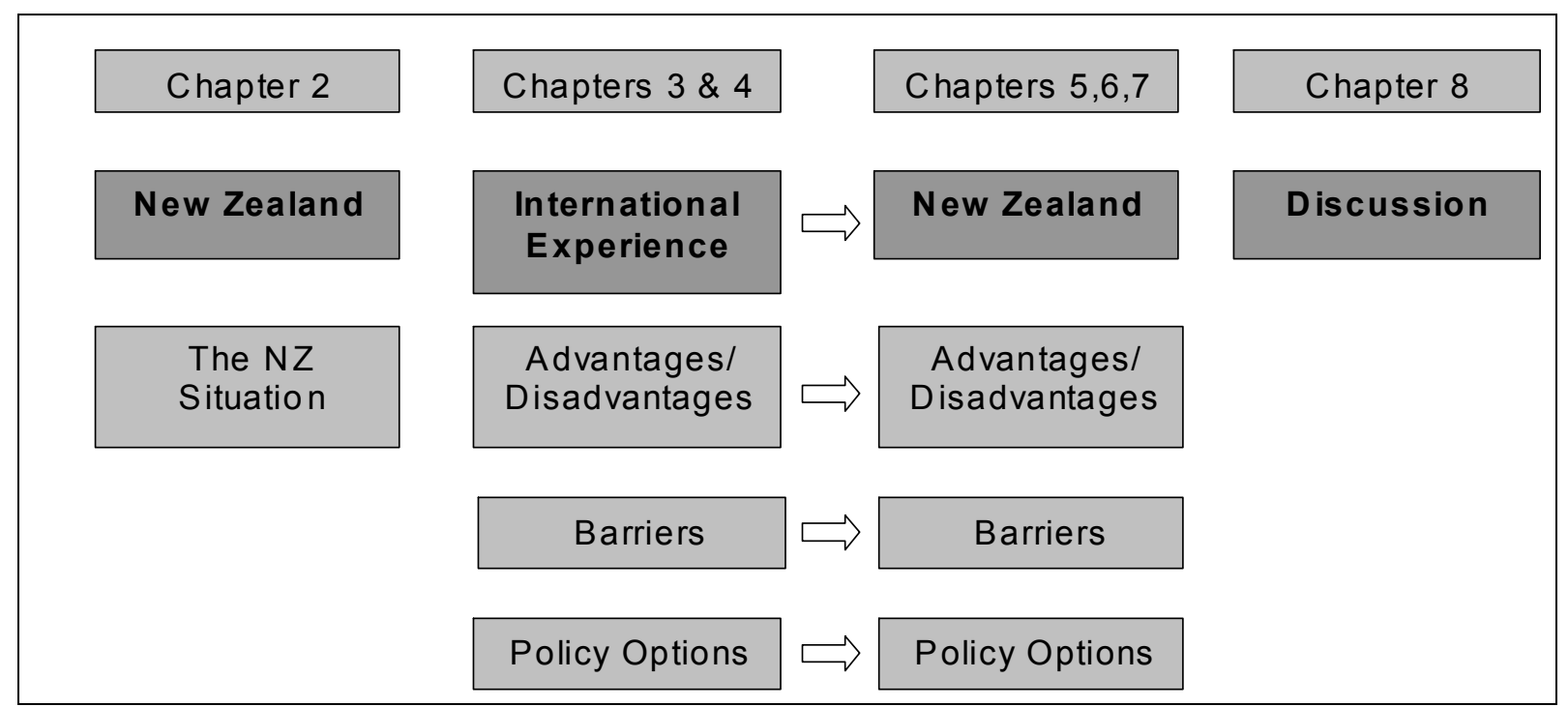

Figure 1: An overview of this thesis

\subsection{Method and Approach}

My purpose with this thesis is to illuminate issues relating to the development of New Zealand's wind industry, and in particular, SSW in New Zealand. This research is exploratory, as it involves working in an area that has not yet been studied in detail in New Zealand. The study also aims to add to the understanding of how the New Zealand public perceive wind energy, an area in which little statistical research has been undertaken to date (see section 1.4.3.2). Also, it may contribute to the establishment of community ownership of SSW in New Zealand.

Information was collected using a data triangulation strategy, because I wanted to use different methods and sources to see whether the findings corroborate each other (Silverman, 2005). Information was gathered from a literature review, interviews (qualitative) and a questionnaire survey (qualitative and quantitative). This strategy was also advantageous because information can be obtained more effectively and is likely to be more representative if based on a combination of data collection strategies (Silverman, 2005) 


\subsubsection{Background and Conceptual Framework}

In Chapter 2, I provide background on New Zealand's energy situation, including key institutions such as legislation and policy, with a more detailed discussion on the wind energy industry. Sources for this chapter included publications from government and private agencies, the New Zealand Wind Energy Association website and various newspaper articles.

A conceptual framework for the analysis of SSW is provided in Chapters 3 and 4. Sources for these chapters included academic journals, international wind energy association websites, the Wind Power Monthly magazine, foreign newspapers and publications from foreign government departments. Additional sources included publications of various international organisations such as the International Energy Agency, the European Wind Energy Association, the Global Wind Energy Council and the Renewable Energy Network.

\subsubsection{Applying the Approach to New Zealand}

As noted, both qualitative and quantitative research methods were used in the research. Qualitative research was conducted through a series of interviews and the quantitative research through a mail-out survey.

\subsubsection{The Interviews}

Interviews were conducted with 19 stakeholders in the energy industry, in order to ascertain their views on the advantages, disadvantages, barriers and best policy options for SSW in New Zealand. Interviewees included: wind farm developers, energy consultants, the Electricity Commission, the Parliamentary Commissioner for the Environment, the Electricity Networks Association, New Zealand Meat and Wool, Wellington Regional Council and the Major Electricity Users Group. A full list of people interviewed and their respective organisations is found in Appendix A.

I selected these interviewees using purposeful sampling techniques, where participants were chosen on the basis of their relevance to the research (Hay, 2005).

I recruited the interviewees by internet searches, literature reviews, white pages or by snowballing (where one interviewee recommends another interviewee). Initial 
contact was made with every interviewee by phone and each one was willing to be interviewed. 16 interviews were face-to-face, two were by telephone and one was through email. Interviews were recorded using note taking. Interviewees were given the option of having their views identified and quoted in this thesis, or having them presented anonymously. These options were stated on the Ethics Approval form (Appendix B), which was given to each interviewee before the interview.

Interviews were in a semi-structured format and based around six questions that are listed in Appendix C. The semi-structured format was chosen for a number of reasons. First, it provided flexibility in the way issues were addressed by the interviewees, meaning I could obtain a greater breadth of perspective and information. For example, discussions with people who opposed the idea of government supporting the wind industry tended to branch off into ideological debates over ethics and sustainability. It was through these discussions that I gained better insight into the rationale behind their views. Second, it meant interviewees could comment freely on other issues they deemed relevant, and these additional comments are included in this thesis.

In reporting on these interviews I have summarised what I perceived as the key points raised by the stakeholders. I made considerable effort to present the stakeholders' views in an objective, impartial way. In particular, I made full effort to fairly represent the views of those interviewees I personally don't agree with, and to fairly explain their rationale for holding that view.

The quotes I used from these interviews have been used with full ethical consideration. That is, the context in which they were taken from the interviews is the same as the context in which they are placed in this thesis.

\subsubsection{The Rural Survey}

The quantitative research component of this thesis was carried out through a mail-out survey to every rural landowner listed on New Zealand Post's Rural Delivery Network in the Masterton and New Plymouth regions. The sample size and response rate are provided in Table 2. 
Table 2: Sample size and response rate of the rural landowner survey

\begin{tabular}{|c|c|c|c|}
\hline Masterton & \multicolumn{2}{|c|}{ New Plymouth } & Both Regions \\
\hline $\begin{array}{l}\text { No. residences in region } \\
\text { (No. surveys sent out) }\end{array}$ & 861 & 759 & 1620 \\
\hline No. responses & 230 & 108 & 338 \\
\hline Response rate (\%) & $26.7 \%$ & $14.2 \%$ & $20.9 \%$ \\
\hline
\end{tabular}

In reviewing the literature, it appears that this survey is the third largest wind energy public perception survey conducted in New Zealand to date. Previous studies conducted in New Zealand include: a national survey for EECA by the MRL Research Group in 1994 (1,000 responses) (Baines, 2005) and again in 2004 by (UMR, 2004) (750 responses); a survey of Franklyn District residents regarding Project Awhitu by (Watts, 2005) (205 responses); a survey of Ashurst residents regarding Project Te Apiti by Taylor Baines and Associates in 2005 (49 responses) and two additional surveys in the same area by Shepherd in 2003 and 2005 (combined 77 responses) (Baines, 2005); a survey of Makara residents regarding Project West Wind by (Gleisner et al., 2005) (50 responses); and a survey of residents living near the then proposed Tararua Wind Farm by (Berg, 2003) (nine interviewees).

The survey questionnaire had six questions: most using a Likert-scale format. The full survey form is provided in Appendix $D$. These questions are listed below, along with the reasons why I included them in the survey.

Q1. Do you support/oppose wind power as a means of generating electricity in New Zealand? $\begin{array}{ccccc}1 & 2 & 3 & 4 & 5 \\ \text { Strongly support } & \text { Support } & \text { Indifferent } & \text { Oppose } & \text { Strongly oppose }\end{array}$

Firstly, this question was included in the 2004 survey by EECA, where it found that $82 \%$ of New Zealanders approve of wind energy as a means of generating electricity in New Zealand (UMR, 2004). If I obtained similar results to this survey it would help validate my findings, implying that the rest of the survey results might be representative of most of New Zealand. Secondly, those respondents who were either very positive or positive toward wind in general had their responses tabulated against results in questions 2 and 3. This was to see if the Not-In-My-Backyard (NIMBY) phenomenon is different for large versus SSW farms. 
Q2. Please imagine a new small-scale (2 turbine) wind farm placed in your district. How would you view the impact of such a wind farm? (A photomontage of a 2-turbine wind farm was provided).

Q3. Now please imagine a larger wind farm (14 turbines) in your district. How would you view the impact of such a wind farm? (A photomontage of a 14-turbine wind farm was provided).

$\begin{array}{ccccc}1 & 2 & 3 & 4 & 5 \\ \text { Strongly support } & \text { Support } & \text { Indifferent } & \text { Oppose } & \text { Strongly oppose }\end{array}$

I wanted to see if people perceive the idea of SSW being developed in their local area any differently to a large-scale wind farm. Similar studies have been done overseas, where it was found that people tend to be more positive about SSW being developed in their local area (see section 3.1.1). I wanted to see if the same was true in New Zealand. Perception studies conducted in New Zealand have asked people how they feel about a wind farm being built in their area under a number of assumptions, such as "if you could not see or hear the windmills from your house" and "if you could not hear them, but could see them as distant windmills on the skyline from your house" (UMR, 2004). An investigation of how New Zealanders view different scales of wind farms has not yet been conducted here (PCE, 2006).

Q4. In Germany and Denmark community ownership of wind farms is widespread. For example, more than 1,000 wind turbines in Denmark are owned by farmers.

Is the idea of installing a wind turbine on your land appealing to you?

Q5. Imagine the government provided financial assistance to ensure the return on a private wind turbine investment was comparable with other forms of investment, like government 10year bonds. Under these conditions would this you be interested in investing in and installing a wind turbine on your land?

$\begin{array}{ccccc}1 & 2 & 3 & 4 & 5 \\ \text { Very Interested } & \text { Possibly Interested } & \text { Not sure/ } & \text { Probably } & \text { Definitely } \\ & & \text { Don't know } & \text { Not Interested } & \text { Not Interested }\end{array}$

I wanted to investigate the level of willingness of farmers to invest in a turbine on their land. I did not find any New Zealand studies researching this question, and research of this nature is a necessary first step if community ownership were to be introduced into New Zealand. Question 5 was included to see if the introduction of government support would give a different response. 
Q6. Do you perceive any barriers to installing a wind turbine on your farm? Please rank the following from 1 to 7 (with 1 being the greatest barrier to 7 the least). Write N/A next to any you don't consider to be a barrier.

1. Upfront cost, 2. Getting an adequate sale price for the electricity generated, 3. Getting resource consent for installing the turbine, 4. Long-term security of the investment, 5 . Getting access to the local electricity lines network, 6 . Obtaining adequate and reliable information

(e.g. technical, legal, financial), 7. Adverse impact, e.g. visual, noise etc.

I wanted to see if the barriers identified in the interviews were similar to those identified by potential developers (in this case rural landowners). Respondents were also asked to add any other barriers they considered relevant, and some of these comments are included in chapter 6.

The purpose of this survey was to support the overall objectives of this thesis. That is, to test the hypothesis that an advantage of SSW is that people are more accepting of them being developed in their local area compared with large wind farms.

Secondly, to identify the perceived barriers toward SSW as perceived by rural landowners.

The Masterton and New Plymouth regions were selected because they are of similar size, and were both identified by EECA as having a good wind resource (see section 2.2.2). Also, I wanted to see if people who live near turbines (Masterton region where there are two existing wind farms) view wind energy any differently to people who do not (New Plymouth - where there are no wind farms). Local and international research has found that people living near turbines are more accepting of wind energy than those people who do not (see section 5.1.1).

Rural regions were chosen over urban areas because the uptake of SSW overseas has generally been more prevalent in rural areas, and part of the purpose of this survey was to analyse the scope for developing SSW in rural New Zealand. Also, urban wind turbines are, with present technology, much less likely to be accepted.

A pilot survey was developed and tested on 10 fellow students. This was to check the quality of the questions and ensure the survey form was easily answered, selfexplanatory and without ambiguity. The survey was expected to take the respondent between five to ten minutes to complete. 
This survey may be subject to a possible response bias. Wind energy is a very contentious topic in New Zealand and people generally have strong feelings about wind, whether it be for or against. These attitudes may have influenced whether people completed the survey form or not.

Graphs were done using Microsoft Excel. Statistical assessments and tabulations were done with SPSS, with the following tools being used: ANOVA Tukey Post-hoc comparison, chi-square and paired sample t-test. Using traditional statistical convention, I deemed a p-value of $<0.05$ as being statistically significant.

Finally, although the $26.7 \%$ response rate from the Masterton region is considered statistically viable, the lower $14.2 \%$ response rate from New Plymouth is not. Regardless, the response rate from both regions taken together is viable (20.9\%) and therefore the combined data is referred to in this thesis. The validity of these findings could be tested by replicating this study in other rural regions throughout New Zealand.

\subsection{Positionality and Disciplinary Context}

I am in favour of wind energy becoming a widely used electricity generation source in New Zealand. It should therefore be noted that I bring a degree of bias and subjectivity to the issues discussed in this thesis. Nevertheless, as noted above, I have endeavoured to distance my personal views from the process of data collection and interpretation.

The topics in this thesis cross three main disciplines: environmental economics; the social sciences; and environmental policy. Wind energy is a highly relevant topic in environmental economics discourse, as it involves discussion on a number of relevant issues. These include internalising the full cost of electricity generation, discounting, justifying government intervention for a public good, the preservation of natural capital and the ever-increasing importance of energy supply security. The key social science issues covered are the importance of aesthetic factors in relation to wind energy (perception of landscape impacts), and the concept of community ownership. Finally, environmental policy is also drawn on as this thesis discusses government's use policy mechanisms employed to enhance environmental sustainability, energy transition management, and draws in a comparative way on other countries' wind generation policy approaches. 


\subsection{Summary}

The use of both qualitative and quantitative methods allowed me to gain a broader insight into the issues surrounding SSW internationally and in New Zealand. It enabled me to assess whether the advantages and barriers perceived by stakeholders in the interviews were similar to those perceived by stakeholders on the ground (in this case rural landowners). It also enabled me to test these findings against research conducted overseas. A better understanding of these issues is important because it not only helps clarify issues in relation to government support, but also in determining what form that support might take. 


\section{CHAPTER 2: THE NEW ZEALAND SITUATION}

This chapter includes a description of the current electricity framework in New Zealand, along with the current status of wind generation. It concludes with a description of the policy and legislative framework that is relevant to distributed, SSW in New Zealand.

\subsection{New Zealand's Electricity Sector Framework}

\subsubsection{Electricity Market Structure}

New Zealand's electricity market was deregulated in 1999, when it moved from a state-owned, centrally planned monopoly structure to a more competitive generation and retail market, with a mix of private and state-owned companies. Most of the dominant players in the market are vertically-integrated, meaning they are electricity generators as well as retailers. As such, they are commonly referred to as 'gentailers'. Around $90 \%$ of generation capacity is provided by five companies Meridian Energy, TrustPower, Genesis Energy, Contact and Mighty River Power and the first four of these cover about $80 \%$ of the retail market (EC, 2007). The lines sector is managed by about 28 lines companies throughout the country, who are mostly owned by community electricity trusts (EC, 2007).

\subsubsection{Key Issues}

New Zealand's electricity sector is currently facing four key problems.

Lack of Competition in the Generation Market: Around $90 \%$ of electricity is generated by only five companies, suggesting there is a lack of competition in the generation market. This situation is currently being investigated by the Electricity Commission in its State of Competition and Barriers work (EC, 2007).

Investment Shortage in Transmission: In recent years there has been a notable lack of investment in New Zealand's transmission network. Meridian Energy CEO Keith 
Turner believes the transmission grid in New Zealand is so overworked that some lines cannot be taken out of action for servicing (Daniels, 2005). As seen in Figure 2 no new transmission length has been built in New Zealand since 2000.

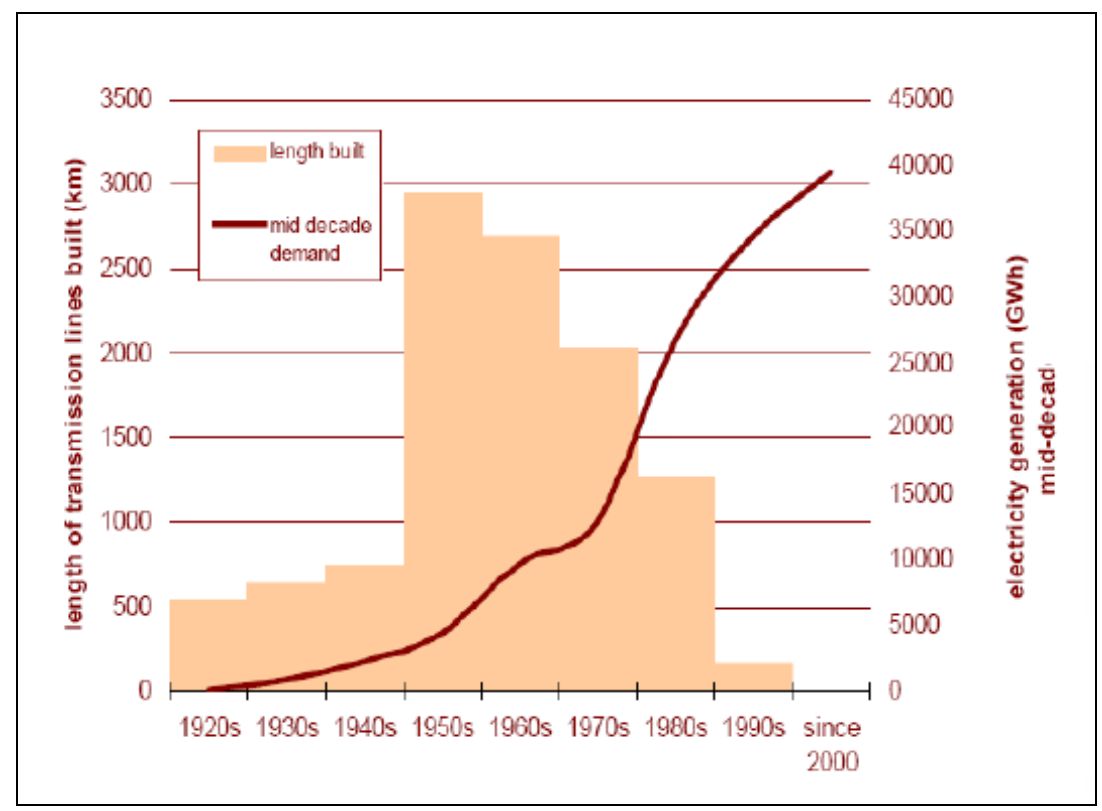

Figure 2: Investment in transmission in New Zealand along with electricity generation Source: (Hunt, 2006).

Mighty River CEO Doug Heffernan believes transmission is the key issue for the electricity industry, and that building new generation capacity closer to regions of high demand is part of the solution (NZPA, 2006). Despite this, investment in new generation continues to be mostly large-scale plants, located in regions remote from demand. Only a very small proportion (around 3\%) of installed electricity generation capacity occurs in amounts of less than $10 \mathrm{MW}$.

Increasing Concerns Over Security of Supply: New Zealand's electricity requirement increases by around $2 \%$ per year, yet the potential for expanding existing generation sources is either limited or likely to become increasingly expensive. New Zealand's main gas reserve - the Maui gas field - is expected to be exhausted by 2010 , and while a recent assessment of known gas reserves indicates enough indigenous gas supply to 2016-2018, future supplies beyond that are uncertain (ACG, 2006; MED, 2006). Geothermal electricity generation is expected to nearly double to $15 \%$ by 
2025 , but emissions gains from this look to be offset by the declining contribution of gas (MfE, 2005). Global oil reserves have been increasingly prone to issues of supply availability and rising prices. Most of New Zealand's coal reserves are lowquality, dirty-burning lignite (MED, 2006) which will become increasingly expensive as a world price is placed on carbon. There is also limited potential for future development of large-scale hydro, because many suitable rivers lie in protected areas (IWPDM, 2006).

Declining Contribution of Renewables: The proportion of electricity generated from renewables has steadily declined in recent years. New Zealand has traditionally generated a large proportion of its electricity from hydro. In 1980 around $73 \%$ of electricity was generated by hydro stations, but by 2005 this fell to around $61 \%$ (MED, 2007b). The contribution of thermal generation has increased steadily, reaching a record high in March 2006 (StatisticsNZ, 2006). While countries such as the UK and Denmark have increased the proportion of their electricity generated by renewables, in New Zealand it has fallen, despite a rise in wind generation.

As a result of increased thermal generation, $\mathrm{CO}_{2}$ emissions from electricity generation rose 134\% between 1990 and 2005 (MED, 2007b). New Zealand has ratified the Kyoto Protocol and is currently facing a Kyoto deficit of at least 41.2 million units of $\mathrm{CO}_{2}$ equivalent (MfE, 2006). New Zealand will likely face a penalty of the world price of carbon for every tonne of $\mathrm{CO}_{2}$ emitted between 2008-2012. In the longer term this price is likely to increase. As at $31^{\text {st }}$ January, 2007, New Zealand's Kyoto liability was estimated to be around $\$ 578$ million (Treasury, 2007). But if the world price of carbon reflects current prices on the European Emission Trading Scheme (around $\mathrm{NZ} \$ 30$ per tonne of $\mathrm{CO}_{2}$ ) then liability would be $\$ 1.2$ billion or more.

In summary, there is a shortage of competition in the generation market and an under-investment in transmission capacity in New Zealand. Also, as the issues of energy supply security and climate change become more pressing, there will be an increased need to build a more sustainable energy supply. Given that wind has been assigned a key role in this transition by the central government, it is important the wind industry grows at a relatively constant and sustainable rate and in a way that fully optimises the available wind resource. 


\subsection{New Zealand's Wind Energy Industry}

\subsubsection{A Brief History}

At present, there is just less than $171 \mathrm{MW}$ of wind energy capacity installed in New Zealand. This is made up of 181 turbines, contributing around $2 \%$ toward the country's total electricity requirement. Table 3 below provides detail on the projects currently operating in New Zealand. Because attention has frequently focussed on the period of time needed to gain resource consent under the RMA for new developments, data on these are also included.

Table 3: Wind projects operating in New Zealand as at April 2007

\begin{tabular}{|l|l|l|l|l|l|l|}
\hline Date & Project & Location & Developer & $\begin{array}{l}\text { Number } \\
\text { of } \\
\text { turbines }\end{array}$ & $\begin{array}{l}\text { Total } \\
\text { size } \\
\text { (MW) }\end{array}$ & $\begin{array}{l}\text { Time taken to } \\
\text { get resource } \\
\text { consent }\end{array}$ \\
\hline 1993 & Brooklyn Turbine & Wellington & Meridian Energy & 1 & 0.225 & 3 months \\
\hline 1997 & Hau Nui & Wairarapa & Genesis Energy & 7 & 3.5 & $\begin{array}{l}1 \text { month } \\
\text { (non-notified) }\end{array}$ \\
\hline 1999 & Tararua I & $\begin{array}{l}\text { Tararua } \\
\text { Ranges, } \\
\text { Manawatu }\end{array}$ & Trustpower & 48 & 31.7 & 4 months \\
\hline 2003 & Gebbies Pass & $\begin{array}{l}\text { Banks } \\
\text { Peninsula, } \\
\text { Christchurch }\end{array}$ & Windflow NZ & 1 & 0.5 & 5 months \\
\hline 2004 & Tararua II & $\begin{array}{l}\text { Tararua } \\
\text { Ranges, } \\
\text { Manawatu }\end{array}$ & Trustpower & 55 & 36 & 4 months \\
\hline 2004 & Te Apiti & $\begin{array}{l}\text { Ruahine } \\
\text { Ranges, } \\
\text { Manawatu }\end{array}$ & Meridian Energy & 55 & 90.75 & 5 months \\
\hline 2004 & Hau Nui expansion & $\begin{array}{l}\text { Wairarapa } \\
2005\end{array}$ & Southbridge & $\begin{array}{l}\text { Southbridge, } \\
\text { Canterbury }\end{array}$ & Energy & \\
\hline 2006 & Te Rere Hau & $\begin{array}{l}\text { Tararua } \\
\text { Ranges, } \\
\text { Manawatu }\end{array}$ & $\begin{array}{l}\text { Wind Farm } \\
\text { Developments } \\
\text { Ltd }\end{array}$ & 5 & 2.5 & 9 months \\
\hline
\end{tabular}

New Zealand's wind industry began with the installation of a Danish turbine at Brooklyn, Wellington. The turbine was installed as part of a research project and is owned by Meridian Energy.

Hau Nui was New Zealand's first wind farm and claims to be the world's first wind farm built without without any form of subsidy or market support (IEA, 2002). 
The Tararua wind farm is the country's largest and is being built in three stages. The third stage is under construction and is expected to be operational by July 2007 (NZWEA, 2007).

Te Apiti was New Zealand's first wind farm to be connected to the national grid, and is located on an adjacent mountain range to the Tararua wind farms, at the western end of the Manawatu Gorge. Te Rere Hau currently has five turbines but has obtained resource consent to extend this to 97 turbines.

The Southbridge turbine is located on a private farm near Christchurch and is owned and operated by Energy ${ }^{3}$. The turbine output is sold to Meridian Energy under a long-term contract. The Gebbies Pass turbine was installed as a prototype and is owned and operated by New Zealand's sole turbine manufacturer, Windflow Technology Ltd. Its output is purchased by Christchurch City Council.

Te Apiti, Te Rere Hau, Tararua II and the Hau Nui extension received government support under the PRE scheme (see section 2.3.4).

At the time of writing two wind farms totalling $151 \mathrm{MW}$ were under construction (Tararua III and White Hill), which are expected to be on line by July and June 2007 respectively. According to the New Zealand Wind Energy Association CEO Fraser Clark, there are no new projects planned for construction for 2008 and 2009. More than $300 \mathrm{MW}$ of wind capacity has secured consent in the past 12 months and just over $600 \mathrm{MW}$ is currently going through the consent process. Table 4 gives details on some of these proposed projects.

Table 4: Some proposed wind projects in New Zealand as at April 2007

\begin{tabular}{|l|l|l|l|l|l|l|}
\hline Project & Location & Developer & $\begin{array}{l}\text { Number } \\
\text { of } \\
\text { turbines }\end{array}$ & $\begin{array}{l}\text { Total } \\
\text { size } \\
(\mathrm{MW})\end{array}$ & $\begin{array}{l}\text { Consent } \\
\text { lodged }\end{array}$ & Status \\
\hline Tararua III & $\begin{array}{l}\text { Tararua } \\
\text { Ranges, } \\
\text { Manawatu }\end{array}$ & Trustpower & 31 & 93 & $\begin{array}{l}\text { November, } \\
2005\end{array}$ & $\begin{array}{l}\text { Under } \\
\text { Construction }\end{array}$ \\
\hline White Hill & $\begin{array}{l}\text { Mossburn, } \\
\text { Southland }\end{array}$ & $\begin{array}{l}\text { Meridian } \\
\text { Energy }\end{array}$ & 29 & 58 & $\begin{array}{l}6^{\text {th }} \\
\text { October, } \\
2004\end{array}$ & $\begin{array}{l}\text { Under } \\
\text { Construction }\end{array}$ \\
\hline Taumatatotara & $\begin{array}{l}\text { Taharoa, } \\
\text { Waitomo } \\
\text { District }\end{array}$ & Ventus & 22 & 44 & $\begin{array}{l}\text { March, } \\
2005\end{array}$ & Consented \\
\hline
\end{tabular}




\begin{tabular}{|l|l|l|l|l|l|l|}
\hline Titiokura & $\begin{array}{l}\text { Te Pohue } \\
\text { region, } \\
\text { Hawkes Bay }\end{array}$ & $\begin{array}{l}\text { Unison } \\
\text { Networks/Hydro } \\
\text { Tasmania }\end{array}$ & 15 & 48 & $\begin{array}{l}10^{\text {th }} \text { June, } \\
2005\end{array}$ & $\begin{array}{l}\text { Consented } \\
\text { after } \\
\text { Environment } \\
\text { Court } \\
\text { appeal }\end{array}$ \\
\hline West Wind & $\begin{array}{l}\text { Makara, } \\
\text { Wellington }\end{array}$ & $\begin{array}{l}\text { Meridian } \\
\text { Energy }\end{array}$ & 70 & 210 & $\begin{array}{l}8 \text { th July, } \\
2005\end{array}$ & $\begin{array}{l}\text { Consented } \\
\text { after } \\
\text { Environment } \\
\text { Court } \\
\text { appeal }\end{array}$ \\
\hline Awhitu & $\begin{array}{l}\text { Awhitu } \\
\text { Peninsula, } \\
\text { Auckland }\end{array}$ & Genesis Energy & 18 & 18 & April, 2004 & $\begin{array}{l}\text { Consented } \\
\text { after } \\
\text { Environment } \\
\text { Court } \\
\text { appeal. } \\
\text { But on hold }\end{array}$ \\
\hline Motorimu & $\begin{array}{l}\text { Tararua } \\
\text { Ranges, } \\
\text { Manawatu }\end{array}$ & $\begin{array}{l}\text { Alco Wind } \\
\text { Energy }\end{array}$ & 129 & 110 & $\begin{array}{l}\text { August, } \\
2006\end{array}$ & $\begin{array}{l}\text { Consent } \\
\text { lodged }\end{array}$ \\
\hline Hayes & $\begin{array}{l}\text { Lammermoor } \\
\text { Ranges, } \\
\text { Otago }\end{array}$ & $\begin{array}{l}\text { Meridian } \\
\text { Energy }\end{array}$ & 176 & 630 & 12 th July, & $\begin{array}{l}\text { Consent } \\
\text { lodged }\end{array}$ \\
\hline
\end{tabular}

United Networks also planned to develop a 37 turbine wind farm on the Te Waka Range south-west of the Titiokura Wind Farm, but this was declined in April 2007 in an appeal to the Environment Court (HDC, 2007).

In summary, there are seven wind projects currently operating throughout New Zealand. Three of these are SSW projects (two of which are research projects), while the remaining four are large wind farms. Four of the seven projects are owned by large power companies, two by wind farm developers and one by a New Zealand based turbine manufacturer.

\subsubsection{New Zealand's Wind Resource}

New Zealand has one of the best wind resources in the world (Ashby, 2004; Meridian, 2006; Pretli, 2003). New Zealand is a long, thin landmass with good exposure to coastal winds, along with a number of mountain ranges and regions with elevated terrain. Also, New Zealand lies in the middle of a strong mid-latitude air current known as the Roaring Forties, known for its strength due to being unhindered by any land mass (Meridian, 2006). 
To illustrate the strength of the local wind resource, the productivity of turbines operating in New Zealand can be compared with other countries. One commonly used productivity measure for wind turbines is the capacity factor, a measure of the amount of electricity produced by a turbine relative to its theoretical maximum ${ }^{1}$. Table 5 demonstrates that the turbines operating in New Zealand are significantly more productive than all other countries shown, and are operating at nearly double the global average.

Table 5: Capacity factors for selected countries during 2004 and/or 2005.

\begin{tabular}{|l|r|}
\hline Country & $\begin{array}{r}\text { Average } \\
\text { capacity } \\
\text { factor (\%) }\end{array}$ \\
\hline UK $^{*}$ & 26.6 \\
\hline Australia* & 35 \\
\hline Finland $^{*}$ & 25 \\
\hline Italy $^{*}$ & 17 \\
\hline Mexico $^{*}$ & 31 \\
\hline Sweden $^{*}$ & 20.3 \\
\hline Netherlands $^{*}$ & 25 \\
\hline Germany $^{\star *}$ & 16 \\
\hline Denmark $^{\star *}$ & 24 \\
\hline Global average $^{* * *}$ & 24 \\
\hline New Zealand $^{* * * *}$ & $\mathbf{4 5}$ \\
\hline
\end{tabular}

Sources: * (IEA, 2006b), ${ }^{* *}\left(\right.$ WPM, 2006), ${ }^{* * *},{ }^{* * *}($ EECA, 2005)

Wellington city is well known for its high winds. The turbine installed on the hills overlooking the city, Brooklyn turbine, holds the world record for the most energy produced per meter of blade for 10 of its first 12 years (HBWF, 2005). Figure 3 compares the capacity factor of the Brooklyn turbine with that of 246 turbines of equivalent size and capacity operating in Denmark.

\footnotetext{
${ }^{1}$ The capacity factor is calculated by dividing the amount of electricity a turbine generates in a year by the total amount it could potentially generate if it ran at full capacity.
} 


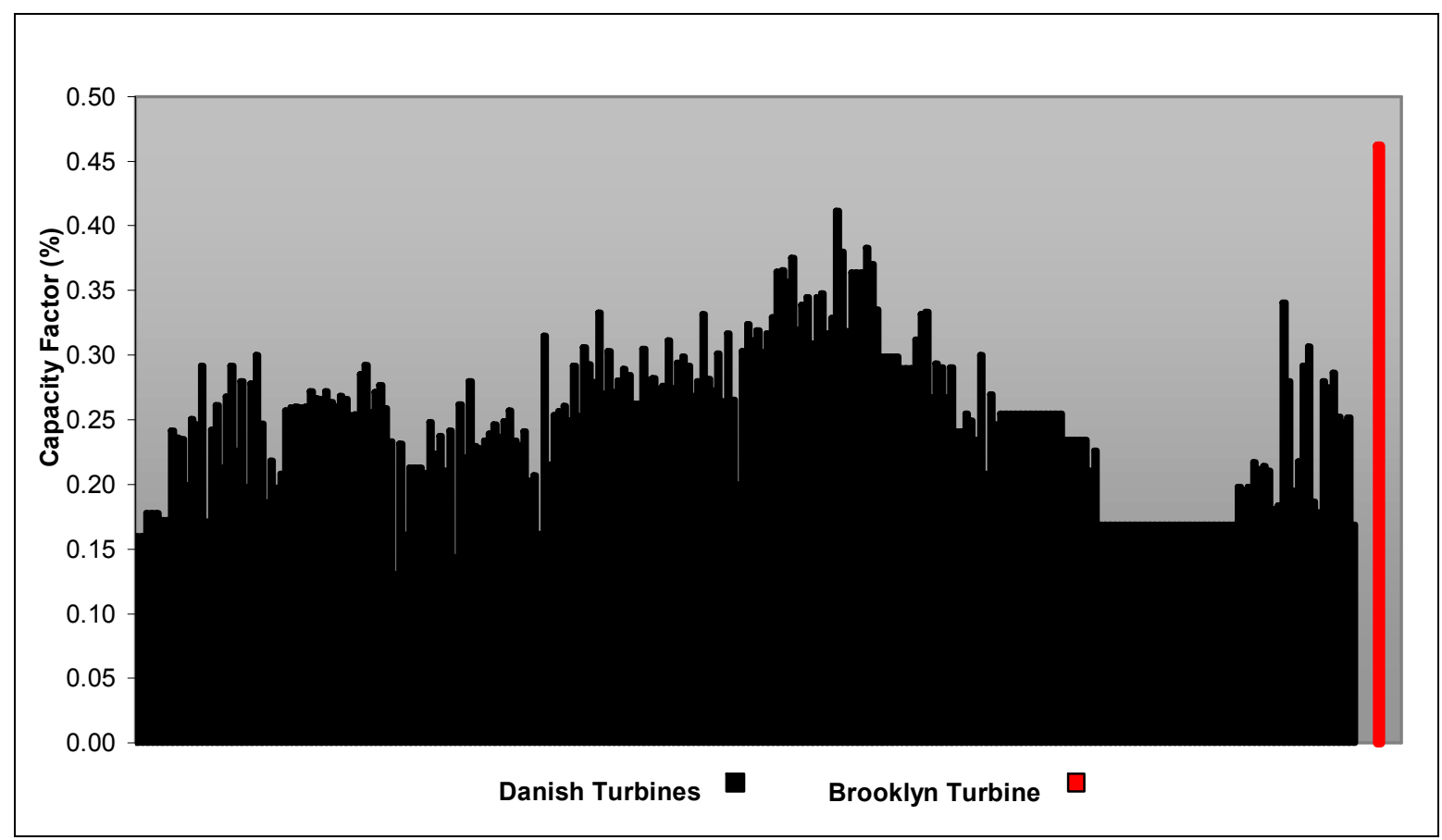

Figure 3: Average capacity factor of the Brooklyn turbine compared with 246 Danish turbines of equivalent size (1994-2005).

Source: Output data from the Danish Wind Energy Association and Meridian Energy.

\subsubsection{Key Issues}

Arguably, New Zealand's wind industry is failing to utilise the world-class wind resource it has available. Many other countries have experienced much higher rates of growth despite having a far inferior wind resource. As stated in a press release by the NZWEA CEO Fraser Clark:

"While wind energy is growing somewhere between $25-35 \%$ per year globally our growth has been inconsistent in the last couple of years due to a lack of clear Government policy on renewable energy and climate change..." (Clark, 2007a).

Figure 4 demonstrates that industry growth has been intermittent, with no projects going online in seven out of the 15 years the industry has been operating in New Zealand. 


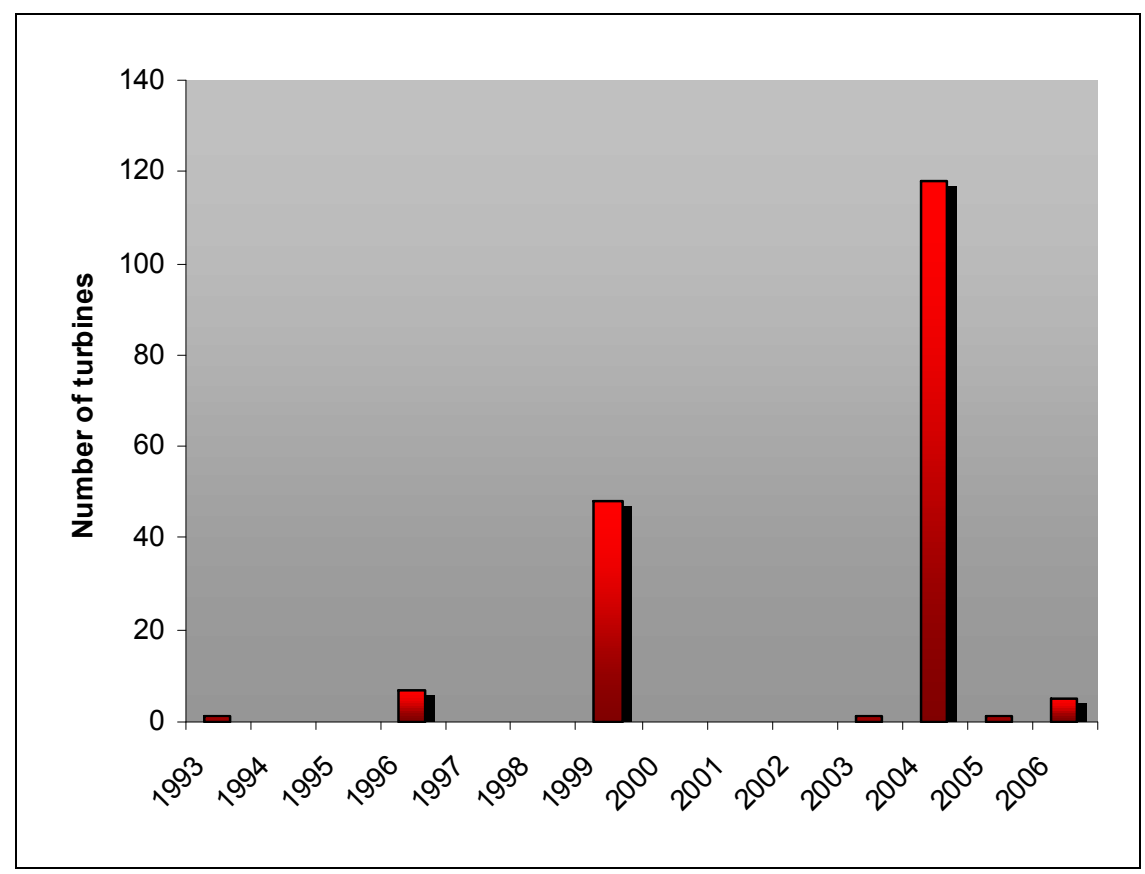

Figure 4: Number of turbines installed each year in New Zealand

Figure 5 compares the cumulative growth rate of New Zealand's wind industry with a number of other countries. To obtain a reasonable comparison, these countries are chosen because they are developed countries with similar populations to New Zealand's (the largest being Denmark with around 5.4 million people). New Zealand is clearly lagging behind these other countries.

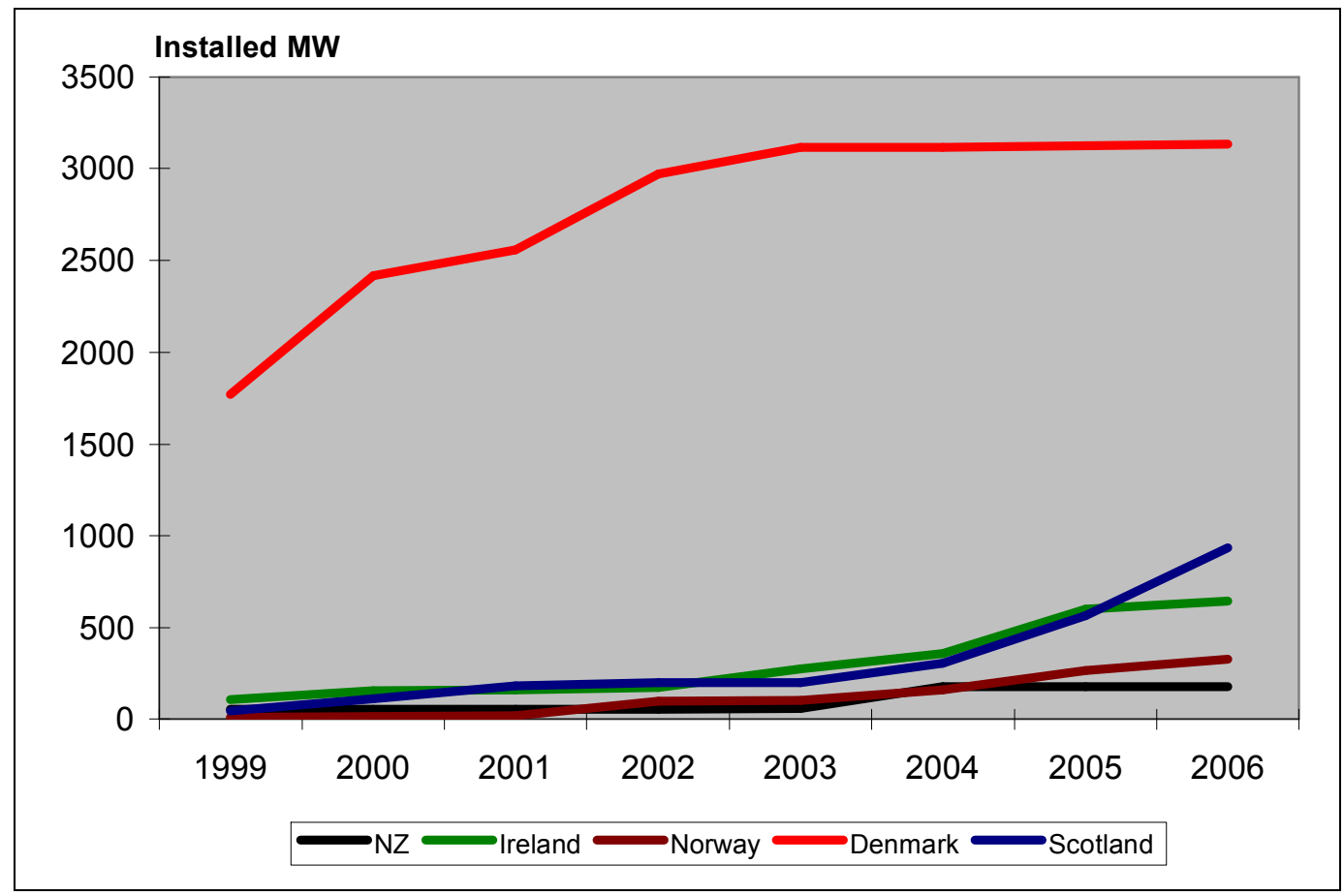

Figure 5: Cumulative wind industry growth rate in countries of similar population to New Zealand 
As shown from a comparison of the two maps in Figure 6, New Zealand's wind resource is not being fully utilised. The map on the left illustrates a number of potential regions identified by EECA as being suitable for wind developments. The map on the right gives the locations of New Zealand's existing wind farms, showing that only three of the thirteen high wind resource regions have been developed. Note that two of these regions, Wellington and Christchurch, only have one turbine installed.

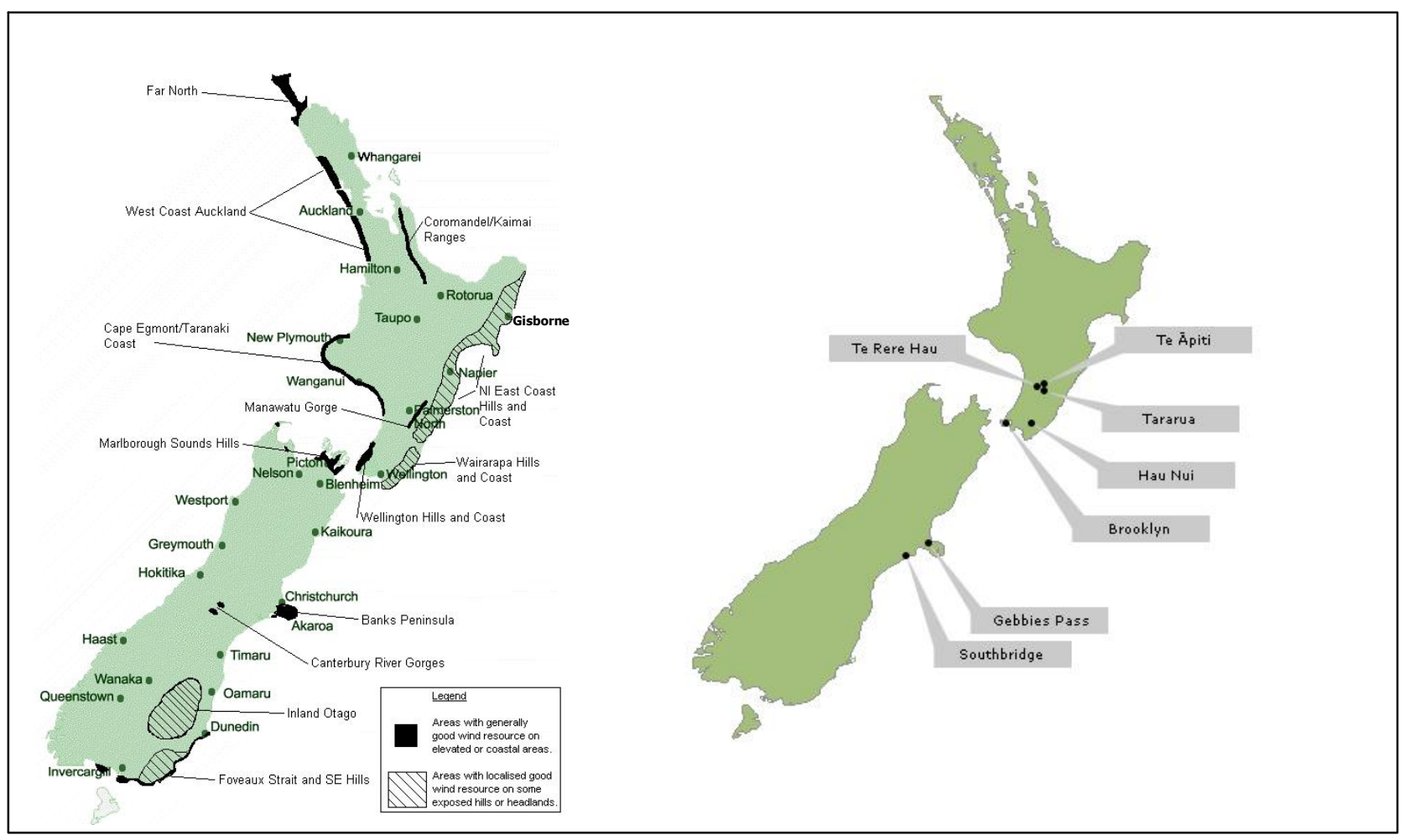

Figure 6: Wind locations most suitable for wind energy development (left) and locations of projects currently operating in New Zealand (right).

Many other countries have implemented extensive policy support regimes over the past two decades and have experienced much higher rates of growth than New Zealand. Apart from the PRE (which only lasted two years), industry development in New Zealand has largely been left to the market. As a result, four industry characteristics have emerged that will arguably limit the potential growth of wind in New Zealand. These characteristics are discussed below. 


\subsubsection{Trend Toward Large Scale}

There is a clear trend among wind farm developers in New Zealand to build largescale wind farms, with $98 \%$ of installed capacity coming from farms with 15 or more turbines. In looking at the scale of proposed projects it appears this trend will continue. Arguably, this trend is limiting the potential growth of wind in New Zealand, because it is leading to increasing opposition to wind farm developments among local communities. As a result, developers are facing increasingly long consent processes (Fisher, 2005).

The 70-turbine Project West Wind has been delayed more than 18 months due to an Environment Court appeal, adding around $\$ 80$ million to overall project costs (NZHOR, 2006). Also, a number of resident lobby groups have formed in response to project proposals in recent years, such as Rational Energy Debate RED (Project Hayes) (Mayston, 2006) and the Aokautere Guardians (Te Rere Hau).

Public perception of wind power is critically important for any wind industry, because public opposition to wind proposals can lead to major delays, higher costs in obtaining resource consent or even cancellation of projects. Social acceptance is one of the limiting factors of wind energy's potential growth (EREC, 2004; Wolsink \& van de Wardt, 1989). Wind support policy in the United Kingdom resulted in the development of large-scale, commercially-owned wind farms, which also caused high levels of opposition. As a result, the industry faced prolonged consent processes and growth stagnated, despite the United Kingdom having the best wind resource in Europe (Bolinger, 2004; Toke, 2005).

This trend of building large-scale wind farms is arguably due to a mix of economic factors and an unsupportive policy environment. In New Zealand at present, developing wind projects is relatively expensive, and is only economic at high wind sites or on a large scale when the benefits of economies of scale can be realised (Meridian, 2006; PCE, 2006). Economies of scale lead to reductions in a number of project costs, including obtaining resource consent, grid connection, road construction, concrete making, crane hire and the turbine cost itself.

Murray Jackson, CEO of Genesis Energy, has stated that he considers that wind is still not commercially viable in most instances in New Zealand (Steeman, 2006a). According to Trustpower the expansion of the Tararua wind farms was only made feasible through the carbon credits awarded under the PRE scheme. Trustpower 
believes wind farms are still "extremely marginal", and the price of power would have to increase further before the company would consider developing more wind farms (NZPA, 2004).

The 55 turbines that Meridian purchased for Te Apiti were part of a larger order of 105 turbines, with the other 50 being used for Meridian's Wattle Point Wind Farm in South Australia. The benefits of economies of scale of this bulk purchase helped improve the economics of Te Apiti, making the project "economic to do in New Zealand", according to Meridian's Alan Seay (V. Hyde, 2004: 68).

If a more supportive policy environment were in place, for example one which facilitated resource consenting, or gave a price premium for renewables, wind would be less expensive and there would be less of a need to build large scale in order to make a project economically viable.

Not all wind industries are dominated by large-scale wind farms. For example, wind energy growth in Germany and Denmark (two of the world's largest wind industries) has traditionally been characterised by wind farms of three to six turbines (Ashby, 2004). Figure 7 below shows the scale of wind farms in a number of selected countries/states.

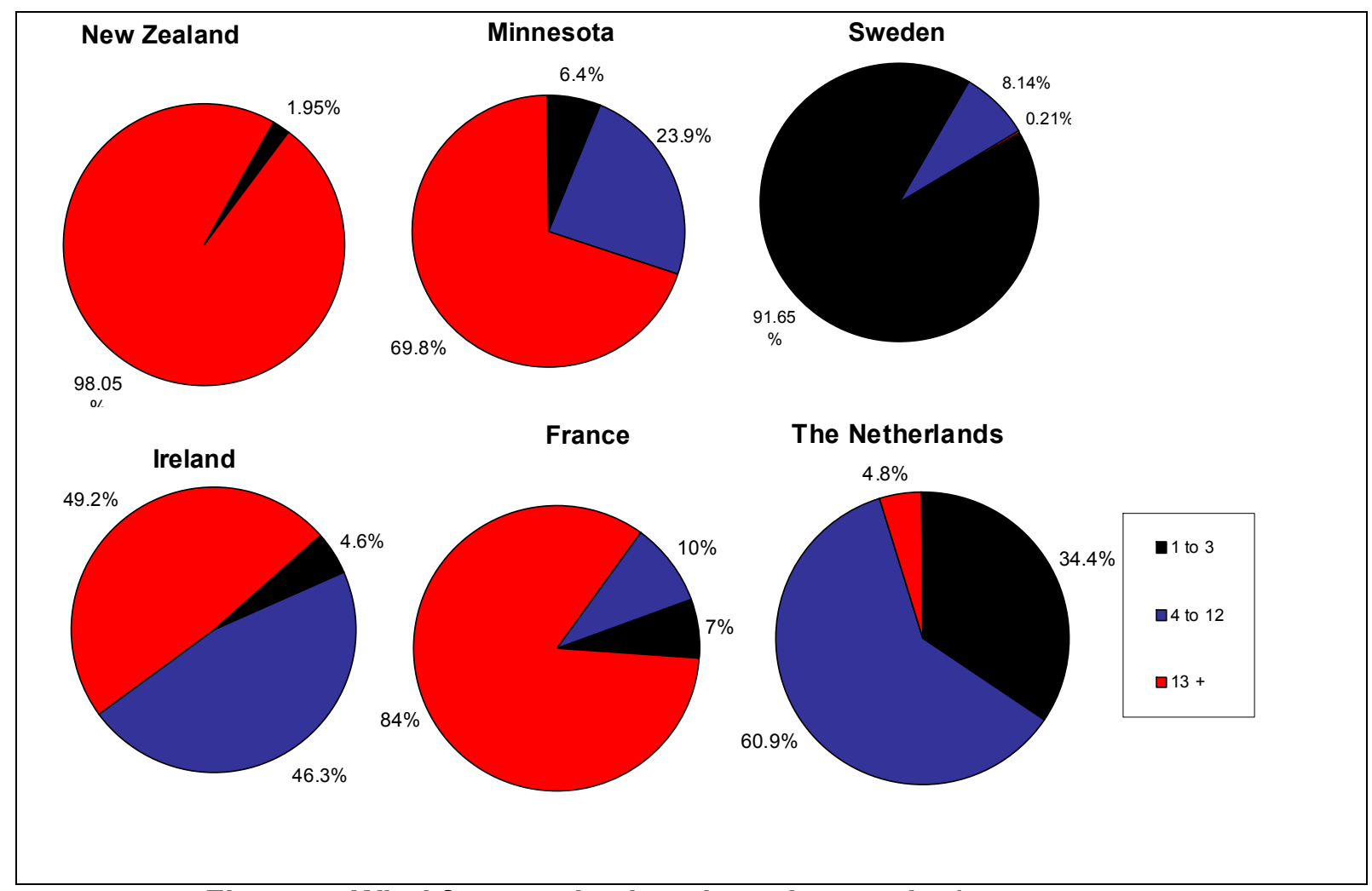

Figure 7: Wind farm scales in selected countries/states

Sources:(AWEA, 2007; FWEA, 2007; IWEA, 2007; NWEA, 2007; NZWEA, 2007; SWEA, 2007). 
This shows that wind industries in some countries, such as the Netherlands and Sweden, have fewer large-scale wind farms and are dominated by SSW and medium-sized wind farms.

\subsubsection{Limited Flow of Investment}

There are a limited number of companies investing in the industry, with more than $98 \%$ of total generating capacity being owned by only three developers: Meridian Energy, Trustpower and Genesis. However, Contact Energy has recently announced it is "actively engaged" on the development of two wind farm sites throughout the country (Contact, 2007). This situation may be limiting the potential growth of New Zealand's wind industry because growth is largely being left to the activities of three or four companies.

A greater number of developers could access investment capital from a larger investor pool and there might be a greater potential for industry growth. It is also possible that more projects would be developed concurrently leading to a more even growth pattern compared to the intermittent growth seen to date.

This situation could be compared with two other countries of similar population sizes: Ireland and Denmark. In Ireland there are more than 40 companies or groups investing in the wind industry (IWEA, 2007), while in Denmark (where community ownership is prevalent) there are around 150,000 investors (Sorensen, Hansen, Hammarlund, \& Larsen, 2004).

Two of the largest developers - Meridian Energy and Trustpower - are also developing wind farms in South Australia. Meridian is developing a 91MW project at Wattle Point, while Trustpower is developing a AU $\$ 200$ million, 42 turbine wind farm near Snowtown. Trustpower CEO Keith Tempest referred to this project as a 'beachhead' into the Australian market, suggesting the company is planning to build more wind farms over there (NZPA, 2007b).

Although this investment overseas provides potential benefits - such as the economies of scale benefits discussed earlier - the fact that these developers are lured to the Australian market may limit the potential flow of investment into the New Zealand wind industry. This argument assumes that Meridian and Trustpower have 
a finite amount of resources available to invest in generation, which is arguably a fair assumption given they operate in a competitive market. If this assumption is correct, then investment in the Australian wind industry would therefore be at the expense of investment in New Zealand's wind industry.

This situation has arguably been created because of inadequate government policy. Firstly, the fact that wind energy is economically marginal in New Zealand - apart from in large-scale cases and at high-wind sites - means that only companies with large capital backing are able to compete. If government support was offered that would ease market access, the industry would attract a greater range of investors and thus more capital. Secondly, the fact that the market is dominated by a small number of companies suggests there are barriers to entry facing small, independent developers. A more effective policy framework could remove or reduce these barriers.

\subsubsection{High Geographic Concentration}

New Zealand's wind capacity is highly geographically concentrated, with around $93 \%$ of capacity being installed in the Manawatu gorge. There are two reasons why this geographic concentration is limiting the potential growth of wind in New Zealand.

Firstly, the clustering of wind farms in the Manawatu has intensified the intermittency effects of wind on the grid and wholesale market. The wind farm cluster has created large swings in generation output (of up to $100 \mathrm{MW}$ within a five-minute trading period), creating problems for the system operator in terms of scheduling, dispatch and frequency keeping. According to the draft NZES, the economic cost of these effects may put an upper limit on wind generation (MED, 2006). With a more geographically dispersed wind capacity, swings in the combined output of all wind farms will be minimized and the limits on wind integration will potentially be higher (Bolinger, 2001; MED/EECA, 2005).

Secondly, developers in the Manawatu region have faced increased public opposition to additional wind farm developments (Tararua III and Motorimu), suggesting local residents have reached their threshold of tolerance for additional turbines in the area (PCE, 2006). 
This high geographic concentration is due, at least in part, to a lack of government policy. The fact that wind energy is relatively expensive in New Zealand - apart from on a large scale and at high-wind sites - has led to a rush to develop the windiest sites first. If government support was offered that made wind economically viable at a greater number of sites, then developments would be more geographically dispersed.

\subsubsection{Limited Manufacturing Capacity}

There is limited turbine manufacturing capacity in New Zealand, with only one manufacturer operating at present, Windflow Technology Ltd. Lack of an adequate local manufacturing base means that New Zealand developers are heavily reliant on imported turbines. This reliance is limiting the potential growth of the wind industry because the global turbine market is currently experiencing a major supply shortage. This shortage has meant turbines are not only becoming more expensive, but also increasingly difficult to source. If the local manufacturing base was better developed then the industry would, at least in part, be insulated from the impacts of this global shortage.

In a 2006 report Meridian Energy acknowledged the potential short-term impact of this shortage "...developers without established relationships with wind turbine manufacturers may struggle to get turbines over the next few years although this should not be a problem in the longer term" (Meridian, 2006: 54). However, if global demand for wind energy continues to grow, and all indications suggest it will, the problem may continue to get worse.

Concerns about this shortage were also raised at the recent New Zealand Wind Energy Conference by Deion Campbell of Trustpower, stating: "the biggest problem is getting turbines" (Cambell, 2007).

Rising turbine prices was the main reason why Genesis Energy cancelled plans to develop its Awhitu wind farm near Auckland. According to Genesis' public affairs spokesman Richard Gordon, there had been a $30 \%$ rise in the cost of wind turbines between January 2005 and September 2006 (Steeman, 2006c). Rising prices is also one of the main reasons why Meridian Energy's Project West Wind at Makara, considered the best wind site in the world, is now marginally viable (Wier, 2007). 
A report prepared for MED looked at projected future costs of wind energy and concluded that the unit price of turbines and exchange rate variations were two significant influences on the future cost curves for wind energy (EHMS, 2005). These two factors were identified by the International Energy Agency as one of the main market barriers to the development of wind power in New Zealand (IEA, 2005).

The turbine shortage has affected the growth of wind industries worldwide, including Italy (Pirazzi, 2006) Canada and Portugal (IEA, 2006b), Scotland (Akilade, 2006) and the USA (EER, 2006). This situation is expected to continue for several years to come (Akilade, 2006). "A continuing challenge for the industry is the ability of developers to get their hands on wind turbines, whatever they cost" (WPM, 2006: 53).

"The major wind turbine manufacturers are sold out, most until 2008. The constraint on the global wind market in the next two years will be limited supplies, not lack of orders...The log jam was first felt in the US at the start of the year but has spread worldwide" (WPM, 2005: 78).

New Zealand's limited turbine manufacturing capacity is compounded by a lack of government support. Firstly, turbine manufacturing is an expensive, capital intensive industry, requiring a substantial $R \& D$ and testing process. Without government assistance these costs could be sufficiently high to make the turbine manufacturing industry seem unattractive to potential investors. Secondly, the lack of a clear and consistent policy framework has contributed to the unstable intermittent growth of the wind industry. International experience has shown that if a stable, domestic market is provided then manufacturers will be attracted to the industry (Bolinger, 2001; Lewis \& Wiser, 2005; Loiter \& Norberg-Bloom, 1999; Pretli, 2003).

As the issues of climate change mitigation and energy supply security becomes increasingly important, it is likely that more governments will begin to invest more heavily in building their local turbine manufacturing capacity. 


\subsection{Relevant Policy and Legislative Framework}

\subsubsection{Government Policy Statement on Electricity Governance (GPS)}

In December 2001 the Government released the GPS, which outlines Government's approach to electricity policy.

The GPS recognises that the "development of renewable energy resources is a key part of the Government's strategy for managing climate change and long-term energy security". To further this aim, one of the Government's objectives is to ensure that the efficient uptake of renewable generation is promoted.

The GPS defines distributed generation (DG) as "generation which is connected to local distribution lines rather than the transmission grid" (MOE, 2006: 29). It states that DG is "expected to play an increasingly important role in meeting electricity demand as the cost of smaller-scale and new renewable technologies continues to decline...accordingly, it is important that there are no unnecessary barriers to its development" (MOE, 2006: 29).

These are aspirations only and they require other polices to translate them into effect. The removal of barriers to investment in distributed SSW implies that critical issues such as pricing and market access (discussed below) are addressed.

\subsubsection{Electricity Act 1992}

The Electricity Commission was set up under the Electricity Act 1992 to oversee the operation of New Zealand's electricity industry. The Commission was formed in 2003 , with the following principal objective: "to ensure that electricity is produced and delivered to all classes of consumers in an efficient, fair, reliable and environmentally sustainable manner" (Section 172N).

The Act also requires the Commission to seek to achieve the following outcomes:

- Barriers to competition in the electricity industry are minimised for the longterm benefit of end-users 
- The full costs of producing and transporting each additional unit of electricity are signalled

- The removal of barriers to investment in new generation technologies, renewables, and distributed generation (Section $172 \mathrm{~N}$ ).

To date these objectives have not yet been realised. Since 2003 there has been only one SSW development, while the electricity market is still dominated by a small number of large companies. Also, New Zealand's energy mix is becoming less, not more environmentally sustainable.

\subsubsection{Resource Management Act 1991 (RMA)}

The RMA is the principal piece of environmental legislation in New Zealand. Any wind project must be authorised in some form under the RMA, whether it is through permissive plan provisions, a resource consent or a designation (PCE, 2006).

The RMA is effects based legislation, meaning the decision whether to approve a wind project is assessed against the adverse environmental effects that project may create. The decision-making authorities are typically local and/or regional councils who balance these effects against the project's potential benefits. In the case of wind energy, effects are typically borne locally (visual and noise pollution) while the benefits are enjoyed at a national level (greater use of renewable energy). This divergent incidence of costs and benefits is largely responsible for the local tensions that arise when wind projects are proposed.

When resource consent applications are lodged and the consent is publicly notified, affected parties can make submissions for or against the proposal. In almost every wind farm development to date in New Zealand, local residents have forwarded submissions objecting to the development (PCE, 2006).

Any party who made a submission on the resource consent can appeal the decision to grant the consent or its conditions to the Environment Court. At the time of writing, four projects had been appealed to the Environment Court: Awhitu, Titiokura, Te Waka and Project West Wind. Awhitu, Titiokura and West Wind were approved by the Court (HDC, 2007; NZWEA, 2005), while Te Waka was declined (HDC, 2007). 
The divergence between local costs and national benefits, along with the wide provisions for public involvement in the consents process, has meant many wind projects have faced delays under the RMA process. As shown in Tables 3 and 4, it appears these delays have increased. It can be seen that all four projects that have been appealed to the Environment Court lodged the original resource consent within the past three years. This suggests a possible trend whereby wind projects are increasingly likely to have to go through the Environment Court process.

As a result, the Act has been widely blamed for slowing the development of New Zealand's wind industry. In spite of this, it should be noted that wind farms can cause significant local environmental effects, and it is important from a sustainable management point of view that these effects are duly considered.

The problem of obtaining resource consent has led the Energy Minister David Parker to introduce a consolidated consenting process for wind projects that would enable a pool of projects to be called in and considered by the same decision-making panel (Parker, 2006).

\subsubsection{Projects to Reduce Emissions (PRE)}

To date the only significant policy instrument used to support the wind industry in New Zealand is the PRE, which ran in 2003 and 2004. PRE was a government run tender programme for projects that would contribute to a reduction in greenhouse gas emissions. It was terminated because officials advised that it was uncertain whether it was contributing to a reduction in New Zealand's carbon emissions deficit, beyond the units allocated to the projects (CBC, 2005). Whether this was wise advice is beyond the scope of the analysis here.

Winning tenders received one carbon credit for every tonne of $\mathrm{CO}_{2}$ that would have been emitted if their project did not go ahead. These projects could relate to electricity generation, heat generation or energy efficiency, and had to provide a minimum reduction in emissions of 10,000 tonnes of $\mathrm{CO}_{2}$-equivalent in the First Commitment Period (2008-2012 under the Kyoto Protocol). For an electricity generation plant this equates to about $10 \mathrm{MW}$ of capacity. These carbon credits could then be sold on the international market (NZCCO, 2007). 
Thirteen wind projects were successful recipients of carbon credits under PRE: Tararua Stage II, Te Apiti, Te Rere Hau, Awhitu, Wainuiomata Hills, the Hau Nui extension, Mokairau, Taraponui, White Hill, Tararua stage III, Titiokura, Awakino, Rock and Pillar Wind Farm (NZCCO, 2007). As noted earlier, PRE credits made a critical difference to whether wind projects would go ahead or not. Despite receiving these credits, most of these wind farms are yet to be developed.

Tendering programmes are also used in a small number of other countries, including the UK, Canada and China, but are generally not considered as effective as either price-based or obligation/certificate systems. New Zealand is the only country in the top 20 wind industries in the world yet to adopt either of the two latter systems (see section 4.1.4).

There are a number of issues with the PRE. As all winning tenders went to existing market players, it did not attract new investors to the wind industry, such as community groups, farmers or large power users. This was probably due to the minimum size requirement. The payment system did not offer cash up-front, but rather a complicated payment mechanism with relatively high transaction costs. The PRE offered little financial certainty, given the uncertainty of future carbon credit pricing on the international market and the fact that if the Government pulled out of the Kyoto Protocol the tender contracts would be terminated. Three requirements for successful wind policy are having a well-designed payment mechanism, low transaction costs and the provision of a stable investment climate (Sawin, 2004).

\subsubsection{Distributed Generation Regulations}

Most lines companies do not have standard terms and conditions for connecting distributed generators, meaning each generation project requires an individually negotiated connection agreement (MED, 2003).

On the $13^{\text {th }}$ of April, the MED released draft regulations for the connection of DG to local lines networks. These include regulations aim to facilitate the use of DG by ensuring that it does not face undue barriers in connecting to local lines. The regulations specify the terms and conditions that apply to the connection of DG, including among others, the process for obtaining approval to connect, a dispute 
resolution process and the timeframe for connection contracts between generator and distributor. The pricing principles in the regulations include consideration of whether the new generator could result in avoided transmission costs, or in other words, defer the need for investment in the local lines network. It is intended that final regulations be in place mid-2007 (MED, 2007a).

\subsubsection{The New Zealand Energy Strategy (NZES)}

A draft NZES was released in November 2006 and the final Strategy is due for release mid-2007. The draft Strategy sets out the Government's proposed vision for New Zealand's energy future and the broad direction by which this could be achieved. The Strategy states that it is preferable that all new generation capacity built is renewable, and recognises that wind is expected to play a "vital role" in New Zealand's sustainable energy future. It also articulates concerns over barriers facing DG in New Zealand (MED, 2006).

The Energy Minister David Parker recently gave a strong indication that the NZES would include a cap and trade system to support renewables in New Zealand (NZPA, 2007a).

\subsection{Summary}

New Zealand's electricity sector is facing a number of issues: a lack of competition in the generation market, a shortage in transmission capacity, concerns over security of supply and climate change, and a declining contribution of renewables.

Despite New Zealand's excellent wind resource, the wind industry has a poor and uneven growth rate. This is most likely due to a lack of appropriate support policy, which has left industry development largely to the market. As a result, four characteristics have emerged from the industry that are limiting the potential development of the industry. While these conditions continue to hold, New Zealand's wind industry is unlikely to reach a growth rate that demonstrates it is making full use of the world-class wind resource New Zealand has available. 


\section{CHAPTER 3: THE ADVANTAGES, DISADVANTAGES AND BARRIERS OF SMALL-SCALE WIND INTERNATIONALLY}

This chapter discusses the actual and potential advantages and disadvantages of SSW, and barriers to its development. It evaluates a number of significant economic, social and environmental issues, thereby illuminating whether there is a prima facie case for encouraging SSW.

Regardless of its scale, wind's advantage is that it is essentially pollution free, releasing little or no $\mathrm{CO}_{2}, \mathrm{NO}_{\mathrm{x}}$ and $\mathrm{SO}_{2}$ emissions (apart from during turbine manufacturing, construction and erection). Wind is a renewable energy generation source, meaning it is infinite in supply and is essentially free once operating (apart from operating costs and parts replacement). In terms of a fuel source, wind involves no geopolitical risk or dependence on foreign markets for price or availability. Wind is a locally available resource, which means it contributes to security of energy supply (EWEA, 2005).

\subsection{Advantages}

\subsubsection{Higher Local Public Acceptance}

A number of international studies have found people tend to be more positive about SSW projects in their local area than large-scale ones. The most likely reason for this is that SSW projects make less noise and are less visually intrusive on the landscape. Noise and visual pollution are generally considered to be the most common causes of local public opposition when wind projects are proposed (Gleisner et al., 2005; Wolsink, 1989). "While there are good economic reasons for building large wind farms, they also produce the greatest amount of opposition" (V. Hyde, 2005: 54).

A perception study of 1200 residents in Ireland found that public acceptance was significantly greater for small wind farms (5 turbines) than larger ones (25 turbines). $49 \%$ of those surveyed were either fairly or very positive toward small wind projects, 
while only $27 \%$ were equally as positive about larger wind farms. The survey responses are provided in Figure 8. The vertical axis represents the percentage of responses in each category.

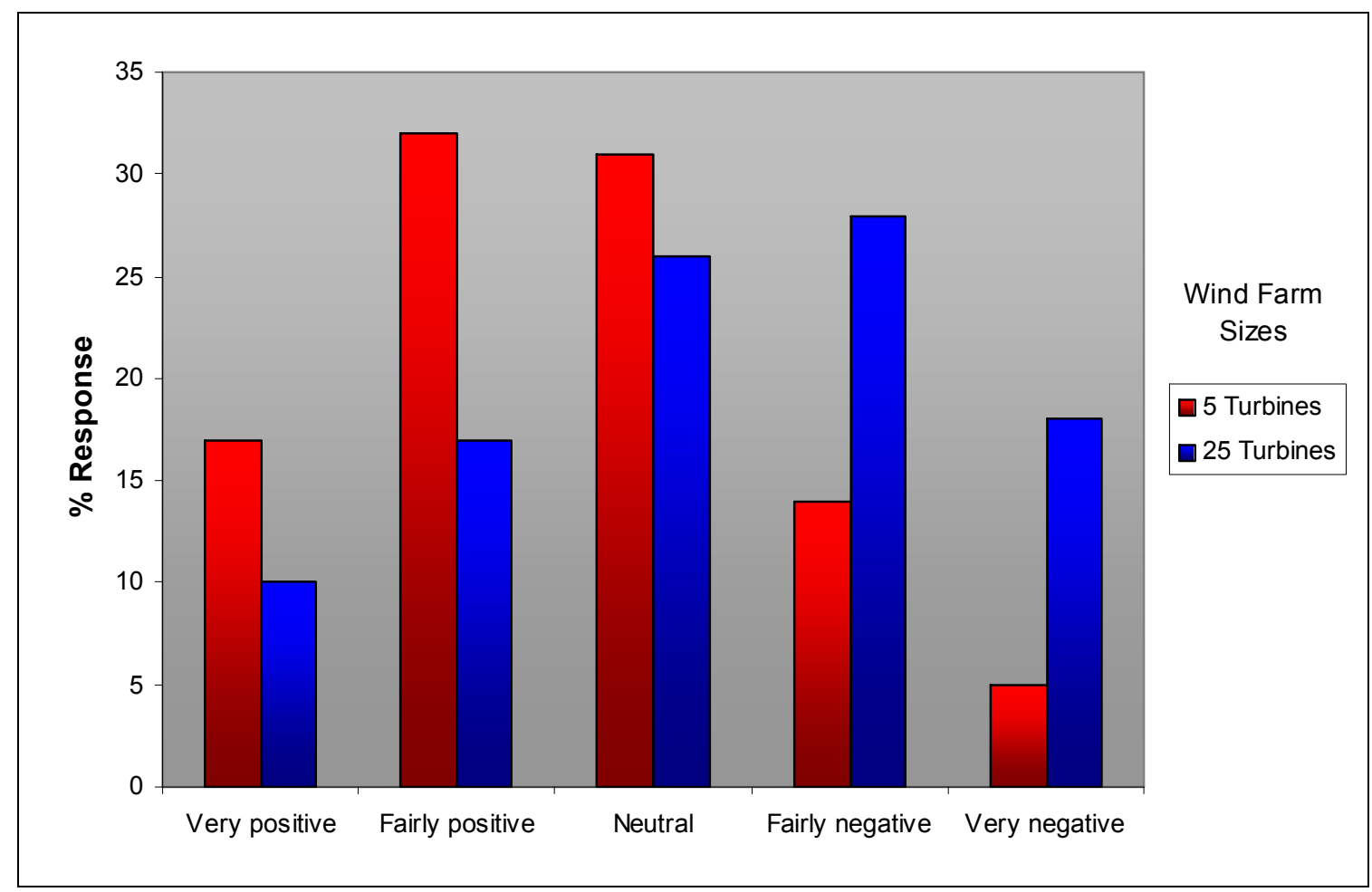

Figure 8: Attitudes to different wind farm sizes in Ireland

Source: (SEI, 2003).

The study identified a favourability gradient, where a 5-turbine wind farm was perceived most positively, two clusters of 10 turbines was perceived next most positively and one wind farm of 25 turbines least positively (SEI, 2003).

A British study of 1,962 participants assessed public attitudes towards an increasing number of turbines. Perceptions of wind farms with 8, 16, 30, 50 and 100 turbines were tested. A favourability gradient was also identified, with participants' acceptance of wind projects decreasing as the number of turbines increases (Lee, 1989).

A survey of 1,587 people in the Netherlands found a higher level of support for scattered and solitary sited wind turbines compared to large wind farms (Wolsink, 1989). It was found that the formation of this support is not related to other factors that determine support for wind power, such as increased distance from dwellings, 
opinions of local planning authorities or political orientation. These findings indicate that people prefer smaller wind projects irrespective of whether they are for or against the idea of wind power in general.

A Dutch study by van de Wardt \& Staat (1989) concluded that the strongest influence on perceived scenic quality was caused by the number of visible wind turbines in the landscape. In other words, the greater the number of turbines, the greater the perceived intrusion on the landscape. The influence of turbine size was found to be relatively small compared with the influence of the number of turbines (cited in MLURI, 2005).

From these studies it appears that people are generally more accepting of SSW than they are of large-scale wind farms. This suggests that SSW projects might face less local opposition when proposed in an area, meaning resource consents might be easier to obtain and projects can be built faster.

\subsubsection{Facilitates Community Ownership}

Because SSW projects are considerably cheaper than large wind farms they are more affordable to smaller investors, like community groups or farmers. Thus, an advantage of SSW is that it facilitates community ownership of wind energy. Community ownership can make a significant contribution to a country's wind industry. Figure 9 illustrates that around $85 \%$ of the Danish wind capacity is owned privately (either wind co-operatives or farmers). At the end of 2002 around 150,000 Danish households owned shares in the industry (EWEA, 2005; Sorensen et al., 2004). 


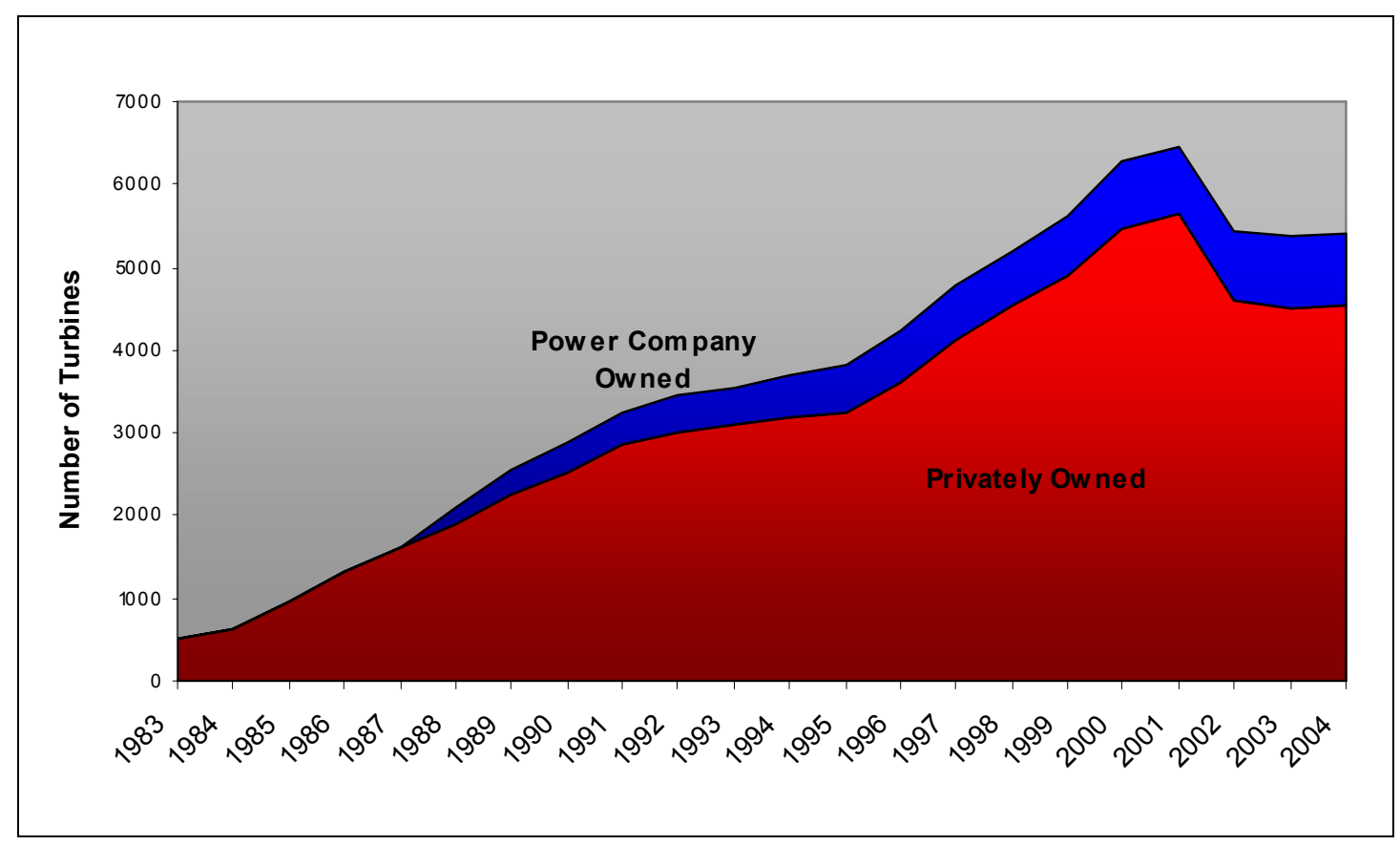

Figure 9: Ownership structure of the Danish wind industry.

Source: Danish Wind Energy Association website ${ }^{2}$

In Germany - the country with the world's largest installed wind capacity (see Table 1 ) - around $45 \%$ of wind capacity is owned by farmers and local co-operatives, with around 200,000 people registered as belonging to a wind co-operative (EEG, 2005; Toke, 2005). Likewise, in the Netherlands around $60 \%$ of wind capacity is owned by farmers (Toke, 2005).

The three principal benefits of community ownership are that it increases public acceptance of wind, provides local economic benefits and represents an additional source of capital to build the industry.

\section{Increased public acceptance}

Community ownership is considered to create higher levels of local public acceptance of wind projects (Bell, Gray, \& Haggett, 2005; Gipe, 2004; Toke, 2005). This is for four main reasons:

- Local residents have a direct financial stake in the project, so the economic benefits are concentrated within the local community. This means the

\footnotetext{
${ }^{2}$ www.windpower.org
} 
economic benefits of a wind project accrue to those people who bear the project's costs (impacts on visual amenity and noise pollution etc). "It is much easier to accept a little noise and the view of a turbine if it reminds you of the fact that the turbine gives you money when the wind blows" (Meyer, 2004: 29).

- It allows local residents to be directly involved in the planning and decisionmaking process, providing a sense of control.

- In some cases local residents oppose wind projects simply because they feel they are being intruded upon and exploited by large, commercial developers. Community ownership removes this concern (Krohn, 1999).

- The perceived impact of wind turbines on landscape and amenity is reduced (PCE, 2006).

An important outcome of increased public acceptance is a smoother and faster planning approval process (Sorensen et al., 2004).

Community acceptance can create a wider constituency supporting wind and other renewables. This in turn may be important in sustaining or accelerating a broader transition away from fossil fuels.

"The biggest advantage of community ownership is that it generates a wider cultural and political atmosphere that is favourable to wind power. The domination of the wind power industry by the electricity utilities in the UK appears to have the opposite effect" (Toke, 1999: 7).

Studies in the UK have found that people with shares in wind co-operatives are significantly more positive about wind power than those who do not (Krohn, 1999).

\section{Provides local economic benefits}

Community wind projects tend to provide more economic benefits to local communities, not only through the ownership of shares but also the creation of employment. Conversely, the economic benefits of projects built by outside commercial developers tend to "leak" outside the local region (Galluzzo, 2005).

This is because community owned projects are generally more likely to use local labour and expertise, providing short-term employment in areas such as concrete making, road construction, foundation construction, installing cables and wires 
connecting to the grid. One estimate is that community ownership brings five times the jobs (both short- and long-term) to a local community as projects owned by outside companies (OSEA, 2005).

A model developed by the National Renewable Energy Laboratory (who operate under the USA Department of Energy) compares the economic benefits - in terms of jobs created, income generated and economic activity of the designated region - of developing a single large wind farm versus a number of smaller ones. The model assumes that the large wind farm (40 MW) is owned and financed by an out-of-area investor, while the 20 small-scale farms ( $2 \mathrm{MW}$ each) are developed by local landowners with financing by local lending institutions. Table 6 below shows that small-scale, locally owned wind projects can generate significantly higher job and spending benefits for a given region (Galluzzo, 2005).

Table 6: A comparison of the economic benefits of community ownership with commercial ownership

\begin{tabular}{|c|c|c|c|}
\hline County & Project size & $\begin{array}{c}\text { Local annual O \& M* } \\
\text { spending (US\$ million) }\end{array}$ & $\begin{array}{c}\text { Total jobs (direct \& indirect) } \\
\text { during operating years }\end{array}$ \\
\hline Buena Vista & $1 \times 40 \mathrm{MW}$ & 1.3 & 23 \\
\hline Buena Vista & $20 \times 2 \mathrm{MW}$ & 7.2 & 48 \\
\hline Cherokee & $1 \times 40 \mathrm{MW}$ & 1.3 & 25 \\
\hline Cherokee & $20 \times 2 \mathrm{MW}$ & 7.2 & 22 \\
\hline Dickinson & $1 \times 40 \mathrm{MW}$ & 1.3 & 48 \\
\hline Dickinson & $20 \times 2 \mathrm{MW}$ & 7.2 & 52 \\
\hline \multicolumn{4}{|c|}{ * Adapted from (Galluzzo, 2005). } \\
\hline \multicolumn{4}{|c|}{ *O M: Operating and maintenance spending } \\
\hline
\end{tabular}

\section{Additional source of capital}

Community ownership represents an additional source of investment capital, which can therefore increase the potential for industry growth. Investors might include farmers, community co-operatives or private, independent developers. This capital is also available at a lower cost, because private investors are generally more willing to accept a lower rate of market return than traditional commercial investors. As a result, smaller projects - that would be unattractive to commercial investors - can be developed (Bolinger, 2004). 
In many countries where community ownership has been promoted, like Germany, Denmark and the USA, farmers have played a key role in developing the wind industry. Farmers might either invest in the entire turbine themselves, or as part of a wider co-operative. For the farmer, installing turbines is a form of land diversification that can dramatically increase the productivity of the land; this is because turbines can be placed amongst stock and most crop types (AusWEA, 2004).

Community ownership, then, has a number of unique advantages over commercial ownership. With community ownership wind projects can potentially develop faster, and with greater acceptance, while an additional source of funding can be used to build the industry.

\subsubsection{Utilises Small Exposed Sites}

SSW can exploit the potential of small or localised sites with high wind speeds. This is especially beneficial when those sites would not be profitable or feasible for larger developments (PCE, 2006). However, such sites would still only be economic with suitable road access and proximity to local lines networks.

As stated by a SSW developer in the UK; "One of the beauties of small projects is that you can fit a couple of wind turbines on to a good wind site where a larger project would be more difficult" (Massey, 2005: 39). The implication is that SSW could increase density of wind resource use, even if the scale of that use is lower for some sites.

As SSW projects are built on a greater number of sites a higher geographic diversity of wind capacity is achieved. A valuable outcome of this is the potential for system benefits of DG.

\subsubsection{Potential for Distributed Generation System Benefits}

In countries where SSW is well developed, high levels of DG have been achieved. For example, Figure 10 shows the geographic diversity of the numerous wind projects in Denmark. 


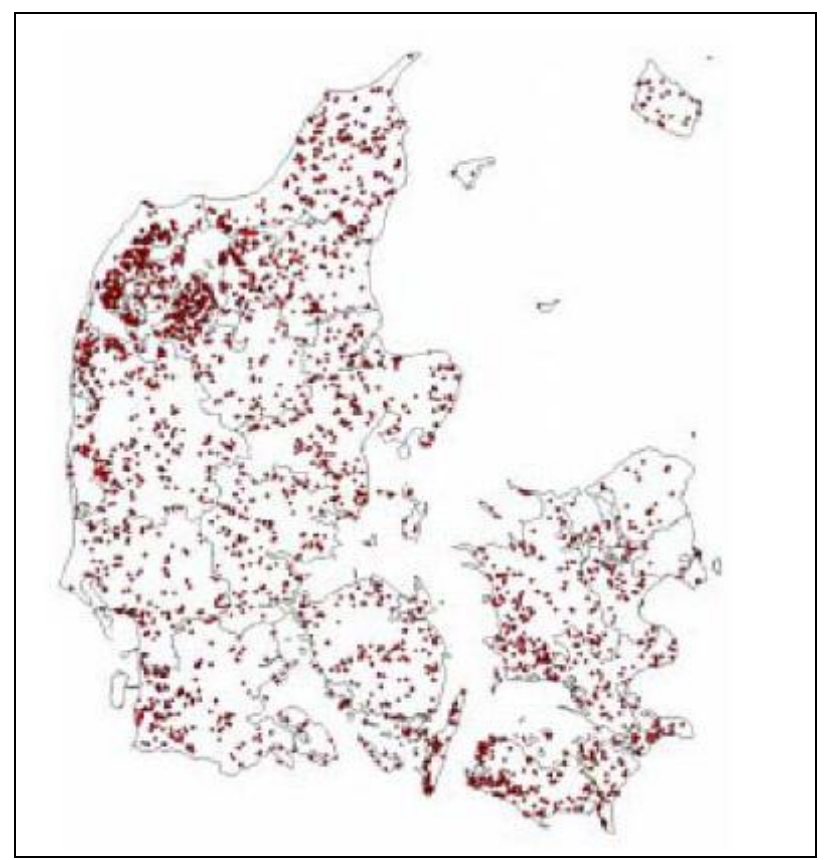

Figure 10: Location of wind projects in Denmark

Source: Danish Wind Energy Association

Therefore, SSW can provide for a more decentralised electricity system. Increased levels of DG can offer a number of potential system benefits:

- A reduction in transmission losses, because electricity is transported over shorter distances. Transmission losses are when electricity is lost as heat as it travels through the network. Losses in the transmission system can raise prices by up to $1 \mathrm{c} / \mathrm{kWh}$ in nodes where electricity has travelled a long distance (EHMS, 2005).

- A reduction in lines constraints. Lines constraints occur when power flowing through transmission and distribution lines reaches the maximum level they are able to carry. Where DG is able to reduce pressure on a transmission line, the effect should be a reduction in nodal prices that are associated with that constrained line, which should flow through to reduced consumer prices (MED, 2003). Another benefit of easing this constraint is that it can defer the need for construction of new transmission and distribution lines, since electricity is generated closer to load (MED/EECA, 2005).

- Providing voltage support in areas where distribution networks are weak 
- Greater energy security. A more decentralised electricity system reduces vulnerability to centralised failures, creating a more diversified and resilient electricity system (OSEA, 2005).

The extent to which SSW benefits local distribution networks is largely dependent on the time correlation between wind generation and load, in other words, the synchronisation of when the power is produced and when it is used. Some authors believe that when these optimal conditions are not present, distributed SSW will only provide a modest level of system benefits to local distribution networks (NWCC, 2001).

There are however new developments in battery storage technologies, which can increase the ability to match capacity to demand (discussed in more detail in section 3.2).

\subsubsection{Supports Local Industry}

SSW could support the development of a number of local industries, including turbine and blade manufacturing, construction, a service industry with installation skills, and possibly a local inverter industry. Wind development is often credited with creating more jobs per dollar invested and per kWh generated than fossil fuel power generation (Kammen, Kapadia, \& Fripp, 2004).

The creation of a stable SSW market effectively creates demand for turbines, in response to which local turbine manufacturers are able to compete. The widespread use of SSW in Denmark provided the perfect test-bed for local manufacturers to perfect their designs, cradling the early stages of the local turbine manufacturing industry.

\footnotetext{
'For many years, wind development in Denmark occurred in 'onesies' and 'twosies' a few turbines at a time. This gradual and steady development enabled the Danish wind turbine manufacturing industry to learn from experience what worked and what did not, and allowed it to correct any problems as they arose" (Bolinger, 2004: 51)
}

As a result, by the end of 2003 around $99 \%$ of all turbines installed in Denmark were locally made (Lewis \& Wiser, 2005). Also, the Danish manufacturing industry is now the largest in the world, with a global market share of just less than $40 \%$ (DWIA, 2005). 
This bottom-up, incremental approach is considered more effective at supporting innovation, technological change and accumulation of knowledge in local turbine manufacturing, as opposed to the large-scale, top-down efforts seen in other countries like Germany, the USA and the Netherlands (Heymann, 1998, Kamp, 2002, Karnoe, 1991 cited in Buen, 2005). Experience in the United States suggests that even with substantial research and development funding, a lack of local markets means local manufacturing is considerably less likely to succeed (Loiter \& NorbergBloom, 1999).

The provision of a stable market for SSW has proven to be effective in facilitating the development of a domestic turbine manufacturing capacity. If the global turbine shortage continues into the medium term then the possession of this local industry will likely become more valuable.

\subsubsection{Summary}

This chapter has set out a number of important advantages of SSW for the development of a wind industry. It has shown that people are generally more accepting of SSW compared to large wind farms and that SSW facilitates the development of community ownership, often associated with the provision of additional financial resources. Also, because SSW can be built in a greater number of areas, it opens the potential for system benefits of DG. Finally, provision of a stable market for SSW can help improve the environment for local turbine manufacturers. 


\subsection{Disadvantages}

There are a number of disadvantages associated with wind energy in general.

Turbines are commonly regarded as having a negative visual effect on landscapes.

This effect is accentuated given that they are generally placed on ridgelines and on hilltops where wind speeds are higher, thus increasing their visibility from a distance. Noise is another commonly cited issue. Noise comes from movement of the turbine's gearbox and generator, along with the swooping sound of airflow over the blades. Other disadvantages include bird collision and effects on aviation, radar and telecommunications (EWEA, 2005).

Unlike conventional power generation, wind is a variable and unpredictable energy source, causing possible difficulties for power system management. For example, regular fluctuations on the local lines network can create difficulties for the System Operator in terms of forecasting, planning, scheduling and dispatch of electricity. Variability is an important disadvantage because it means power must be constantly and readily available from additional sources (back-up generation) for when the wind stops blowing (Milligan, 2004).

Unlike conventional fuels, such as gas and coal, wind cannot be stored. However, the power generated from wind can be stored in batteries, though in many cases this is still a relatively expensive technology. However, a recent feasibility study by Sustainable Energy Ireland found that the benefits provided by the Vanadium Redox Battery Energy Storage System (such as reduced variability and need for back-up generation, and improved power quality and dispatch reliability) make such storage systems economically viable (SEI, 2007). As these storage technologies become more commonplace, wind will be able to be dispatched in much the same way as a conventional power stations.

The two disadvantages that are more pronounced in the case of SSW are the high capital cost and high operating cost. 


\subsubsection{High Capital Cost}

SSW projects cannot spread the fixed costs of a project - such as legal fees, turbine price, obtaining resource consent and crane hire - over a greater number of turbines as is possible with a large wind farm. As a result, the cost of each unit of electricity generated is higher than with larger projects (Bolinger, 2001). For example, building $20 \mathrm{MW}$ of wind capacity in a single large wind farm would be significantly cheaper than achieving that capacity with 20 single turbine installations.

A New York study estimated that installation costs are 25\%-33\% higher for SSW projects (1MW - 10MW range) than for larger wind farms (NYSDPS, 2004).

However, these higher costs can be offset in situations where existing infrastructure is utilised, which is more likely to be possible with small-scale developments. For example, in situations when existing roads can be used, or when projects are connected directly into existing distribution lines, the need to build additional lines or a substation can be avoided (SEED, 2005). The relatively high resource consent costs of large wind projects might also be avoided or reduced in situations where SSW projects are locally owned and developed.

\subsubsection{System Integration Costs}

Most electricity systems were designed to support large-scale, centralised power stations, where power is transported long distances from point of generation to the point of consumption. These systems were generally not designed for decentralised generation sources (Stern, 2007). As a result, the system integration costs can be relatively higher for distributed renewables, like SSW, at least before the system is gradually reconfigured as DG is introduced.

High levels of distributed SSW can create continuous fluctuations of power and voltage through local lines networks. This can potentially make lines management more difficult in terms of frequency keeping, monitoring, maintaining power quality and load management. Also, because the direction and quantity of real and reactive power flows change, the operation of network control and protection equipment may be affected (NWCC, 2001). Overall, it can be more costly to have a large number of small intermittent generators than to have a small number of larger, non-intermittent 
generators, in terms of lines management effort required per kWh generated (NWCC, 2001).

SSW can also increase the handling and administration costs for the electricity retailers. For retailers with power purchase agreements with small generators, the same type of work needs to be undertaken as with a larger generator, but the economic returns are considerably less. This work includes measuring the quantity dispatched each half hour trading period against the total amount required from other generators, along with calculating the difference between the spot market price and the price payable under the power purchase agreement.

To summarise, there are a number of disadvantages of both SSW and wind energy in general, though two disadvantages that are more pronounced in the case of SSW are the high capital cost and high operating cost. Intermittency disadvantages would be significant where there is a concentration of SSW in a local area, but development of battery technology promises to mitigate these. 


\subsection{Barriers}

This section discusses a number of barriers facing SSW internationally.

Understanding these barriers is important because it not only provides a basis for considering government intervention, but also provides a way of establishing the best form that intervention might take. In reviewing international renewable energy markets the Renewable Energy Network concluded:

"The high renewable energy penetration scenarios could only be achieved with active intervention from governments in energy markets. Such market interventions involve removing existing market barriers and correcting market distortions limiting development and investments in renewable energy" (REN21, 2005: 14).

Each of the following barriers relate to wind energy in general, though the first two barriers, Cost and Discounting and Lack of a Level Playing Field are particularly significant in the case of SSW.

\subsubsection{Cost and Discounting}

The relatively high cost of SSW is arguably the most significant barrier constraining its uptake. As stated earlier, SSW projects do not realise cost savings from economies of scale available to larger wind farms, meaning the cost per $\mathrm{kWh}$ produced is considerably higher.

A cost element of increasing relevance to wind is discounting. The discount rate is used to compare the present value of a dollar spent or earned today with one spent or earned at some point in the future. The rate used affects both the net present value (NPV) of future revenue generated from a wind project, and also the rate at which capital costs are levelised over time.

If a high discount rate is used - as is used in commercial markets - the earnings or benefits in say 20 years' time will have very little present value now. This means an investment that yields long-term future environmental benefits, like a wind farm, is less likely to be undertaken. However if a lower discount rate is used, then the same stream of benefits would have a higher present value, so the investment would appear more favourable. In Denmark, utilities generally use a discount rate of $5 \%$, 
while in the USA rates are between 8 and 10\% (SDC, 2005). The argument for a particular discount rate is typically based on different views of the social rate of time preference, and on ethics. For example, a lower discount rate places a higher consideration on the welfare of future generations (Stern, 2007).

Figure 11 illustrates the effect different discount rates have on the economic viability of a wind project ${ }^{3}$. It shows that after 20 years, the NPV of total revenue generated is $38 \%$ higher when using a $4 \%$ discount rate than when using an $8 \%$ rate. This illustrates that if lower discount rates were used then wind would become a more attractive investment option.

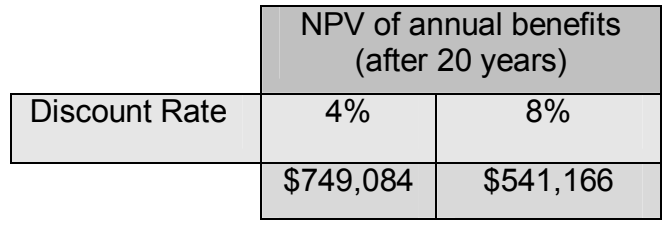

Figure 11: Comparing the effect of two discount rates on net present value

The discount rate used is particularly important when calculating returns from wind investments, because wind is generally more capital intensive than fossil fuel generation. A low discount rate means capital costs are amortised over a greater period of time, effectively lowering the cost per unit of electricity generated. For a typical wind project, around $75 \%$ of total costs relate to capital costs, but for a typical gas power plant this figure is around $40-60 \%$ (EWEA, 2005). As a result, wind is considerably more sensitive to changes in discount rate.

Table 7 is taken from a study by the UK Sustainable Development Commission. It shows at a $5 \%$ discount rate that wind is only $0.3 \mathrm{p} / \mathrm{kWh}$ more expensive than gas, but at a $10 \%$ discount rate the gap widens to $0.9 \mathrm{p} / \mathrm{kWh}$. This demonstrates that a lower discount rate makes wind considerably more cost-competitive with gas.

Table 7: The effect of the discount rate on generation costs

\begin{tabular}{|c|c|c|}
\hline Plant & $\begin{array}{c}\text { Test discount } \\
\text { rate (\%) }\end{array}$ & $\begin{array}{c}\text { Generating cost } \\
\text { (pence/kWh) }\end{array}$ \\
\hline CCGT (Gas) & 5 & 2.1 \\
\cline { 2 - 3 } & 10 & 2.3 \\
\hline \multirow{2}{*}{ Wind } & 5 & 2.4 \\
\cline { 2 - 3 } & 10 & 3.2 \\
\hline \multicolumn{2}{|c|}{ Source: (SDC, 2005). }
\end{tabular}

\footnotetext{
${ }^{3}$ Assumptions: Annual turbine output is $706,530 \mathrm{kWh}$ (amount generated by the Brooklyn turbine during 2005). Annual benefits are calculated by multiplying this output by the average monthly spot price for 12 selected nodes throughout New Zealand (these selected nodes are considered to be indicative of average prices established at all nodes throughout the country.
} 
There is no 'correct' discount rate and the choice of an appropriate rate to apply in respect of wind farms is complex. Nevertheless, if the wider social (including climate change) benefits of wind farms are considered, there is a case for applying a lower discount rate than the standard discount rate that investors would otherwise apply.

The use of a lower discount rate not only increases the NPV of future revenue, but also spreads the cost of a wind project over a longer period of time, thereby lowering the cost barrier to wind investment. In contrast, use of a higher discount rate makes a wind project more expensive, thus making it less attractive to investors.

\subsubsection{Deregulated Electricity Markets}

Over recent decades, there has been an international trend for countries to deregulate their electricity markets. Market liberalisation has created a major barrier for emergent technologies like wind because in a competitive market environment where the profit dimension takes precedence and externalities are not internalised wind is more expensive than established sources like large-scale hydro, coal and gas (Menz, 2006).

When private firms consider investing in a wind project they weigh up investments against a number of financial criteria. These might include the profitability of a project based on projected future electricity prices, the financial strength of the investor and the return on investment relative to other investments. However, the benefits associated with wind are also non-financial, accruing beyond the firm to society and the environment. If all these benefits were included in the firm's decision to invest then wind would be a more attractive option. At present, the private optimal level of investment in wind power will likely always be less than the socially optimal level. Given this disparity - and assuming that that environmental benefits of renewables are a public good - it could be argued that in many cases deregulated electricity markets exhibit a form of market failure. 


\subsubsection{Infrastructure}

In many countries, the design of electricity infrastructure is generally tailored toward the operation of large centralised power plants, which may create a bias towards centralised generation. For example, system operators may not be sufficiently equipped to deal with DG, while the transmission and distribution networks themselves may not be able to absorb electricity from a large number of smaller sources (SUSTELNET, 2004). This means that technologies like SSW may struggle to enter the market, even if that technology is itself commercially viable (Stern, 2007).

\subsubsection{Institutional Inertia}

Jeremy Rifkin is a leading international author on the impacts of scientific and technological changes on society and the economy. In an interview with the EWEA ${ }^{4}$ he was asked for his views on why support for renewable energy typically faces resistance from decision-makers:

"There are three primary elements to explain the resistance of decision-makers. One is vested interests in the old energy sources, another is the inability to think in new ways and the third is a deep belief in control from the top down. Conventional energy systems go together with control by elites; by contrast, wind is egalitarian and participatory" (EWEA, 2006b: 35).

Institutional inertia, the resistance to think in new ways, does not only appear at the decision-making level. Large power companies in Germany and Denmark actively tried to resist the implementation of wind support policies, something they viewed as a threat to their competitive market positions.

Until the end of the 1980s, renewable energy in Germany faced a political-economic electricity supply structure that was largely hostile. The electricity system was dominated by a small number of large utilities, who relied mostly on coal and nuclear generation. These utilities were opposed to small and decentralised forms of generation, which they, at that time, deemed as uneconomic and foreign to the system (Jacobsson, 2006). This opposition led them to resist the implementation of the feed-in tariff tariff law that was introduced in 1991 (Toke, 1999). Resistance also came from the Minister of Economic Affairs, who argued that new energy

\footnotetext{
${ }^{4}$ The European Wind Energy Association
} 
technologies had to prove themselves in the market, and that there should be no subsidies of immature technologies unfit for the market (Jacobsson, 2006). Power companies showed similar resistance in Denmark when the feed-in law and other subsidies were introduced there (Buen, 2005; Meyer, 2004). The same problem was encountered in the late 1970s in the USA, when power utilities tried to prevent the passing of the Public Utility Regulatory Policies Act 1978 (Weinburg, 2007). This Act required utilities to connect renewable generators to the grid and to purchase all of their power generated.

Thus, the transition from a conventional energy system to one that is based more heavily on renewables can experience resistance from a number of players and on a number of levels.

\subsubsection{Lack of a Level Playing Field}

Wind energy and renewables in general are not competing on a 'level playing field' with conventional generation sources for two reasons: first, because of subsidies provided to other generation sources; and second, because many pricing systems do not reflect the full costs associated with the generation of electricity.

In many countries, including New Zealand, generation sources such as coal, gas and hydro have received, and continue to receive, extensive government subsidies. For example, in 2004 the government announced $\$ 15$ million of funding for the gas industry to support the exploration of new gas reserves (MOE, 2004). These subsidies keep the costs of these technologies artificially low, which puts wind at a competitive disadvantage in the marketplace. The reduction of these subsides helps to level the playing field so that wind is better able to compete on a cost basis (Sawin, 2004).

In a competitive market environment generation costs are used to compare wind with fossil fuel generation, but this is not a consistent comparison. A level playing field comparison incorporates the full costs and benefits associated with the generation of electricity from each source. 
If the benefits of distributed SSW - such as cleaner air, climate protection and deferred need for lines investment - were internalised then the cost of the electricity generated would be lower.

If the full costs of fossil fuel generated electricity - such as damage to human health, global warming and pollution - were internalised then the price of fossil fuel generated electricity would be significantly higher. For example, a European Commission-funded project, ExternE, estimated that the cost of producing electricity from coal would double and the cost of electricity production from gas would increase by $30 \%$, if external costs were taken into account (Zervos, 2005). Electricity markets that do not reflect the full cost to society of electricity production constitute a form of market failure (Zervos, 2005).

Figure 12 presents the results of the ExternE project in Europe, which quantified the external costs of various generation sources.

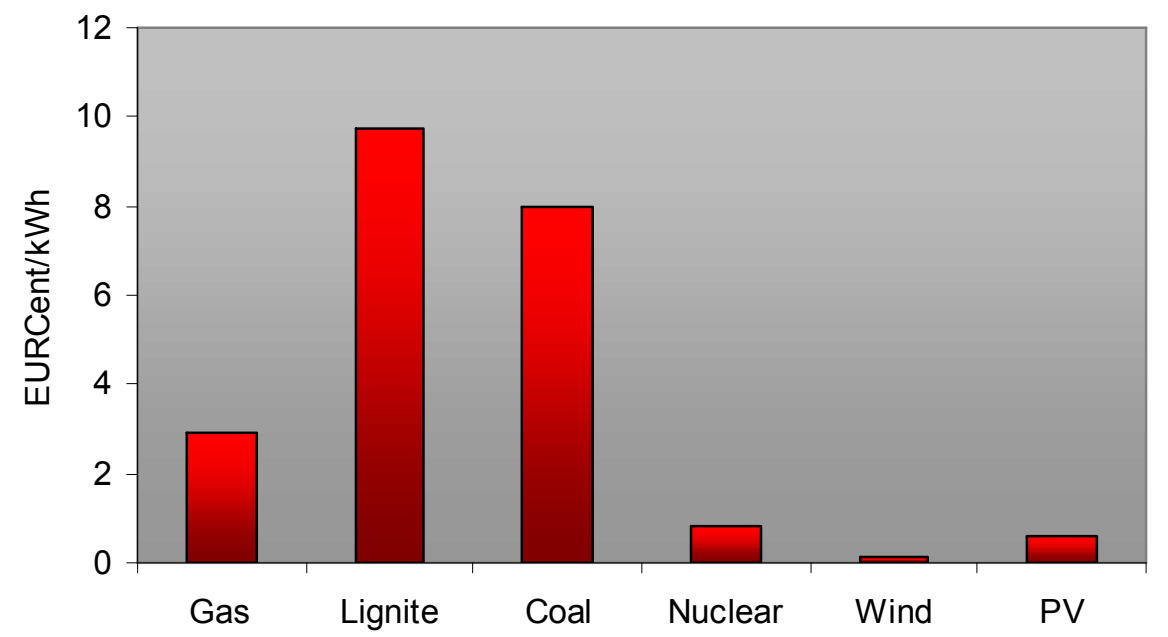

Figure 12: External costs of electricity generation in Europe ${ }^{5}$

Source: (Pieprzyk, 2004)

International experience shows that those countries who have actively intervened to provide a level playing field are the ones who have experienced the highest growth rates of wind energy and other renewables (EECA, 2006; REN21, 2005).

\footnotetext{
${ }^{5}$ If the cost of insurance for reactor catastrophes is included the external cost for nuclear is EUR 180 cents.
} 


\subsubsection{Summary}

There are a number of barriers to the uptake of SSW internationally. In economic terms, SSW is more costly than many conventional generation sources and therefore sometimes appears less desirable in competitive market situations. Critically, SSW competes with these sources within a market environment that typically fails to recognise the full costs and benefits associated with different forms of electricity generation.

Renewables policy generally aims to correct these market failures by providing a level playing field in which wind and other renewables can compete on fair and competitive terms with the more traditional generation sources. Those governments that have intervened actively and created these market conditions have generally experienced the greatest wind industry growth. The various policy instruments used internationally are discussed in the next chapter. 


\section{CHAPTER 4: PUBLIC POLICY OPTIONS FOR SUPPORTING SMALL-SCALE WIND}

This chapter presents some of the various regulatory, financial and legislative policy instruments used to support wind internationally. This chapter focuses on those policies that directly or indirectly support SSW.

\subsection{Regulatory Mechanisms}

There are two main types of regulatory policies used to promote wind internationally, the feed-in tariff (FIT) and quantity-based systems.

Internationally, these two types of regulatory policies are typically used as the main policy instruments in a given country. Other regulatory policies such as fast-tracking planning consent, and the use of various economic instruments (discussed later) are generally used in a supporting role (Clement, Lehman, Hamrin, \& Wiser, 2005; Gipe, 2006).

\subsubsection{Feed-In Tariff (FIT)}

The FIT guarantees the sale of wind-generated electricity at a pre-determined price that is set by government. The price is usually set above the average wholesale market rate and is usually guaranteed over a specified period of time (Sawin, 2004).

The aim of the FIT is to provide investors with a stable, predictable future revenue stream with an attractive rate of return. A stable price is particularly important for independent investors, such as farmers, citizens and community groups who would be less willing to take the risk associated with a fluctuating wholesale market price. International experience shows that a stable price greatly improves the likelihood of these smaller investors obtaining finance from banks and other lending institutions (Gipe, 2006; Sawin, 2004). The FIT is one of the primary drivers behind the strong growth of community ownership in Germany and Denmark (Bolinger, 2001; Gipe, 2006). 
A FIT was first used in the USA in 1978 and is now widespread throughout the world.

By the end of 2005 the tariff had been introduced in 33 countries (Figure 13).

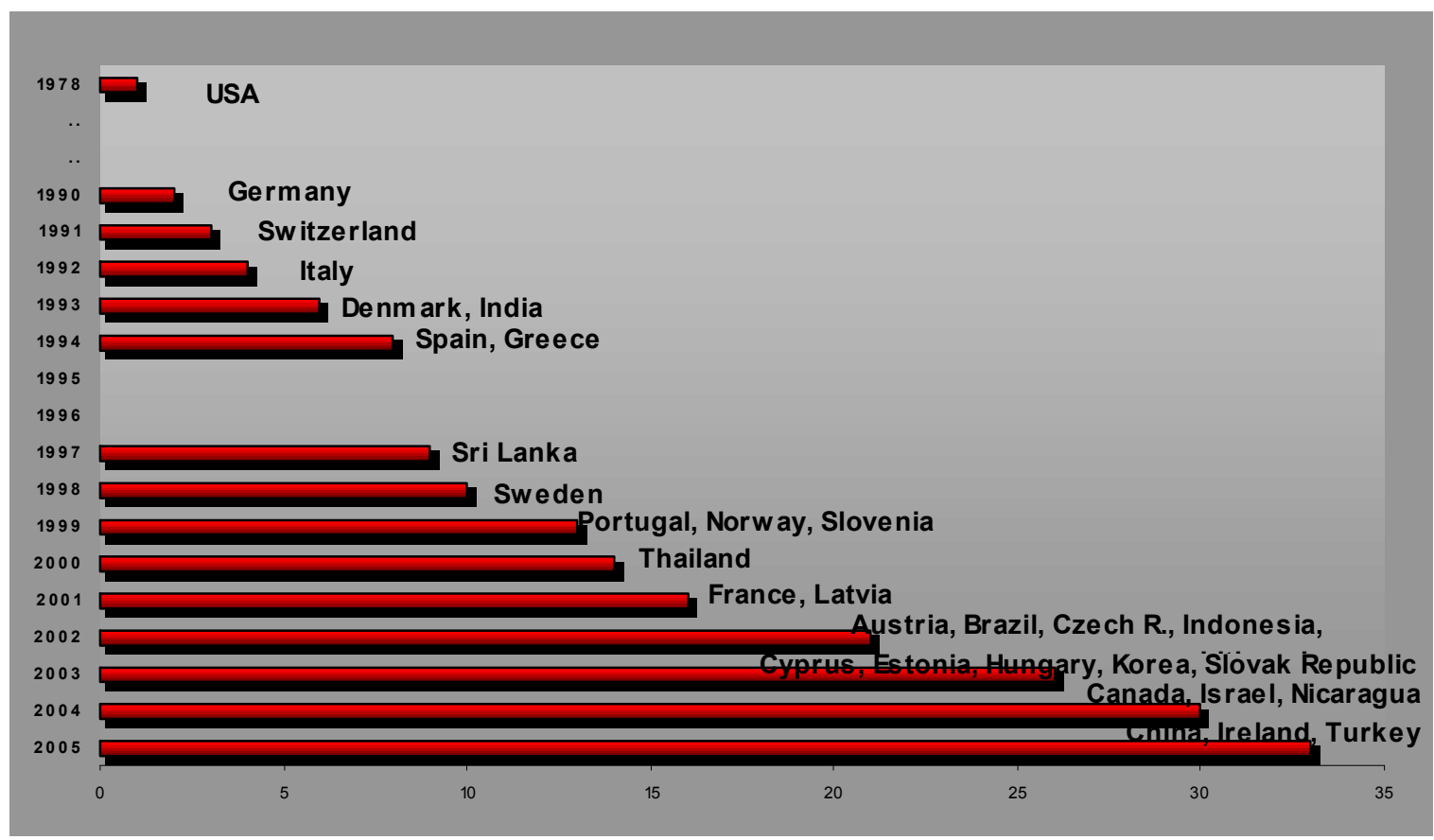

Figure 13: Cumulative adoption of the feed-in tariff internationally

Source: REN21 (2005)

The way in which the FIT is implemented can vary among countries, though there are a number of key design elements that appear in most cases. These design elements are contract duration, means of establishing the sale price, nature of eligible participants, how the price is adjusted over time and the use of stepped tariff design. Table 8 demonstrates the different ways in which these design elements can be applied. 
Table 8: Applications of the various design elements of the feed-in tariff

\begin{tabular}{|c|c|c|}
\hline Element & Variations & Used in \\
\hline \multirow{4}{*}{$\begin{array}{l}\text { Duration of tariff } \\
\text { contract }\end{array}$} & No limit & Hungary, Spain \\
\hline & 20 years & Ontario, Canada, Germany \\
\hline & 15 years & France, Czech Republic \\
\hline & 10 years & Luxembourg, Netherlands \\
\hline \multirow[t]{3}{*}{$\begin{array}{l}\text { Establishing the } \\
\text { price }\end{array}$} & $\begin{array}{l}\text { Percentage of the average retail } \\
\text { electricity price }\end{array}$ & Germany $1991-2000$ \\
\hline & Fixed & Portugal, Slovenia \\
\hline & $\begin{array}{l}\text { A premium over the wholesale market } \\
\text { Price }\end{array}$ & Spain, Czech Republic, Netherlands \\
\hline \multirow{3}{*}{$\begin{array}{l}\text { Eligible } \\
\text { Participants }\end{array}$} & Restricted to community groups & Minnesota, USA \\
\hline & Available to anyone & Germany, Denmark, Spain \\
\hline & Projects smaller than $12 \mathrm{MW}$ & France \\
\hline \multirow[t]{3}{*}{$\begin{array}{l}\text { Adjusting the } \\
\text { price over time }\end{array}$} & $\begin{array}{l}\text { Provisionally adjusted with the } \\
\text { electricity market annually }\end{array}$ & Spain \\
\hline & Held constant for a period & Denmark \\
\hline & Set to decline over time & Minnesota, USA \\
\hline \multirow{2}{*}{$\begin{array}{l}\text { Stepped tariff } \\
\text { design }\end{array}$} & Higher price for smaller projects & Ireland, Slovenia, Luxembourg \\
\hline & Higher price for low-wind sites & Cyprus, Germany 2000-, France \\
\hline
\end{tabular}

Sources: (EEG, 2006; Gipe, 2006; IEA, 2004, 2006b; Sawin, 2004).

Funding sources for the FIT also varies among countries. For example, in the Netherlands the FIT is funded by central government, while in most other European countries it is funded through a surcharge placed on electricity consumers. In Austria and Denmark, this surcharge is lower for electricity-intensive industries compared with householders, while in Luxembourg it is distributed equally among all electricity users (EEG, 2006). In Denmark and Germany, the surcharge costs the average person around $\mathrm{NZ} \$ 80$ and $\mathrm{NZ} \$ 26$ per year respectively (Clark, 2007b).

The FIT mechanism is widely regarded as the most successful wind support policy used worldwide. Its main advantages are its simplicity, low transaction costs and its high degree of flexibility. The FIT also makes SSW more attractive to a wide range of investors and provides long-term certainty which makes accessing finance easier (Butler \& Neuhoff, 2004; Gipe, 2006; Sawin, 2004; Stenzel, Foxon, \& Gross, 2003). “...Worldwide, Standard Offer Contracts (or tariffs) are the most prevalent and successful mechanism in stimulating distributed renewable energy" (OSEA, 2005: 13). 
The most commonly cited disadvantage of the FIT is that if prices are not adjusted over time then consumers and government may end up paying unnecessarily high prices to support the scheme (Sawin, 2004).

\subsubsection{Quantity-Based Systems}

While the FIT fixes the price of wind-generated electricity, quantity-based systems ensure market share for wind generated electricity through government mandated targets or quota (Sawin, 2004). In doing so, they guarantee that a certain minimum quantity of wind power is produced.

There are two main types of quantity-based systems used around the world, obligation/certificate and tendering systems. Below is a brief description of the quota obligation systems used in Australia and the USA, and the tendering system used in Ireland.

\subsubsection{Obligation/Certificate Systems}

In general, obligation/certificate systems require electricity generators or retailers to source a specified amount of their electricity requirement from wind. In most cases the specified amount increases each year, with a specific final target or end date set (Sawin, 2004).

Australia's Mandatory Renewable Energy Target (MRET) was introduced in April 2001 and is the primary wind support policy used in Australia. The scheme successfully boosted the wind industry from $30 \mathrm{MW}$ in 2001 to over $708 \mathrm{MW}$ by the end of 2005 (AusWEA, 2005).

MRET requires large energy users and energy wholesalers to source an additional $2 \%$ of their electricity from renewable sources (including wind) each year by 2010 . To monitor compliance, a system of tradeable certificates called Renewable Energy Certificates (RECSs) is used. Each eligible renewable generator produces one REC for each MWh it produces and sells these on the certificate market. Retailers and large energy users buy these as a way of demonstrating compliance with MRET's obligations. The REC price is determined by supply and demand in the certificate market, which operates separately to the wholesale electricity market. Figure 14 
below shows the average bimonthly REC prices over the past one and a half years. It illustrates that REC prices can be variable and hard to predict.

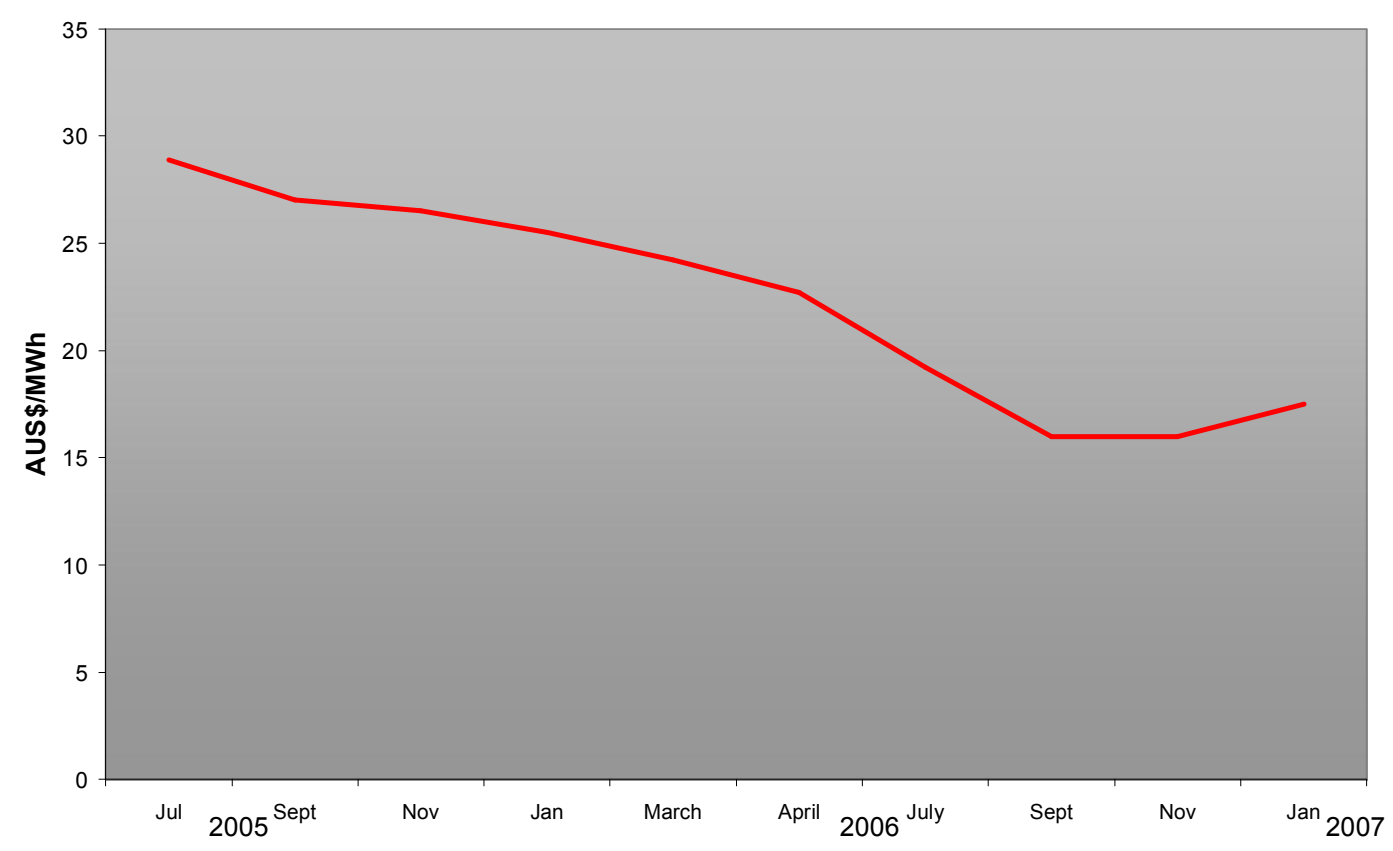

Figure 14: Average bimonthly REC prices under MRET

Sources: AFMA data and the Australian Business Council for Sustainable Energy

The American version of the obligation/certificate system is the Renewable Portfolio Standard (RPS), which had been implemented in 21 states as at February 2007 (Rickerson \& Grace, 2007). In Minnesota state, the purchase obligation for utilities includes a specific amount for wind projects smaller than $2 \mathrm{MW}$. The total obligation currently stands at 1,125 MW to come from wind energy, of which $160 \mathrm{MW}$ must be from SSW .

The key advantages of obligation/certificate systems are that they provide certainty regarding future market share and are perceived as being more compatible with open or traditional electricity markets. In addition, they provide policy makers with clarity about the quantity of renewables they are supporting and the carbon emission reductions this will provide. They also avoid the dissemination of funds by government agencies, which can be bureaucratic and inefficient (Butler \& Neuhoff, 2004; Sawin, 2004).

The key disadvantages of obligation/certificate systems are that they have relatively high transaction costs and tend to restrict developments to areas with the best wind 
resource. They are relatively complex to design and administer and once targets are met there are no incentives to install beyond the mandated level. Also, they do not provide any certainty over future revenue, because prices are established in the certificate trading market, as opposed to being fixed as in the FIT (Sawin, 2004).

\subsubsection{Tendering}

Under tendering systems, regulators specify an amount of wind capacity to be built and project developers then submit bids for price contracts. Generally, those potential developers who offer the lowest bids are accepted first, from which point successively higher bids are accepted until the desired level of capacity is reached. Those who win the tenders are guaranteed the sale of their electricity at that contracted price (Sawin, 2004). The PRE used in New Zealand was a form of tendering system (see section 2.3.4).

Tendering is no longer used in any European country as the primary support policy because tendering systems are not considered as effective as either the FIT or obligation/certificate systems (Strengers, 2006).

The Ireland Tendering Scheme was used as the main wind support policy for Ireland between 1995 and 2003. Winning tenders under the scheme were awarded a 15year power purchase agreement with central government. The tendering rounds were amended in 2001 to include a separate category for wind projects less than 3 MW. Small wind projects received a higher contract price of EUR 5.3 cents/kWh for electricity generated, compared to the EUR 4.8 cents/kWh that was offered to projects larger than $3 \mathrm{MW}$ (EEG, 2005). This scheme was replaced by the FIT in 2005.

One of the major criticisms of tendering schemes is that tenders are generally only awarded to the lowest price bidders. This limits entry to smaller investors, and effectively forces developments to be of larger scale (to achieve economies of scale) and concentrated in high wind areas (Sawin, 2004). In the UK this led to increased resistance from local communities and prolonged consent approval procedures (DTI, 2005; Mitchell, 2004). Also, tendering systems generally have high transaction costs, and can be excessively bureaucratic and expensive to administer (Sawin, 2004). 


\subsubsection{Grid Access}

Most commonly, access to the local grid is provided as part of these regulatory mechanisms. Successful support policy offers non-discriminatory grid access, where developers are not exposed to lengthy and costly connection procedures (Gipe, 2006). Grid access is important for independent developers because it ensures access to the market, while enabling a more accurate estimation of the cost of interconnection in advance (Bolinger, 2001).

Standardising the interconnection process - by developing a set of rules and procedures - helps to streamline the connection process and minimise the transaction costs involved, which can be disproportionately large for smaller projects.

In countries where SSW is commonplace - such as Germany, Denmark and Sweden - the developer must pay for the low voltage transformer and connection to the nearest feasible point on the grid, while the distribution company must pay the costs of any necessary strengthening or upgrading of the lines (Bolinger, 2001).

\subsubsection{Comparing The Feed-in Tariff With Quantity-Based Systems}

Figure 15 illustrates the types of regulatory mechanisms used throughout the European Union. It shows that the FIT is clearly favoured over both obligation/certificate and tendering systems.

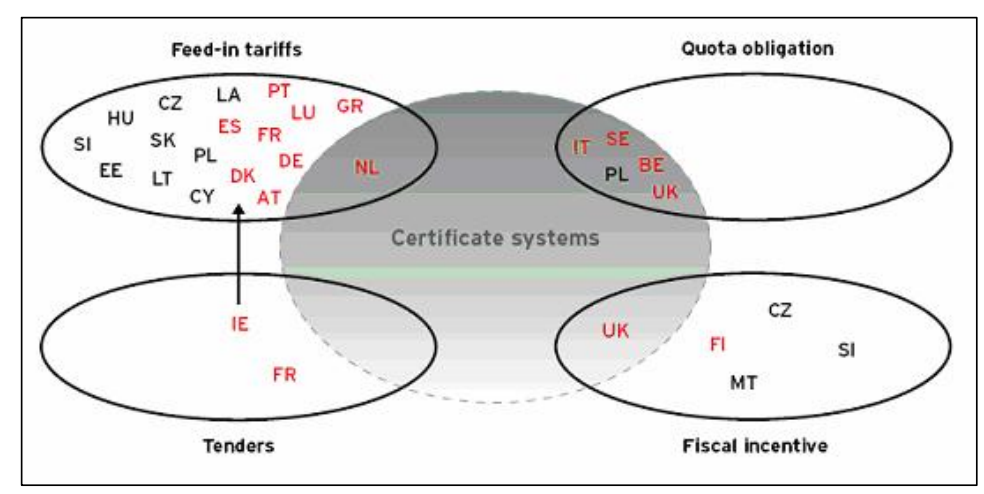

Figure 15: Promotion models of renewable electricity in the EU Source: (BMU, 2006)

As shown in Table 9 below, 20 of the 21 largest countries (in terms of wind industry size) in the world have implemented either the FIT or obligation/certificate systems at some point. 
Table 9: The world's 21 largest wind industries and the respective regulatory policy instrument/s used

\begin{tabular}{|c|c|c|c|c|}
\hline $\begin{array}{l}\text { Global } \\
\text { Rank }\end{array}$ & Country & $\begin{array}{c}\text { Capacity } \\
2006 \\
\text { (MW) }\end{array}$ & $\begin{array}{c}\text { Feed-in } \\
\text { tariff }\end{array}$ & $\begin{array}{l}\text { Obligation/ } \\
\text { certificate }\end{array}$ \\
\hline 1 & Germany & 20,622 & $\checkmark$ & $\checkmark$ \\
\hline 2 & Spain & 11,615 & $\checkmark$ & \\
\hline 3 & US & 11,603 & $\checkmark$ & $\checkmark$ \\
\hline 4 & India & 6,270 & $\checkmark$ & $\checkmark$ \\
\hline 5 & Denmark & 3,136 & $\checkmark$ & \\
\hline 6 & China & 2,405 & $\checkmark$ & $\checkmark$ \\
\hline 7 & Italy & 2,123 & $\checkmark$ & $\checkmark$ \\
\hline 8 & UK & 1,963 & & $\checkmark$ \\
\hline 9 & Portugal & 1,650 & $\checkmark$ & \\
\hline 10 & France & 1,565 & $\checkmark$ & \\
\hline 11 & Netherlands & 1,560 & $\checkmark$ & $\checkmark$ \\
\hline 12 & Canada & 1,451 & $\checkmark$ & $\checkmark$ \\
\hline 13 & Japan & 1,394 & & $\checkmark$ \\
\hline 14 & Austria & 965 & $\checkmark$ & $\checkmark$ \\
\hline 15 & Australia & 817 & & $\checkmark$ \\
\hline 16 & Greece & 756 & $\checkmark$ & \\
\hline 17 & Ireland & 743 & $\checkmark$ & $\checkmark$ \\
\hline 18 & Sweden & 564 & $\checkmark$ & $\checkmark$ \\
\hline 19 & Norway & 325 & $\checkmark$ & \\
\hline 20 & Brazil & 237 & $\checkmark$ & $\checkmark$ \\
\hline 21 & New Zealand & 171 & & \\
\hline
\end{tabular}

Sources: Installed capacity figures (WWEA, 2007); policy instruments

(EEG, 2005; EWEA, 2006a; GWEC/Greenpeace, 2004; IEA, 2006b; REN21, 2006; Sawin, 2004)

New Zealand is notably the only country on the table where neither of these two policy instruments has been used. This lack of policy support is likely to be a key reason why New Zealand's wind industry is failing to experience the higher growth rates seen overseas.

Table 10 below assesses the FIT, certificate/obligation and tendering systems against a set of evaluation criteria. The purpose of this assessment is to assess the strengths and weaknesses of each, in terms their ability to promote new SSW capacity. 
Table 10: An assessment of price- and quantity-based systems against four selected criteria.

\begin{tabular}{|c|c|c|c|}
\hline \multirow{2}{*}{ Criteria } & Price-based systems & \multicolumn{2}{|c|}{ Quantity-based systems } \\
\hline & Feed-in Tariff & Obligation/Certificates & Tendering \\
\hline Effectiveness & $\begin{array}{l}\text { - Consistently proven to be } \\
\text { most successful at promoting } \\
\text { SSW }\end{array}$ & $\begin{array}{l}\text { - Medium degree of } \\
\text { effectiveness. } \\
\text { to benerally forces projects } \\
\text { to be large-scale }\end{array}$ & $\begin{array}{l}\text { Least effective, } \\
\text { especially when tenders } \\
\text { are awarded to lowest- } \\
\text { price bidders, forcing } \\
\text { developments to be large- } \\
\text { scale }\end{array}$ \\
\hline $\begin{array}{l}\text { Encourages } \\
\text { market entry }\end{array}$ & $\begin{array}{l}\text { Attracts all investor types, } \\
\text { from individuals to large } \\
\text { corporations } \\
\text { future revenue stream, } \\
\text { making access to finance } \\
\text { easier. } \\
\text { - No need for negotiated } \\
\text { contract with utilities. }\end{array}$ & $\begin{array}{l}\text { - Tends to disadvantage } \\
\text { small investors because of } \\
\text { associated financial risk and } \\
\text { uncertainty. } \\
\text { - Still a need for negotiated } \\
\text { contracts with utilities - along } \\
\text { with competition with other } \\
\text { developers. }\end{array}$ & $\begin{array}{l}\text { - Competitive bidding } \\
\text { can limit entry to small } \\
\text { investors, especially when } \\
\text { tenders are awarded on a } \\
\text { lowest-price basis. } \\
\text { - Still a need for } \\
\text { negotiated contracts with } \\
\text { utilities - along with } \\
\text { competition with other } \\
\text { developers. }\end{array}$ \\
\hline $\begin{array}{l}\text { Achieves } \\
\text { geographic } \\
\text { diversity }\end{array}$ & $\begin{array}{l}\text { - Can be used to promote } \\
\text { projects in less windier sites, } \\
\text { ensuring that not only the } \\
\text { most favourable sites are } \\
\text { exploited }\end{array}$ & $\begin{array}{l}\text { - Tends to force } \\
\text { developments onto the best } \\
\text { wind sites } \\
\text { in Little incentive to develop } \\
\text { in less windy areas }\end{array}$ & $\begin{array}{l}\text { - Tends to force } \\
\text { developments onto the } \\
\text { best wind sites } \\
\text { - Little incentive to } \\
\text { develop in less windy } \\
\text { areas }\end{array}$ \\
\hline
\end{tabular}

Sources: (Butler \& Neuhoff, 2004; BWE, 2005; Gipe, 2006; Meyer, 2004; Mitchell, 2004; Sawin, 2004; Stern, 2007).

In terms of policy effectiveness and efficiency, a comparison between price-based and quantity-based systems was made in the Stern Report:

"Both sets of instruments have proved effective but existing experience favours pricebased support mechanisms. Comparisons between deployment support through tradable quotas and feed-in tariff price support suggest that feed-in mechanisms achieve larger deployment at lower costs" (Stern, 2007: 366).

In summary, if policy effectiveness is given significant weight, the FIT is the best option for supporting SSW. Firstly, the FIT attracts a greater number of investors to the industry, such as small companies, farmers and community co-operatives, who are more likely to be interested in developing SSW projects. Secondly, unlike tendering systems the FIT does not tend to encourage large-scale developments, because it does not force smaller players to compete with larger ones in a 
competitive bidding process. For the long-term acceptance and development of wind energy, these are important advantages.

\subsection{Fiscal Instruments}

Fiscal incentives generally encourage investment in wind either by lowering the initial set-up costs or increasing the payment received for electricity generated (Sawin, 2004). This section discusses fiscal incentives that are beneficial to SSW, with some examples of how they are applied overseas.

\subsubsection{Subsidies}

Subsidies for wind energy generally come in one of two forms; they are either investment- or production-based (Lewis \& Wiser, 2005).

\subsubsection{Investment Subsidies}

An investment subsidy is when government helps to pay for the initial costs of setting up a wind project. It is particularly important for attracting smaller developers like community groups or farmers who are more likely to need financial assistance. Investment subsidies are one of the most commonly used support policies and are used in at least 30 countries worldwide (REN21, 2005).

Examples of the size of investment subsidies used internationally include:

Finland (30\%) and Norway (25\%) (IEA, 2006b); Sweden (15\%-35\%) (Wang, 2006) and Greece (40\%) (EEG, 2005).

From 1979 to 1989, the Danish government offered a range of investment subsidies to support the wind industry. Initially a subsidy of $30 \%$ of all project costs was offered. As the industry matured and turbine prices fell the subsidy was gradually reduced to $10 \%$ before it was abolished in 1989 . The changing subsidy rates are provided in Table 11. Over the decade, these subsidies amounted to about DKK 275 million (NZ \$63,394,730 at the 2007 exchange rate ${ }^{6}$ ), and supported the installation of about 2,567 turbines (EIA, 2005).

\footnotetext{
${ }^{6} \mathrm{NZ} \$ 1=4.3379 \mathrm{DKK}$ at $20^{\text {th }}$ April, 2007. Source: Bank of New Zealand website
} 
Table 11: The changing subsidy rates for wind projects in Denmark

\begin{tabular}{|c|c|c|c|c|c|c|c|c|}
\hline & May & Jan & Jan & Jan & June & Jan & Jan & Aug \\
& 1979 & 1981 & 1982 & 1985 & 1985 & 1986 & 1989 & 1989 \\
\hline Subsidy & $30 \%$ & $20 \%$ & $30 \%$ & $25 \%$ & $20 \%$ & $15 \%$ & $10 \%$ & $10 \%$ \\
\hline
\end{tabular}

Source: (Nielsen, 2002).

\subsubsection{Production Subsidies}

A production subsidy is when the government supplements the income generated from the sale of wind-generated electricity, and is usually paid on a per kWh basis. For example, if a production subsidy of 2 cents $/ \mathrm{kWh}$ is offered, then a wind project owner will receive 2 cents for each $\mathrm{kWh}$ generated in addition to the revenue earned from the sale of that electricity.

In some countries production subsides are specifically targeted at SSW. For example, production subsidies are available for wind projects smaller than: $2.5 \mathrm{MW}$ in lowa, USA; 2 MW in Minnesota, USA; and 1.5 MW in Sweden (IEA, 2006a).

The subsidy can be fixed or vary over time. For example in Minnesota it is fixed at USD 1.5 cents/kWh. Alternatively, the subsidy can be determined in relation to electricity prices and adjusted annually, for example set at $50 \%$ of the average electricity retail price (J. Bailey \& Morris, 2006; McGovern, 2004).

\subsubsection{Low-Interest Loans}

In a number of countries, governments provide subsidies that enable banks to offer low interest loans to wind farm developers. Low-interest loans are when investors can borrow money from banks or other lending institutions at interest rates lower than the market rate (Sawin, 2004). They are particularly beneficial for SSW, where the developers are community groups or farmers, and the cost of borrowing has a significant impact on project finances.

In Germany, a number of banks offer wind project developers loans at below the market rate. For example, Deutsche Ausgleichsbank (DtA) offered loans at 1 or 2 percent below the market rate throughout the 1990s (NWCC, 2001). 
In Minnesota, USA, low interest loan schemes are specifically targeted at SSW. They are available to farmers buying into a wind cooperative where the project is smaller than $1 \mathrm{MW}$ (NWCC, 2001).

Low interest loans are less transparent a subsidy than the explicit investment and production subsidies, but nonetheless, have a similar effect in terms of improving the economics of a wind project.

\subsubsection{Tax Instruments}

A range of tax instruments is used to support wind, including investment tax credits, tax exemptions, carbon taxes and accelerated depreciation. One of these instruments, accelerated depreciation, has been particularly successful in encouraging SSW.

Accelerated depreciation allows investors to depreciate their wind turbine at a faster rate than typically allowed under tax laws. This asset depreciation expense can then be offset against other forms of income, effectively reducing the amount of taxable income for the investor.

The accelerated depreciation rate of $30 \%$ introduced in Sweden and Denmark was one of the principal reasons why many individual farmers began to install one or two turbines on their land (Bolinger, 2001). For example, the regime introduced in Denmark in 1992 was a key contributor toward the increase in the number of farmerowned turbines from 1013 to 1898 between 1993 to 1997 (Buen, 2005; Toke, 1999).

Accelerated depreciation rates vary among countries, some examples include: up to $30 \%$ in Canada (CanWEA, 2006); 100\% in India (Lewis \& Wiser, 2005) and the Netherlands (Bolinger, 2001); 25\% in Portugal and 60\% in Luxembourg (Clement et al., 2005).

A disadvantage of accelerated depreciation is that it complicates a country's tax system. It is also, of course, a subsidy in all but name, and has the standard disadvantage of a subsidy that its cost must be borne through higher taxes elsewhere in the economy. 


\subsection{Legislative Tools}

\subsubsection{Fast-track Planning Consent}

A number of countries have introduced planning rules specifically tailored for SSW. These rules aim to speed up and therefore lower the cost of obtaining planning approval; a cost that is often disproportionately higher for SSW projects. A common approach has been to make SSW projects exempt from needing to complete an Environmental Impact Assessment (EIA). Table 12 below lists some international examples of where SSW developers are exempt from completing an EIA as part of the planning approval process.

Table 12: International examples of countries where SSW developers are exempt from completing an EIA

\begin{tabular}{|l|l|}
\hline Country & IEA exemption provided: \\
\hline Germany & 3 or fewer turbines \\
\hline Denmark & $\begin{array}{l}3 \text { or fewer turbines, or for turbines with a total } \\
\text { height less than } 80 \text { metres }\end{array}$ \\
\hline France & $<2.5 \mathrm{MW}^{2}$ \\
\hline Belgium, Walloon region & $<3 \mathrm{MW}^{3}$ \\
\hline USA, Minnesota & $<5 \mathrm{MW}^{4}$ \\
\hline Canada, Ontario & $<2 \mathrm{MW}^{5}$ \\
\hline UK & $<5 \mathrm{MW}^{6}$ \\
\hline $\begin{array}{l}\text { Sweden, Laholm } \\
\text { province }\end{array}$ & Single turbines $^{\prime}$ \\
\hline
\end{tabular}

Sources: ${ }^{13}{ }^{3}\left(\right.$ Predac, 2005) ${ }^{2}$ (Chabot, 2003) ${ }^{4}$ (Rhoads, 1998) ${ }^{5}$ (D. Bailey, 2006) ${ }^{6}($ SDC, 2005) ${ }^{7}$ (Khan, 2003)

In a review conducted for the European Union of planning policy tools used in Europe, one of the recommendations was that "An EIA should only be a requirement for larger projects, as experience shows that smaller projects can be planned well without an EIA, and because of the costs involved in developing an EIA" (Predac, 2005: 11). This recommendation suggests that for small wind developments completing an EIA can be an unnecessary practice, and that an EIA exemption is a feasible and useful working policy. 


\subsection{Summary}

Over recent years an increasing number of countries have implemented wind support policy. Wind policies can be broadly classed as regulatory, fiscal or legislative mechanisms, with regulatory mechanisms being used as the principal policy instrument. International experience suggests the FIT is the most effective at supporting SSW. It is straightforward, attracts a broader range of investors to the industry and achieves higher geographic diversity in wind development. 


\section{CHAPTER 5: ADVANTAGES AND DISADVANTAGES OF SSW FOR NEW ZEALAND - STAKEHOLDER VIEWS}

This chapter presents the views of various stakeholders in the electricity industry in New Zealand, concerning SSW (see section 1.4.2). Some interviewees were happy to be identified in this thesis, while others chose to remain anonymous. Views from additional sources have also been added, where relevant comments were made public in the media, relevant publications or reports. The results from the rural landowner survey are also included.

The five main advantages of SSW identified from the interviews and survey are: greater public acceptance (relative to large-scale wind); facilitation of community ownership; increased competition in the generation sector; potential for DG benefits; and that it supports local industry.

\subsection{Advantages}

\subsubsection{Greater Local Public Acceptance}

The survey results support international research findings that people are more positive about SSW being developed in their area than large wind farms.

The three key findings from the survey in terms of increased public acceptance are as follows: 1 . Respondents are significantly more positive about SSW being developed in their area than large-scale wind. 2. This preference was evident regardless of their views about wind energy in general. 3. The NIMBY phenomenon is significantly reduced in the case of SSW.

The survey results showed that rural landowners are significantly ${ }^{7}$ more positive about SSW being developed in their local area than a large wind farm. $80.1 \%$ of

\footnotetext{
${ }^{7}$ Based on a paired sample t-test: $p$ value is $<0.001$
} 
respondents were either very positive or positive about a small (2 turbine) wind farm in their area, while only $50.2 \%$ were as positive about a large one (14 turbines).

Responses in respect of each wind farm size are presented in Figure 16.

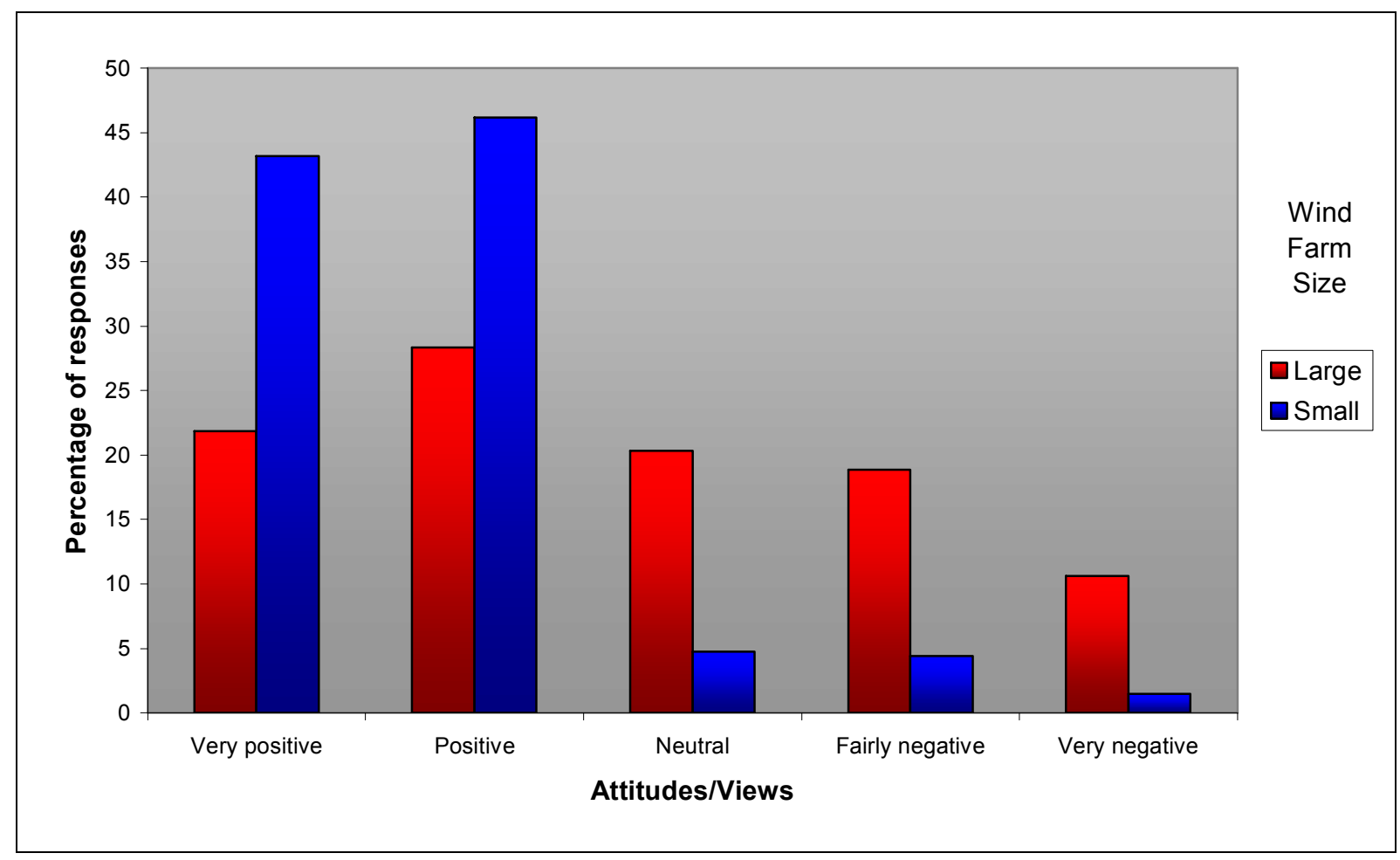

Figure 16: Rural landowners' views about small and large wind farms in their area Source: Survey of Masterton and New Plymouth rural landowners

The survey results also showed that respondents were more favourable toward SSW regardless of their attitude to wind power in general. The first question in the survey asked respondents whether they support or oppose wind power as a means of generating electricity in New Zealand. Responses to this question were categorised into three groups; those that were either very positive or positive were classed as "supportive", those that were either very negative or negative were classed as "antiwind", and those that were neutral as "indifferent".

The results showed that each of these three groups viewed SSW significantly more positively than large wind farms. This is consistent with findings from the Dutch study by Wolsink (1989). This suggests that people who are "anti-wind" and opposed to a large wind farm nearby might be willing to accept SSW in their area. 
The survey results also showed that the NIMBY phenomenon may be significantly reduced in respect of SSW. Of the respondents who were "supportive" of wind power in general, $23 \%$ had a negative attitude toward the idea of a large-scale wind farm being developed in their local area. In contrast, only $3.3 \%$ of this group had a negative attitude toward a SSW farm being developed in their area (Figure 17).

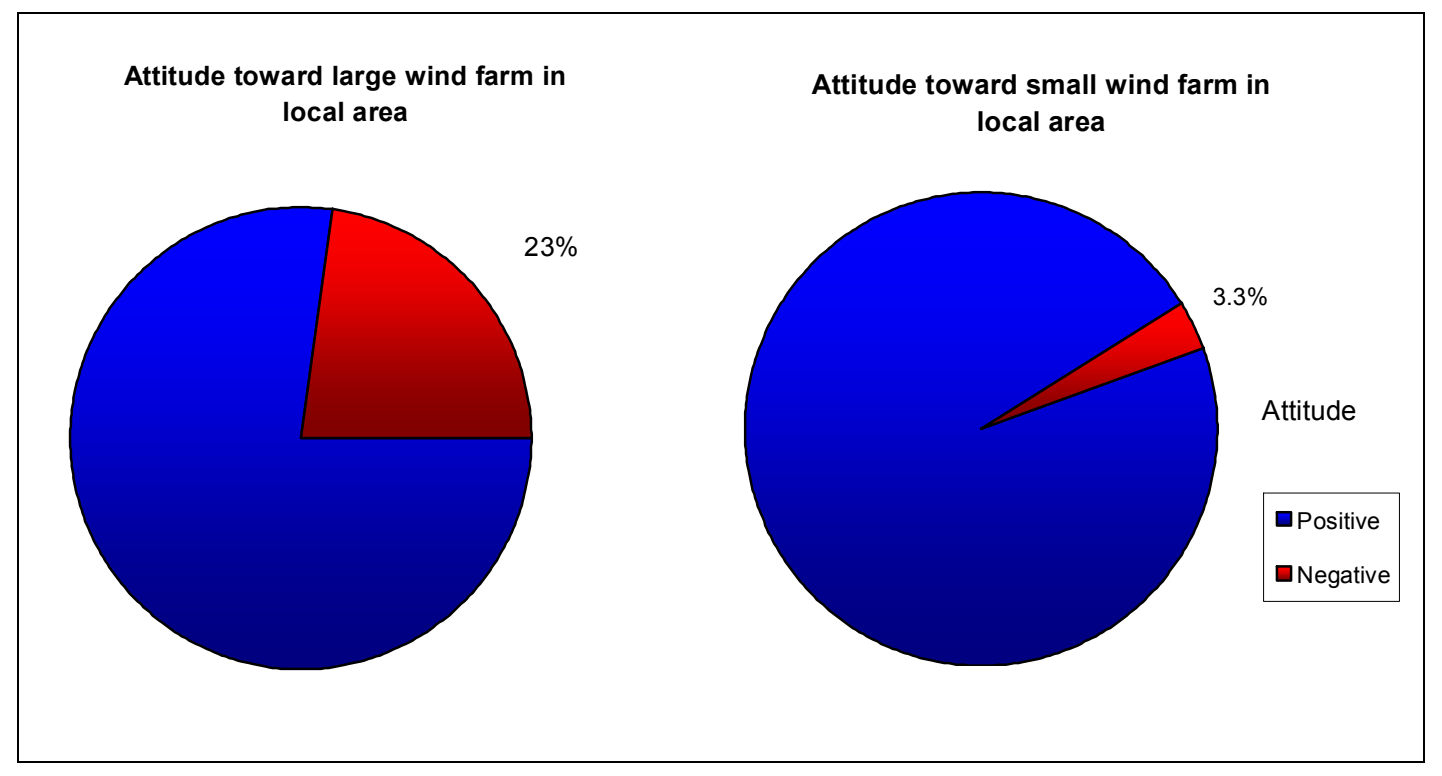

Figure 17: Attitude towards wind farms of different sizes (among the 302 respondents who were supportive of wind power in general)

Source: Survey of Masterton and New Plymouth rural landowners

An additional finding from the survey (not specifically related to SSW) was that respondents in the Masterton region (where there are two existing wind farms) are significantly ${ }^{8}$ more positive of wind energy in general than their New Plymouth counterparts (where there are no wind farms). $91 \%$ of respondents in the Masterton region are "supportive" of wind energy in general, with $4 \%$ being "anti-wind". However in New Plymouth only $85 \%$ were "supportive", with $11 \%$ being "anti-wind". This supports findings from international studies (Ashby, 2004) and local studies (Berg, 2003) that have found people living near turbines are generally more accepting of wind energy than those people who do not. It was also found that respondents in the Masterton region were more positive about both a large- and small-scale wind farm being developed in their local area, suggesting that people

${ }^{8}$ Chi-squared p-value $=0.02$ 
who live near turbines are also more willing to accept further developments in their area.

\subsubsection{Facilitates Community Ownership}

The idea of introducing community ownership of wind generation into New Zealand was received very favourably, with no one among those interviewed disagreeing that it would be good for New Zealand's wind industry.

SSW could be a way for lines companies to get involved in generation, either by sole ownership, or by establishing shared ownership arrangements with local communities. In a press release as Chairman for the NZWEA, Murray Kennedy argued that the Government would be far more likely to achieve its renewable energy targets for 2012 if network companies were allowed to develop wind farms (NZWEA, 2006). As noted by the former PCE: "Lines companies could become major players in the distributed renewable sector" (pers. comm. Williams, 2006).

Encouraging farmers to install SSW on their land was generally considered a sensible way of utilising New Zealand's vast rural wind resource to help address New Zealand's energy supply issues. It is as an opportunity for the agricultural sector to partially offset its greenhouse gas emissions, while the added revenue could reduce the pressure on individual farmers to intensify their land use. "There is opportunity to build resilience in the pastoral farm system by adding a crop called electrons to the current protein crop" (pers. comm. Williams, 2006). Farmer ownership could be especially beneficial in rural regions that are struggling economically, like Northland and the East Cape. There was reasonable confidence that if farmers began making enough money from wind energy, then the idea would soon catch on.

Community ownership is one way of countering the growing tide of local public opposition to wind project proposals in recent years.

"Community wind will remove some of the nimby-ism. There's nothing like being a joint owner in a few turbines that you can see, that it isn't someone else imposing a negative on you... It also helps build familiarity, a vital part of the growth in countries like Germany" (pers. comm. Shearer, 2006). 
Community wind would also increase awareness and understanding of energy related issues among the public. This could support related goals of increasing energy efficiency and usage of green energy in the household sector. A major benefit of community ownership is that it increases society's awareness of and potential for greater control of their energy (pers. comm. Williams, 2006).

The rural landowner survey results show a high level of interest in community ownership, which suggests that New Zealand rural landowners might be ready to support the concept should it be introduced here. $66.1 \%$ of those surveyed in both regions were interested in investing in and installing a turbine on their land. Respondents were also asked whether they would be interested in investing if government support was introduced (to make the investment more secure and profitable). $74.7 \%$ were interested; a statistically significantly higher level of support ${ }^{9}$ (see Figure 18).

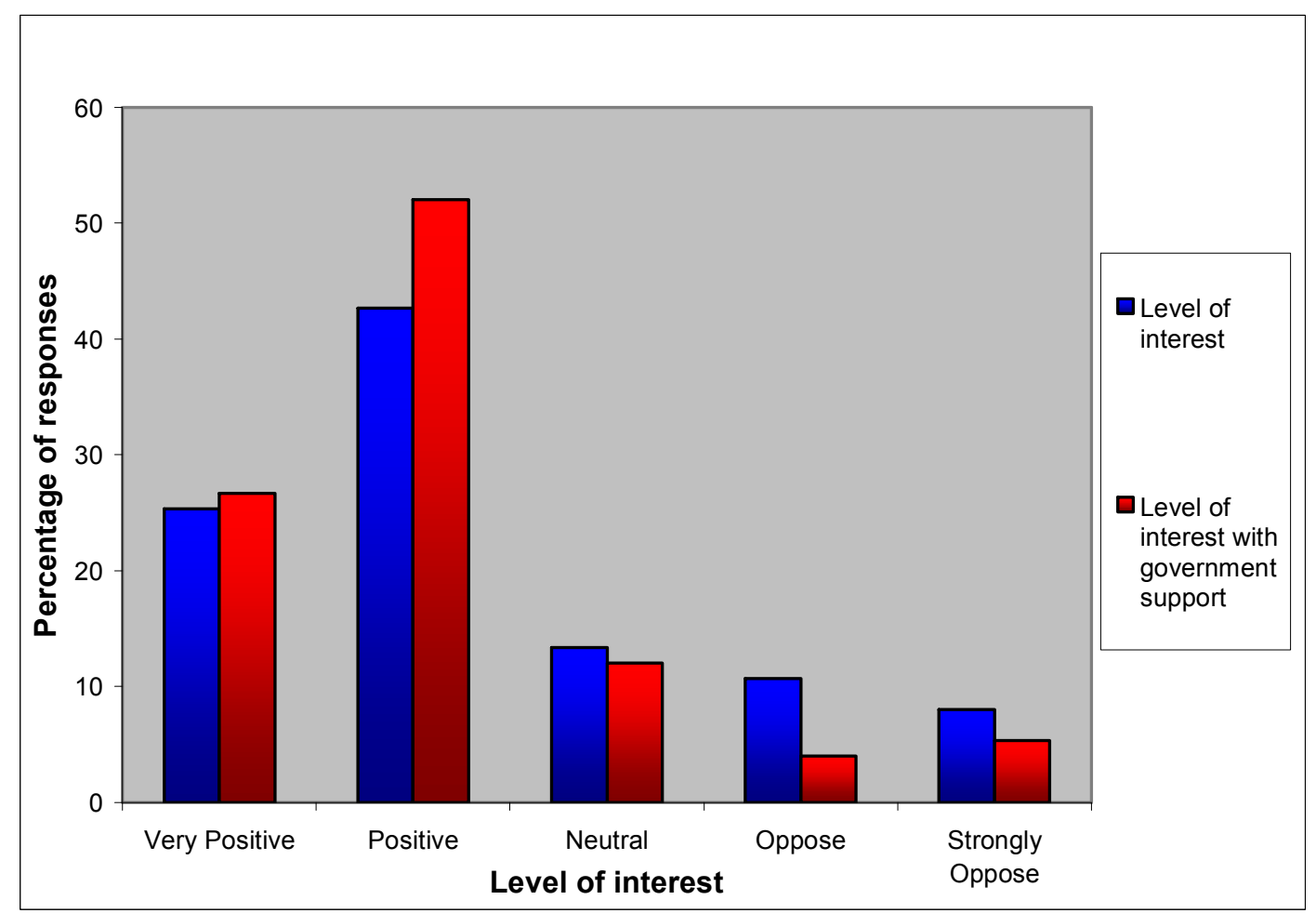

Figure 18: Rural landowners' level of interest towards investing in and owning a wind turbine on their land

Source: Survey of Masterton and New Plymouth rural landowners

\footnotetext{
${ }^{9}$ Based on a paired sample t-test, $p$-value $<0.001$
} 


\subsubsection{Increased Competition in the Generation Sector}

There was widespread recognition among the interviewees of the need for more competition in New Zealand's electricity generation sector. Most interviewees recognised that the current situation was not a healthy competitive environment and could potentially lead to abuses of market power (especially given that most generators are also retailers). " 5 or 6 players is not enough to create real competition" (Interviewee anon). Distributed SSW was seen as a viable way of providing this competition, by way of attracting new investors to the sector. "The pastoral sector could become a serious player in the energy system - as an electricity supplier...it would increase competitiveness in the market" (pers. comm. Williams, 2006).

A side benefit of increased competition is that it could reduce the need for more regulation through the Electricity Governance Rules (EGR), in response to concerns over monopoly power in generation (Heaps \& Hope, 2006).

It is also possible that higher geographic dispersion, together with greater penetration of wind capacity, would also be achieved if network companies and smaller players began to invest in the market (MED/EECA, 2005).

\subsubsection{Utilises Small Exposed Sites}

SSW was seen as having major potential for utilising small pockets of high wind speeds throughout the country. There is a particularly high potential in New Zealand given that such a sizeable proportion of the country is rural landscape, through which extends a well-developed transmission and distribution network.

Developing these sites would give better utilisation of our wind resource. "The 'pepper-potting' approach would be beneficial because there are so many little wind sites throughout the country that the large generators wouldn't be interested in" (pers. comm. Jenkins, 2006)..."The potential for small wind developments is quite immense. In the end it will probably be far higher than it is for big wind farms" (pers. comm. Shearer, 2006). 


\subsubsection{Potential for Distributed Generation Benefits}

It was widely acknowledged among the interviewees that higher levels of distributed wind generation would maximise the potential for wind integration in New Zealand. This is because SSW can be developed on a greater number of sites and be built closer to population centres. This would provide a number of benefits for $\mathrm{New}$ Zealand's electricity network.

Firstly, it would help alleviate a number of transmission and distribution issues. As noted in Chapter 2, New Zealand is suffering from under-investment in transmission and distribution capacity. Due to the higher public acceptance of SSW, projects could be built closer to local communities. In some smaller regions this could defer the need to upgrade local lines. SSW can be connected directly to $11 \mathrm{kV}$ lines, which means, in some cases, that generation can be built without the need for any new lines at all. SSW projects would be particularly beneficial in regions where lines are not strong enough to support the output of larger wind farms, while SSW can also help to strengthen weak lines in the more remote regions of the country. Also, SSW could alleviate lines constraints on supply and transmission losses.

Secondly, SSW could contribute to security of supply. Higher levels of DG would create a more interconnected system, which could increase the resilience of local lines networks, and reduce the vulnerability of remote regions to power outages.

"Security of supply is about having a diverse portfolio of generation assets. Sustainable distributed generation should be a fundamental part of any integrated electricity generation portfolio" (SEANZ, 2006).

Local security of supply will become an important issue for geographically isolated regions after 2013, after which lines companies are no longer obliged to provide power to end users. SSW was seen by some as a serious option to consider as a means of resolving this issue. SSW could be developed in remote high wind regions that are likely to be adversely affected by 2013 .

DG would also benefit lines companies. Lines companies are charged on a per MW basis for the 12 largest peaks of electricity they draw from the national grid each year. If lines companies use more locally generated power then the average size of these 12 largest peaks is likely to be reduced. "If the network can control its load, they can save some money." (Interviewee anon). However, there are potentially additional costs of SSW for lines companies also, and these are discussed later. 


\subsubsection{Supports Local Industry}

It was widely acknowledged that under the current 'big is better' model, the development of New Zealand manufacturing would be limited. This is because New Zealand's only manufacturer, Windflow Technology Ltd. must compete with cheaper, bulk imports from considerably larger companies. Encouraging development of SSW would create a richer market in which local turbine manufacturers would be more able to compete.

"If you have a pool of projects out there looking for supply, you will pull the local manufacturing industry through...the creation of a long-term domestic market is the best way to support local manufacturing" (Interviewee anon).

Expanding a local turbine industry would be beneficial for New Zealand because it would create jobs and give developers alternatives when there are global turbine shortages. "It would be very dangerous to leave ourselves reliant on the ebbs and flows of exchange rates, activities of overseas suppliers and global markets... Turbine shortages are becoming a real issue" (pers. comm. Jenkins, 2006).

An expanding domestic manufacturing base would create jobs in areas such as components manufacturing, assembly and logistics. A report for the Industry Capabilities Network by Business and Economic Research Ltd concluded that for every million dollars of import substitution, 11.8 jobs would be created in New Zealand (ICN, 2004). In other words, for every million dollars that is spent on locally made turbines instead of imported turbines, 11.8 jobs would be created. "There would be significantly more jobs created here if turbines were locally made rather than imported" (pers. comm. Shearer, 2006).

The former PCE Morgan Williams believes that New Zealand should be looking to capitalise on its innovative capacity, and is in a good position to develop a local industry:

"New Zealand should be looking to capitalise on its innovative capacity. We have a strong capacity to innovate, and our reliable winds make New Zealand the best testbed in the world for developing turbines. New Zealand is in a good position to develop resilient systems" (pers. comm. Williams, 2006).

Only a small number of interviewees were aware of the global turbine shortage and rising turbine prices. This is a concern given the impact this shortage has had on overseas industries. 


\subsubsection{Summary}

A range of evidence, including survey and interviewee responses, suggests that SSW could be advantageous in the New Zealand context, for both the wind industry and the wider electricity sector. Figure 19 below illustrates how SSW could alleviate the various issues facing the wind and electricity industry.

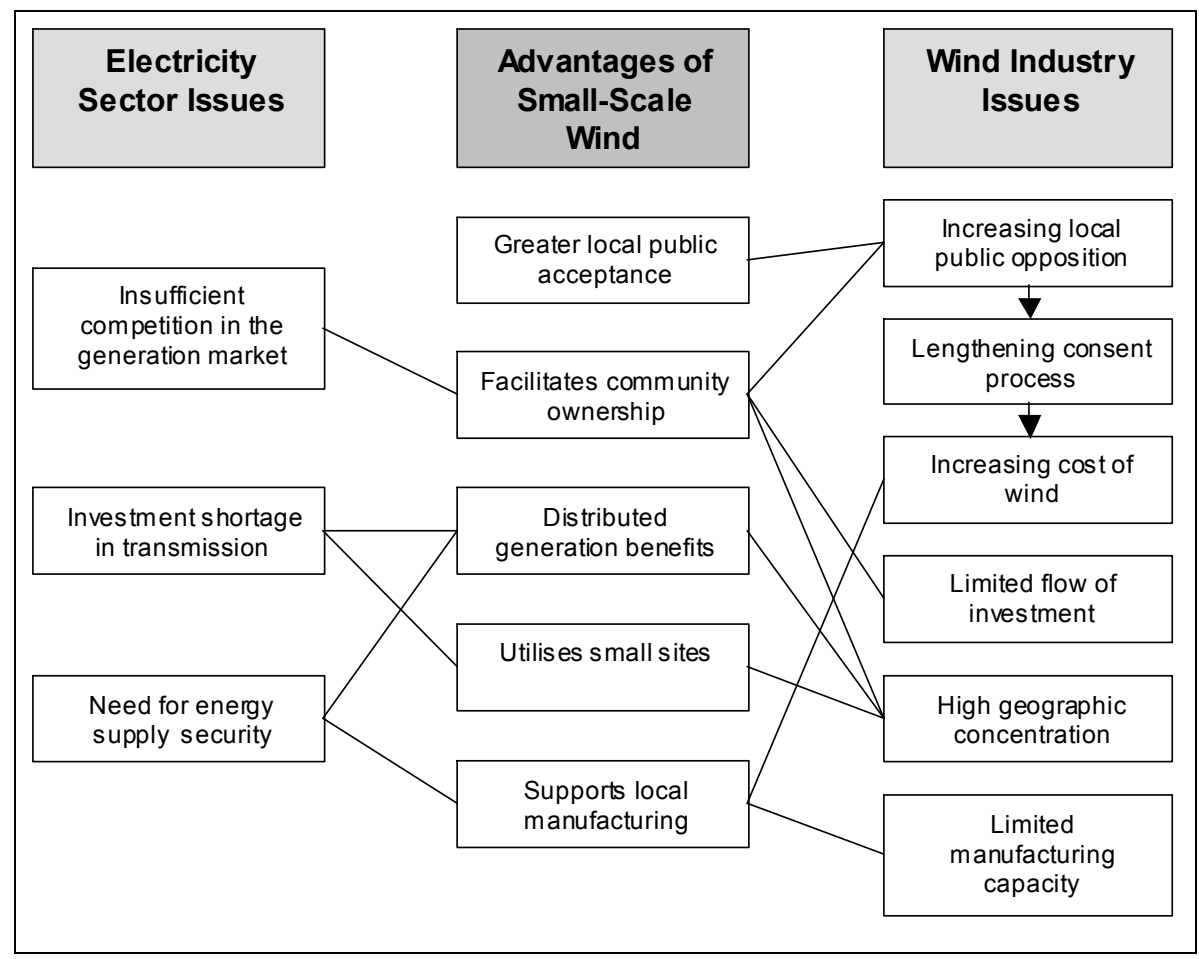

Figure 19: Matching the advantages of SSW with issues in the wind and wider electricity sector

Given that SSW could address these issues facing the wind industry, it can be argued that SSW has the potential to provide for a higher rate of industry growth. Less public opposition could mean that projects can be built faster, with developers facing less delays in the consent process. If there were a greater number of developers then investment capital could be raised from a larger investor pool. Wind projects could be built at a greater number of sites, especially those sites not suitable for larger developments. Also, a stronger local manufacturing base would help contain costs and mean turbine availability would be less of a problem for developers. 


\subsection{Disadvantages}

\subsubsection{High Capital Cost}

The primary disadvantage that interviewees associate with SSW is its high cost. The cost of electricity per kWh generated is higher for SSW due to the diseconomies of scale compared with larger projects. "The problem is that the cost of small developments can be as much as large developments, especially when there's public opposition" (pers. comm. Shearer, 2006). "The efficiencies are in large wind farms" (Interviewee anon).

These costs could be brought down to some extent - at least in the short-term - with government support. Among some interviewees this notion raised ideological questions over whether government should provide support or not. Several stakeholders believed a disadvantage of subsidising SSW is that it would mean that money would be taken from elsewhere in the economy. "Why provide support? It means someone has to pay for it...It takes the resource away from somewhere else" (Interviewee anon). These broader issues are discussed further below (see sections 6.4 and 6.5).

\subsubsection{System Integration Costs}

Distributed SSW poses a number of potential disadvantages to lines companies in the day-to-day operation of their network. These include frequency keeping, maintaining supply quality, protection settings, load management and lines management. It was further noted that lines companies would need to be kept informed of where smaller generators are placed in their networks, so they can get them switched off during maintenance.

For the electricity retailer, there is relatively more administration work involved in dealing with a SSW project than a larger one. For example, the work to be carried out for the day-to-day running of a power purchase agreement for a SSW project is the same as for a large wind farm. Despite this, smaller projects provide considerably less electricity generation, and thus revenue for the retailer. In other words, there is less financial reward for a retailer in terms of the effort required to deal with a small generator. 


\subsubsection{Visual Intrusion}

Some people object to seeing a scattering of SSW projects throughout New Zealand's landscape. These people might prefer wind to be developed in large-scale and on a smaller number of sites. A major disadvantage of SSW is that it takes a large number of projects to achieve the same capacity as a single large wind farm. For example, in order to produce the same output as the Tararua II wind farm (55 $\mathrm{x}$ $0.65 \mathrm{MW}$ turbines), it might take around $18 \mathrm{SSW}$ projects (of 3 turbines). "I have no objection to wind farms but scattering turbines could lead to random proliferation and excessive visual pollution" (Survey respondent).

Despite this, international studies and the survey results suggest these people are in the minority and that smaller developments are generally favoured. Only five of the 170 respondents who were either very positive or positive toward a large-scale wind farm in their area preferred a large wind farm over a smaller one.

Also, many people might argue that wind energy in general should not be developed in New Zealand, regardless of its scale, and that New Zealand should be considering other generation options instead. $5.9 \%$ of survey respondents (20 respondents) were either strongly opposed or opposed to the idea of using wind power as a means of generating electricity in New Zealand. For example: "One small nuclear plant would have a higher output and be less of an environmental problem than any number of wind turbines... wind farms are visual pollutants, they spoil the landscape!" (Survey respondent). On occasion, these views are strongly held:

"The visual destruction of the area round Manawatu Gorge and Palmerston North sickens me and negates any possible benefits for me. If commercial interests prevail then keep the ghastly things out of sight of our main roads and tourists areas. I definitely oppose having a turbine on my land or one next door. Rubbish the idea!" (Survey respondent). 


\section{CHAPTER 6: BARRIERS TO SMALL-SCALE WIND IN NEW ZEALAND - STAKEHOLDER VIEWS}

This chapter discusses the main barriers to SSW as identified in the industry stakeholder interviews and the rural landowner survey. Five primary barriers were identified and are presented in order of perceived importance: high cost; investment risk; obtaining resource consent; the pricing system; and the present market framework. It is interesting to note that the two most important barriers raised in the interviews were also identified as the two most important barriers by survey respondents.

The wording of question 6 in the survey turned out to be too ambiguous and many respondents provided answers that could not be used. As a result there were only 231 viable answers to this question, and only these are presented here.

Respondents were also invited to write comments on barriers and related issues on their survey form. Some of these comments have been included throughout this chapter. Figure 20 displays the number of times each barrier was ranked by survey respondents as being either the most or second most important barrier.

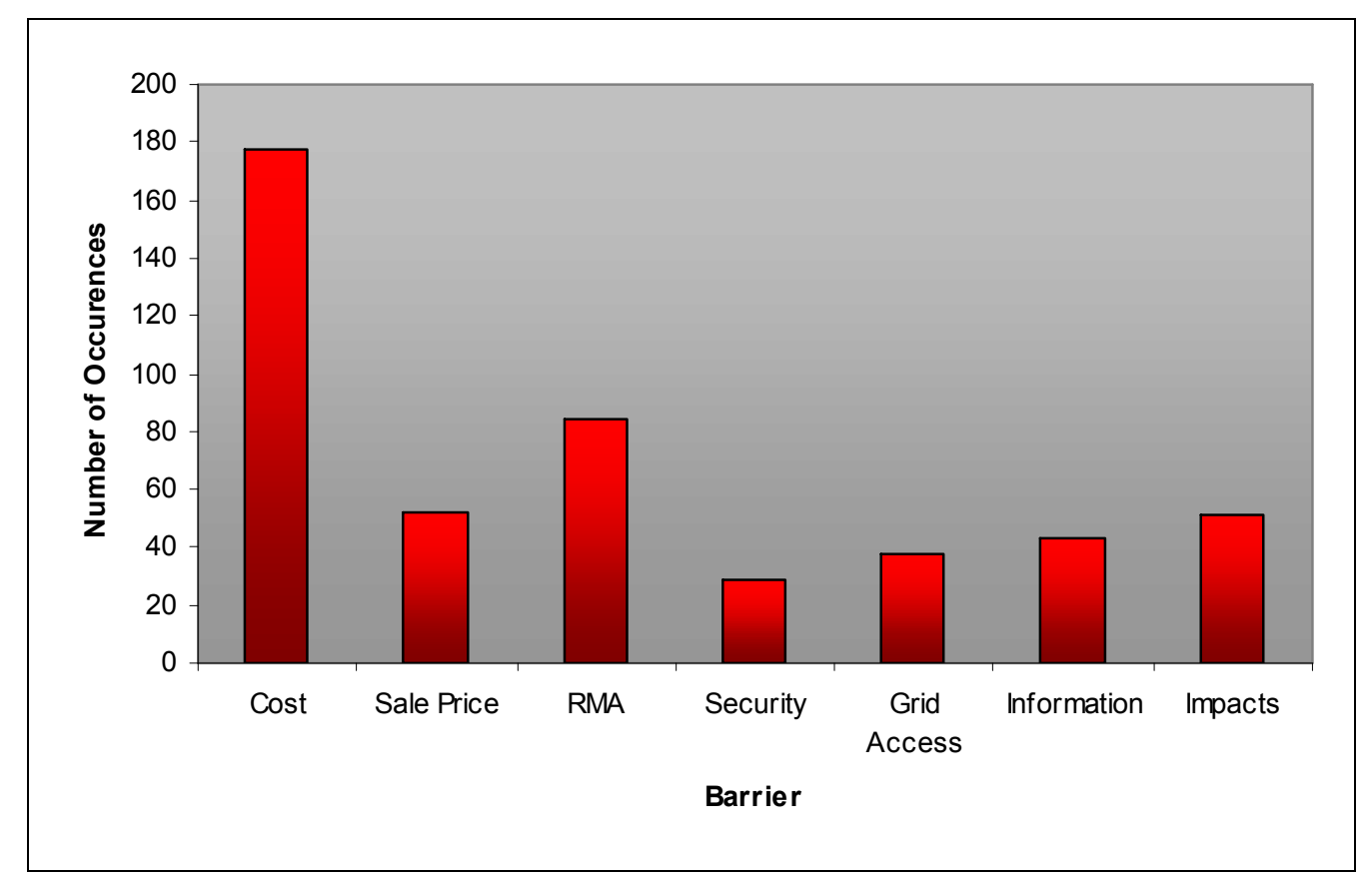

Figure 20: Number of times each barrier was ranked as being the most or second most important barrier by survey respondents 


\subsection{Cost and Discounting}

In the survey, the upfront cost of developing SSW was the most significant barrier identified by rural landowners. It was ranked as the number one barrier by $65.8 \%$ of the 231 respondents, and was considered as either the most important or second most important barrier by $77 \%$ of respondents.

The relatively high set-up cost of SSW was also the most commonly cited barrier by the interviewees. It was a common belief among stakeholders that wind power in New Zealand needs to be large-scale to be economic. The high costs of SSW - due to the effect of diseconomies of scale - were widely regarded as prohibitive. "From a purely economic point of view, SSW will always have the problem of economics" (pers. comm. Matthes, 2006).

It was recognised that this cost disadvantage could be reduced if lower discount rates were used. As noted by the former PCE "Discount rates are crucial to the economic competitiveness of energy sources. As long as we apply current market rates we will seriously disadvantage renewables" (pers. comm. Williams, 2006).

The point was raised that the subsidies provided to other forms of electricity generation throughout the years - such as coal, gas and hydro - have effectively kept the costs of these generation options artificially low. These lower costs unfairly penalise newer, unsubsidised technologies like wind, making it more difficult for them to compete in an open market. This barrier to entry is even higher for SSW because of the effect of diseconomies of scale.

\subsection{Resource Management Act 1991 (RMA)}

The results showed that obtaining resource consent was the second most important barrier identified by rural landowners. It was ranked as the number one barrier by $14.3 \%$ of the respondents, and was considered as either the most important or second most important barrier by $37 \%$ of respondents.

"One possible barrier is getting neighbours to agree...A possible barrier would be obtaining community support... Too close to local community and would create much opposition" (Survey respondents) 
Likewise, the second most commonly cited barrier by the interviewees was the RMA, something many stakeholders considered to have a stifling effect on the wind industry in New Zealand. The consent process is widely seen as too complex, restrictive and expensive. The two main concerns were the cost and time taken to gain resource consent, along with the "excessive" provisions for public involvement in the consent process.

James Glennie, former CEO of the NZWEA, believes that given the RMA process, costs of gaining resource consent are similar irrespective of whether it is a small or large project. The RMA process requires an EIA in terms of visual, noise and landscape effects. High consenting costs, as a proportion of total project costs, means small wind farm developers are, in effect, shut out of the market (NZWEA, 2005). "RMA costs are disproportionately high for smaller projects... The consents process drives developers to build large projects because it is so expensive" (pers. comm. Wilson, 2006).

The RMA was widely criticised by interviewees for having too much scope for public involvement in the consents process. This is particularly important in the case of wind, where local communities bear the costs of a development that is generally consented on the basis of providing a national benefit. "Too many objectors in the appeals process will undermine the growth of SSW" (pers. comm. Matthes, 2006).

"Resource consent is still an issue. It is too easy for objectors to get involved in projects that don't really affect them. People either like wind or they don't, and those that don't like wind get involved for the sake of getting involved" (Interviewee anon).

It is interesting to note that despite the high level of concern over the consents process, all wind projects operating in New Zealand obtained resource consent within six months or less (see Table 3 in section 2.2.1). Nevertheless, a number of recent projects have taken longer to go through the resource consent process, including Project West Wind, TitioKura and Awhitu.

The extent to which the RMA limits the future development of SSW remains to be seen. 


\subsection{Investment Risk}

The current investment climate for SSW was widely perceived as being too unstable and unattractive. This is reinforced by the fact that only three SSW projects have been developed to date. It seems the industry is waiting to see the direction of future government policy, in particular the NZES, which is due for release sometime in 2007. "Lack of certainty on a future carbon price is potentially the biggest barrier right now" (pers. comm. Wilson, 2006).

The investment risk is largely associated with being able to sell the electricity at a fair price. Even though both independent SSW developers (at Southbridge and Gebbies Pass) have secured power purchase agreements, there is no guarantee that future independent developers will be able to do the same.

If such agreements cannot be secured, developers will have to sell to the wholesale electricity market, which brings a higher degree of risk. This is because prices in the wholesale market are highly volatile, making it relatively difficult to predict future revenue streams. Figure 21 illustrates this volatility, showing average monthly spot prices in the New Zealand wholesale electricity market over the past decade.

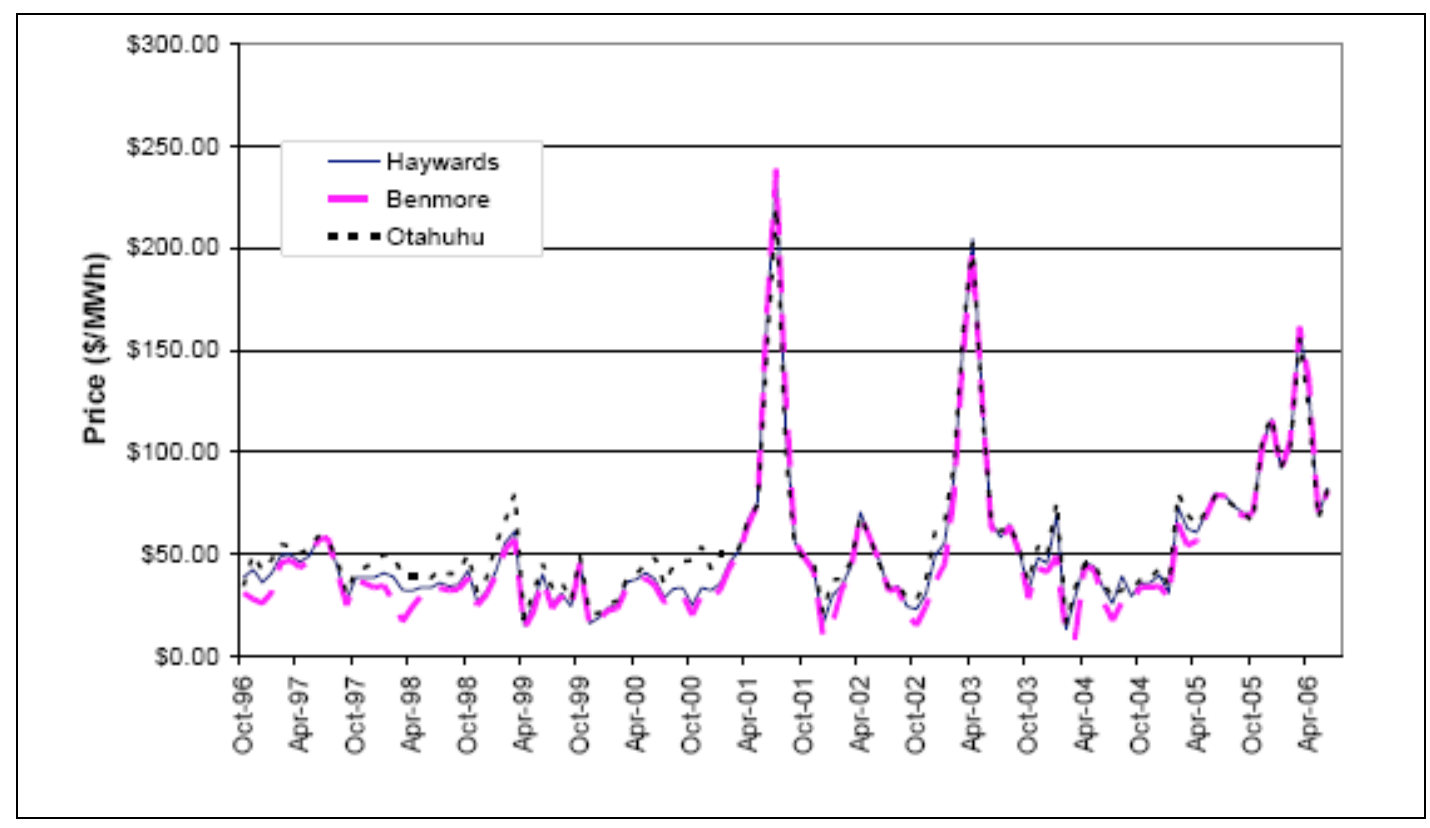

Figure 21: New Zealand wholesale market spot prices

Source: (Dupuy, 2006). 
This volatility is particularly problematic for smaller players, who are less able to bear the level of risk that larger players can. "There is no barrier from selling the electricity to the wholesale market. The barrier is being able to withstand financially the volatility of the wholesale market" (Interviewee anon).

To protect against this volatility developers can in principle purchase hedge contracts, which help make revenue streams more predictable. However, an investigation report by the Electricity Commission found that one of the primary barriers to entry in the generation market is the difficultly for independent generators in finding a hedge contract that adequately covers their spot market exposure (EC, 2004).

\subsection{The Pricing System}

The survey results shows that getting an adequate sale price for electricity generated was the third most important barrier identified by rural landowners. It was considered as either the most important or second most important barrier by $22.5 \%$ of respondents.

The inability of New Zealand's electricity pricing system to fully reflect the social, environmental and technical costs and benefits associated with distributed renewables was considered a barrier to SSW by the interviewees. This applies to pricing both in the wholesale electricity market and grid connection charges.

In terms of the wholesale electricity market, it was a widely held view that if all externalities were internalised, then distributed SSW would become more cost competitive. The biggest impact would be through the price of fossil-fuel based generation becoming higher (through internalising the cost of carbon). "Getting a price for carbon, that has to be done" (pers. comm. Shearer, 2006). Ideally, the price of distributed SSW generation would also become cheaper, through a subsidy that internalised the full benefits of distributed renewables, for example greater security of supply.

"The market pricing system does not recognise the benefits of renewables, it if did that would definitely benefit renewables....The current market only covers price. It doesn't cover $\mathrm{CO}_{2}$ emission reduction potential" (Heaps, 2006). 
This barrier is exacerbated by the fact that electricity in New Zealand is relatively cheap compared to many other developed countries, reflecting traditionally low gas prices and an abundance of large-scale hydro. This makes it even more difficult for SSW to be competitive.

"Economies of scale and the current market regulatory environment tend to favour larger grid-connected generation rather than DG, with correspondingly more concentrated local environmental impacts" (MED, 2006: 53).

In terms of grid connection, one interviewee noted that connection costs can, in some cases, disadvantage distributed SSW. At present, large, centralised generators (who are more reliant on the transmission network) are paying similar charges for lines connection as small, distributed generators (who are less reliant on the network). This means that small, distributed generators are paying relatively more for use of the lines network. The point was also raised that distributed generators are not being adequately rewarded for situations where they provide system benefits, such as alleviating transmission constraints or helping to defer network investment.

\subsection{The Present Market Framework}

A vast majority of interviewees believed the current market framework is not conducive to entry by an independent SSW developer, largely because the electricity market is dominated by a small number of relatively powerful players. The key problem is that smaller players need to negotiate power purchase agreements with retailers who are not only considerably larger, but were also maybe their competitor in the generation market. It was widely perceived that under these conditions smaller players would always struggle to get a fair price for their electricity. "Small players shouldn't have to sell it to someone who is also a competing generator" (pers. comm. Williams, 2006). "The dominance of the existing market players is a barrier: getting someone else to buy the electricity [is an issue]" (pers. comm. Jenkins, 2006).

It was noted by a number of stakeholders that New Zealand's electricity market was designed for large-scale participants, and that the market rules and conditions are illsuited to attracting small investors. 
"Simple connection and market participation arrangements for smaller players do not exist. The complexity and cost of compliance with the market arrangements makes it difficult for new entrants to gain sufficient economies of scale to cover market entry costs" (Heaps \& Hope, 2006: 17).

This was confirmed by a report by MED, stating that the reason why a number of DG projects have not proceeded is because of the difficulty in obtaining long term agreements to sell electricity to a large user or retailer (MED/EECA, 2005).

In terms of negotiating connection agreements, there was general consensus that gaining access to the local network was not a significant barrier for SSW. There was no mention of cases where local lines companies had overcharged for connection or abused their territorial monopoly position. However, a discussion paper by MED stated that a number of DG projects have not proceeded in recent years because of difficulties in obtaining interconnection agreements with local lines companies (MED, 2003).

\subsection{Summary}

It is clear that there are a number of barriers constraining the uptake of SSW in New Zealand. The most important were found to be cost and investment risk, and the dominant factor here is the diseconomies of SSW. The time taken and costs of obtaining resource consent was also a critical barrier. The nature of the electricity market and the lack of internalisation of the adverse effects of fossil-fuel based generation in prices was also widely acknowledged. None of these barriers are insurmountable though, as other countries - through implementing policy - have experienced high levels of growth in this segment of the market. The most appropriate policy instruments for New Zealand, as perceived by industry stakeholders, are discussed in the next chapter. 


\section{CHAPTER 7: POLICY OPTIONS FOR NEW ZEALAND - STAKEHOLDER VIEWS}

This chapter presents the findings from the interviews with industry stakeholders, where interviewees were asked what they consider to be the most appropriate policy instruments to support SSW in New Zealand.

\subsection{Regulatory Mechanisms}

Of the two regulatory mechanisms used internationally, the feed-in tariff was generally regarded as the most appropriate for New Zealand.

However, while a majority of those interviewed were very supportive of the idea, while the rest were generally very unsupportive.

It should be noted that those against the FIT were either unfamiliar with the policy (which means they were not aware of its success overseas) or were opposed to the idea of subsidy support as a matter of principle. It was interesting that these people held this view despite the general failure of the market-based approach to create levels of growth that fully capitalise on New Zealand's wind resource. These people were all employed in positions outside the wind industry.

Most of those in support were familiar with the tariff and either working as a windfarm developer or energy consultant.

Those in support of the tariff believed it would be more effective than any quantitybased system. The view was taken that FITs have been more successful in building SSW overseas and have a greater ability to attract independent investors. "A range of policy options are available, but the tariff is the most important one" (pers. comm. Yates, 2006). "A feed-in tariff would make a huge difference, those countries that have used them have taken off" (pers. comm. Thomas Cameron, 2006).

Supporters claimed the FIT is critical because it removes three major barriers facing SSW in New Zealand. Firstly, the FIT would remove the high level of investment risk 
and uncertainty associated with selling to the volatile wholesale market. According to MED/EECA (2005:45) this market volatility could "conceivably limit the potential for wind integration in New Zealand".

"A tariff system might be necessary because of the large price variation in the spot markets." (pers. comm. Jenkins, 2006). "Single independent generators may be unable to manage nodal price risk in the same way as major players do" (Heaps \& Hope, 2006: 11).

The FIT makes it considerably easier to predict future revenue streams, which will make wind investment more attractive to small developers. This certainty will also make it easier for small developers to obtain finance, which is especially important given that New Zealand banks are not familiar with the concept of community ownership.

A quantity-based system scheme is another policy option, but is also weaker than the FIT in terms of price volatility. Although the trading of certificates in quantity-based schemes operates separately to the wholesale market, they still involve a relatively high degree of pricing risk. Introduction of such a scheme in New Zealand might simply transfer the degree of risk from the wholesale market to the certificate market, meaning the overall degree of risk is the same.

Secondly, the FIT adjusts the pricing system to make it better reflect the full social and environmental benefits of SSW. In setting such a price, SSW developers are competing on a fairer playing field with the thermal-based generators. The prices established in certificate markets cannot be guaranteed to fully reflect these external costs.

Thirdly, the FIT removes the problem of negotiating a sale price with a retailer. This is a significant consideration in the less than fully competitive New Zealand electricity market. Most retailers are also generators and hold very powerful market positions, which makes it potentially difficult for new players to negotiate a fair price for their output. A FIT removes this problem, because the sale price is established in advance and there is no need for negotiation.

It was noted by stakeholders that the revenue certainty associated with the tariff could help tip the balance in regions where wind generation is marginal, which would therefore lead to a greater geographic dispersion of wind capacity. 
The tariff was also seen by many stakeholders as appropriate for New Zealand because of its ability - as seen in Germany and Denmark - to attract farmers to the industry. "There's no doubt the tariff was absolutely critical at feeding the market in Germany. It was by far and away the most effective mechanism at supporting community ownership in Germany." (pers. comm. Shearer, 2006).

Interviewees opposing the FIT gave a number of reasons. Some argued that regulating the wholesale electricity market could lead to perverse outcomes, such as distorting the locational marginal pricing system on which generation investment decisions are based. The tariff was seen as too foreign and complex, and that the spot market would not be able to accommodate it, according to one interviewee. Questions were raised over which agency should have responsibility for administering it and how an equitable and efficient price would be established. Many of those opposed simply viewed the tariff as a subsidy, and were opposed to the idea of wind receiving any form of government support. This is despite the evidence that fossil-fuel based generation gains implicit support through its carbon emissions remaining unpriced.

Further considerations in evaluating these arguments, are that it could be argued that the locational marginal pricing system has failed to operate effectively anyway, given the variability of generation investment in recent years. Also, the fact that the FIT has been successfully adopted in over 30 countries suggests that New Zealand's electricity system should be capable of integrating it.

\subsection{Investment and Production Subsidies}

As with the FIT, the policy option of investment subsidies drew polarised responses among the interviewees. A majority believed subsidies are necessary to boost the SSW market, while the rest believed subsidies are not a good option.

Those supporting the idea believe subsidies are essential due to the relatively high costs involved with SSW. Murray Jackson, Chief Executive of Genesis Energy, estimates a small wind farm would need a 3 cent/kWh subsidy and larger wind farms 1.5 cents/kWh subsidy to be economic (Steeman, 2006b). 
Subsidies could also attract new and smaller players to the industry, which was considered important for increasing competition in the generation market.

The point was raised that a substantial portion of New Zealand's generation capacity - like coal, oil, gas and hydro - was built on subsidies and we accepted those types of subsidies in the past. Moreover, the Labour government, in providing a financial guarantee to the E3P gas-fired station in Huntly in 2004, in effect provided a subsidy on the grounds that it contributed to electricity security.

Opposition to investment subsidies was largely based on the view that subsidies used throughout New Zealand's history have generally led to perverse outcomes and other inefficiencies, and that we should not repeat those mistakes. "If it's not commercially viable then it shouldn't be subsidised. New Zealand still hasn't recovered after 30 years of subsidies. There should be a very clear message. Subsidies distort things." (Interviewee anon).

Similarly, some argued that the benefits of SSW do not warrant subsidy support, and that the market will provide the optimal outcome. "One person's subsidy is another person's tax. The money has to come from somewhere. It would be best to let the market decide" (Interviewee anon)..."SSW needs to prove its merits and become commercially viable in the marketplace on its own" (Interviewee anon).

Some argue that support in the form of a carbon tax will have detrimental effects on the market, in that long-term, low-costs options like gas and coal would be penalised. As stated in a press release by the Major Electricity Users Group "Government subsidies to the wind industry and penalties on non-wind generation sources are distortionary and need to be removed" (Matthes, 2005).

It was interesting to note that interviewees from both viewpoints had considerable doubt that the government would ever actually provide explicit subsidies anyway.

"It's a major shift in government policy to have subsidies. It's hard to see subsidies being introduced into the industry. But this is ironic, because government recently awarded \$15 million to assist in gas exploration. This highlights inconsistencies in government policy" (Interviewee anon). 


\subsection{Streamlining the Consents Process}

Another important policy option raised by interviewees was streamlining the consents process. "Creating a fast-track consent approval process. Gaining resource consent is the number one or two barrier" (pers. comm. Wilson, 2006).

The need to lessen the scope for public involvement in the consents process was consistently raised by interviewees; but there were few suggestions as to how this could be done. "We need a better balance between those genuine objectors and those that aren't' (Interviewee anon).

One suggestion was to encourage councils to develop district plans that distinguish between the greater effects of large-scale developments and the lesser effects of SSW. One way of achieving this could be classifying SSW as a controlled activity under the RMA. This would involve developing plans that specify set standards, terms or conditions that would make a SSW project a controlled activity. These terms or conditions might include distance from housing and workplaces, number of turbines, turbine height and blade span width. If a proposed SSW project complies with these terms or conditions then the consent authority must grant resource consent ${ }^{10}$.

However, classifying SSW as a controlled activity could be received negatively among members of the public who have particularly strong views about turbines being anywhere near them.

In terms of lines construction, one interviewee suggested introducing a separate set of rules in District Plans for constructing lines networks for small generators, distinct from those applying to large generators.

\footnotetext{
${ }^{10}$ Note that under Section 77(b)(2aa) the consent authority is not required to grant resource consent if it has insufficient information to determine whether the proposed activity is a controlled activity or not.
} 


\subsection{Streamlining Grid Connection}

Obtaining grid connection was not considered a major barrier to SSW; this subject was not widely mentioned in the interviews. Two suggestions were raised as to how to make the connection process easier for SSW. Firstly, that a maximum price limit could be imposed on the connection charge. This would also ensure that small generators are not paying relatively more per kWh than large generators. Secondly, that the connection process is standardised and simplified for SSW projects. This implies a process in which SSW developers are not confronted with the same costs and complexities that large-scale developers face. These issues are however being addressed in the draft DG regulations.

The point was raised that rules around grid connection would need to be flexible. "Any prices imposed for grid connection would need to be fair. It would be difficult to introduce a one size fits all approach to grid connection charges, because each situation is different." (pers. comm. Jenkins, 2006).

From the interviews, it would appear that the main benefit of streamlining connection rules would be to simplify the process for SSW developers, by creating a "one-stopshop" for those unfamiliar with the industry. As pointed out by the former PCE, provision of grid access is an essential part of the process. "If small wind is to work in New Zealand, then small players need to have access, as of right, to the grid" (pers. comm. Williams, 2006).

\subsection{Summary}

The FIT is viewed by many (but not all) interviewees, and the author, as the most appropriate regulatory policy mechanism for supporting SSW in New Zealand. This is because the FIT addresses three barriers facing SSW: investment risk; the pricing system; and the market framework. Streamlining the consents process and grid connection are important for dealing with issues surrounding the RMA and grid access. Subsidies are important for lowering the initial cost of SSW, though whether they should be adopted is contentious. 


\section{CHAPTER 8: DISCUSSION}

This section begins by discussing reasons why the government might provide support to develop SSW in New Zealand. Drawing on the main findings of earlier chapters, I then discuss the key barriers that need to be removed if such development is to happen, and the policy instruments that would be most effective in incentivising change.

\section{The Issues}

Despite having one of the best wind resources in the world, New Zealand has a wind energy industry that is lagging behind the rest of the world. Previous chapters have argued that this is due to a lack of appropriate government policy and the fact that industry development has largely been left to a distorted market. These conditions have created a wind industry with the following four characteristics: a predominance of large-scale wind farms (associated with significant and increasing local opposition); a limited flow of investment; a high geographic concentration of wind capacity; and a limited local turbine manufacturing base. These characteristics are limiting the potential growth of New Zealand's wind industry, and highlight the need to reassess the way the industry is developing. SSW has the potential to address these issues - to varying degrees - and should therefore play a more significant role in the future development of New Zealand's wind industry.

\section{Predominance of large-scale wind farms}

This is probably the most significant characteristic limiting the growth of wind in New Zealand, as it is leading to increased opposition among local communities and hence longer consent processes. If wind projects continue to face the same delays as projects such as West Wind, Awhitu or Titiokura, then New Zealand's wind industry is likely to continue to struggle to reach a more stable and robust pattern of growth.

If local public opposition is one of the core issues facing the industry - and most would agree that it is - then there is a clear need to consider ways of increasing local public acceptance of wind. Forcing wind projects through by 'reforming the RMA' to disenfranchise opposition is not a recommended alternative strategy, because it will 
not solve the root cause of this opposition. Further, it is possible that future developers - in seeing a greater chance of obtaining resource consent - will consult less with local communities, which could increase local opposition even further.

The rural landowner survey provided a clear finding - respondents were significantly more positive about SSW being built in their local area than they were about a large wind farm. If this expressed preference translates into less opposition when real wind projects are proposed, then wind projects could be built considerably faster and with less difficulty and cost. Under these conditions the industry would grow at a faster rate than it does at present. While large wind farms are likely to continue to be planned, consented and constructed, SSW projects can meanwhile be progressively installed throughout the country.

Given that the current 'big is better' model appears to be fuelling anti-wind sentiment amongst the New Zealand public, SSW could play a significant role in repairing the public image of wind energy. To the extent that SSW succeeds, the public will learn that wind developments do not necessarily need to be the large, industrial-scale developments currently being built. As a result, New Zealand's wind industry might be able to develop without the level of tension seen under the current model.

It is also possible that people object to wind in their area because, in most parts of the country, wind technology is foreign and people are uncertain about its effects. A spread of small turbine clusters throughout New Zealand could give people a chance to familiarise themselves with wind energy on a scale that they may find more acceptable and less intrusive.

The issue of a lack of familiarity is important in terms of industry development. The rural landowner survey found that respondents in the Masterton region are significantly more positive about wind energy in general, and the idea of further wind farms being built in their area, than respondents in New Plymouth. This could be because respondents in Masterton are more likely to have seen turbines operating for themselves, and have realised that the actual impacts of a wind farm are not as bad as the perceived impacts. Thus, if people are more willing to accept SSW in their local area, and if people who live near turbines are more willing to accept more turbines being built in their area, then introducing SSW in a greater number of regions throughout the country could create a more favourable climate for fostering wind energy development throughout New Zealand. 


\section{Limited flow of investment}

This is probably the second most significant characteristic limiting the growth of New Zealand's wind industry. If SSW was able to attract more investors to the industry, then investment capital could be raised from a larger investor pool and there would be a greater potential for industry growth. This could mean more projects can be built concurrently, leading to a more even growth pattern compared to the intermittent growth seen to date.

Assuming that the existing market players are less likely to be interested in SSW, it is important for the future development of SSW that policies attract smaller and independent developers to the market (discussed later). The added advantage of opening up the wind industry to more players is that it would create much needed competition in the electricity generation market. International experience shows that wind industries are capable of accommodating considerably higher number of investors than what has been seen in New Zealand's industry to date.

Community ownership has been found internationally to be a significant source of investment capital. This ownership structure has not yet been seen in New Zealand, although the survey results revealed high levels of interest in the concept. The survey results showed that respondents were significantly more interested in investing and installing a turbine on their land if a specified level of government support was offered. This finding presents an additional argument for introducing SSW support policy because it suggests - at least among rural landowners in these two regions - that there is a sizeable group of investors willing to invest. It is in itself, however, not a sufficient argument for government support.

There are three main reasons why community ownership should be encouraged in New Zealand. The first is that locally-owned projects tend to face less local resistance, so community ownership could be another way of developing wind energy without inciting local public opposition. Given that community wind provides local benefits, it could also alleviate the tensions that arise between the local and national interest in the context of resource consent decisions under the RMA. To the extent that these tensions are eased, supporting community wind could be a more cost effective means of shortening consent times than altering the consents process or amending the RMA. 
Secondly, New Zealand is a farming country, with extensive rural land that could be utilised for electricity generation. Community ownership can provide the farming sector with a way of offsetting its high level of greenhouse gas emissions, and there have been few alternative solutions to this problem suggested to date.

Thirdly, community ownership could increase the geographic spread of wind capacity. Potential sites, along with the pool of potential investors, extend throughout the country. A greater geographic spread offers potential DG benefits, and also increases the potential extent of wind integration into the electricity system.

\section{High geographic concentration}

If wind projects continue to develop in regional concentrations there will be a technical limit on the potential growth of the industry. Developing the SSW market would achieve a more geographically dispersed wind capacity than seen to date, and would therefore increase the amount of wind generation the system could integrate. This would also represent a better utilisation of the local wind resource. Achieving this would benefit not only the wind industry, but also provide supply security and system benefits for the wider electricity sector.

In order to achieve a greater geographic spread of wind capacity, policies need to be designed to ensure that developments are not restricted to only the best wind regions. This would involve improving the economic viability of wind projects in medium and medium-high wind sites. Given that New Zealand has one of the world's best wind resources, what is deemed a medium wind site in New Zealand is probably considered a high wind sites in many other countries. Therefore, if the government were to introduce a FIT that offered a higher payment to turbines at sites with medium wind speeds (as is used in Germany) it would cost less to encourage developments in these areas than it would in other countries.

In order to maximise the system benefits of distributed SSW, further investigation work is needed. This work would require finding sites: with a good match between wind resource and load requirements; and where lines are relatively weak and would benefit from voltage support.

Three suitable regions for testing SSW developments are Canterbury, Northland and the East Coast. These regions were identified by EECA as having a good localised 
wind resource, and were also highlighted by Transpower as being potentially affected by transmission constraints. Where there are strong wind resources, coupled with transmission and distribution issues, it makes sense to develop SSW.

\section{Limited turbine manufacturing capacity.}

Lack of a sizeable local manufacturing base means that New Zealand developers are heavily reliant on imported turbines. This dependence is not desirable given the current global turbine shortage and price rises, which have already affected a number of projects in New Zealand.

If the government can underpin a stable market for SSW, then the environment for local turbine manufacturers would be radically improved. A stronger manufacturing base would make our wind industry more self-sufficient, and the provision of government support would be consistent with its stated aim of increasing security of energy supply. As turbine demand increases over time in large countries such as India, the USA and China, possession of a local manufacturing industry will likely become increasingly important in years to come. This is especially so if oil and gas prices continue to rise and there is more concerted global action to combat climate change, as is highly likely.

Along with supply security, there are two additional economic benefits of developing New Zealand's turbine manufacturing industry. Firstly, it would create employment. While some may question whether job creation is a high-priority objective given New Zealand's low unemployment rate, there is an argument that the sort of employment created by SSW is likely to be high-skill, and sustained over the medium to long term, given the need for managing the transition in the energy sector worldwide. It would be better for New Zealand in terms of international competitiveness to be part of this progression, rather than at its periphery.

Secondly, it could open a new export market. Due to increases in the price of oil and petroleum (used in petroleum-based electricity generators) a number of Island nations, such as Fiji, Niue, New Caledonia and the Solomon Islands, are beginning to invest in wind. For example, in 2005 Fiji secured a \$26 million contract with a French turbine manufacturer for a $10 \mathrm{MW}$ wind farm (Tabureguci, 2005). Energy supply security, promoting renewable energies and addressing the vulnerability of Pacific Island nations to rising oil prices were some of the key issues on the agenda at the 
recent Pacific Energy Ministers' Meeting (SOPAC, 2007). Given the close relationship between New Zealand and its Pacific neighbours, New Zealand is in a good position to capitalise on these growing markets and develop a significant export industry.

However, the extent to which SSW can address these issues depends on the level of penetration that SSW achieves. The extent of penetration will depend on whether critical barriers are addressed, and whether a suitable support policy framework is offered.

\section{From Barriers to Policy}

A number of barriers have been identified in this research, and their existence is underlined by the fact that there are few investors in the wind industry, and that only three SSW projects have been developed to date.

A key barrier identified throughout the interviews was a widespread reluctance to regulate the electricity market. This was despite recognition that the market is not fully competitive, and international evidence that electricity markets do not function optimally without government intervention. A number of industry stakeholders argued that it is best to leave the "invisible hand" to guide development of New Zealand's wind industry. However, analysis of their arguments did not identify any credible basis for this view, other than a distrust of government support, reliance on a free-market ideology, and a lack of recognition of the adverse effects of fossil-fuelled electricity generation.

When other countries implemented wind support policies they initially experienced resistance from industry players. Similar responses could be expected in New Zealand. This should not be regarded as a major obstacle to implementing policy, but rather a predictable part of the transition toward a more sustainable energy supply. In educating the public about industry responses, it is important for the government and other stakeholders to look to, and explain, the wider public interest.

It is notable that New Zealand's electricity market is less regulated than other developed nations' markets. Understanding the case for regulation and putting in 
place appropriate interventions is a critical first step in building a SSW market in New Zealand.

Figure 23 below illustrates the global trend seen in international electricity markets in terms of the degree of government intervention. The downward slope represents the deregulation experienced in many developed countries throughout the 1980s and 1990s. The upward slope represents the "post-deregulation" phase, as countries restore a degree of regulation in recognition of factors such as that fully deregulated markets fail to support renewables. At present, New Zealand is lying somewhere around the base of the curve, i.e. with minimal intervention. As long as this continues, we are likely to delay the transition to a more sustainable energy supply.

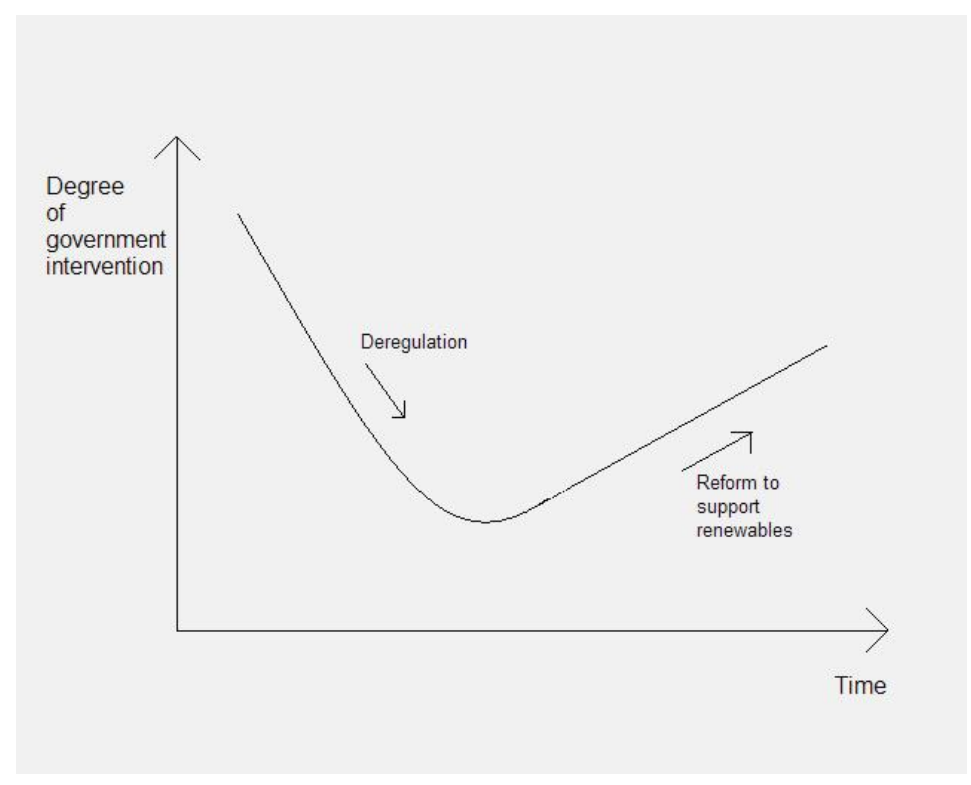

Figure 22: A conceptualisation of the global trend of intervention in electricity markets

The Electricity Act 1992 requires the Electricity Commission to ensure the removal of barriers to investment in renewables and DG, and the GPS states that "encouraging the development of renewable energy resources is a key part of the Government's strategy for managing climate change and long term energy security". Supporting SSW would be consistent with both of these strategic objectives. 
There are five critical barriers constraining the uptake of SSW in New Zealand.

\section{High capital cost}

It is clear from both the rural landowner survey and the stakeholder interviews that the high capital cost of SSW is the primary barrier. The importance of addressing this barrier is accentuated if investment in SSW is to come from smaller, independent investors. This barrier would be reduced - at least in part - if the government and local lending institutions were to support the use of lower discount rates when developing SSW projects. Future research could pin down more exactly the cost differences between SSW and larger wind farms in New Zealand.

\section{Obtaining resource consent}

Obtaining resource consent is proving expensive and timely for developers of many large wind farms in New Zealand. This could be why the RMA was widely cited by both the interviewees and survey respondents as being a barrier to SSW. However, the three SSW projects installed to date have been obtained with relative ease, which suggests that this high level of concern could have been overstated. The exact extent to which the RMA restricts SSW will only be revealed as the SSW market develops into the future.

\section{Investment risk}

The perceived investment risk is concerned with the lack of financial security associated with an investment in SSW, and relates primarily to whether independent developers can receive a fair and economic price for the power generated by their wind project. This risk is present when independent developers sell to a retailer, but mostly applies when output is sold to the wholesale electricity market. International experience highlights the importance of creating a stable investment climate if a renewables market is to grow.

\section{Pricing System}

It appears that the pricing system in New Zealand's electricity market needs adjusting if wind energy, and SSW in particular, is to develop at a significant rate. The pricing signals for investment in generation do not incorporate social, environmental and 
technical costs and benefits, such as the full social and environmental damage caused by fossil-based generation. International experience shows that intervening in the pricing system, to ensure that the full costs and benefits associated with SSW are better reflected in the wholesale price and grid connection costs, is a critical step in fostering a renewables industry. The draft DG regulations do, however, include consideration of the system benefits of DG in the connection pricing regime.

\section{Market Structure}

In situations where developers choose to sell their output to a retailer, the verticallyintegrated nature of the gentailers presents a significant barrier to SSW. This is because new SSW generators are likely to be selling to a company that is also their competitor in the generation market. Situations where developers fail to negotiate an economic price for their output, which in turn discourages them from entering the market, arguably represent a form of market failure.

\section{Key Policy Support Elements}

In addressing these barriers, three key policy elements would be highly desirable to support SSW development in New Zealand - investment subsidies, changes to the way SSW is treated under the RMA, and most importantly, the FIT. Figure 21 below illustrates how these various policy options could address the various barriers facing SSW in New Zealand. 


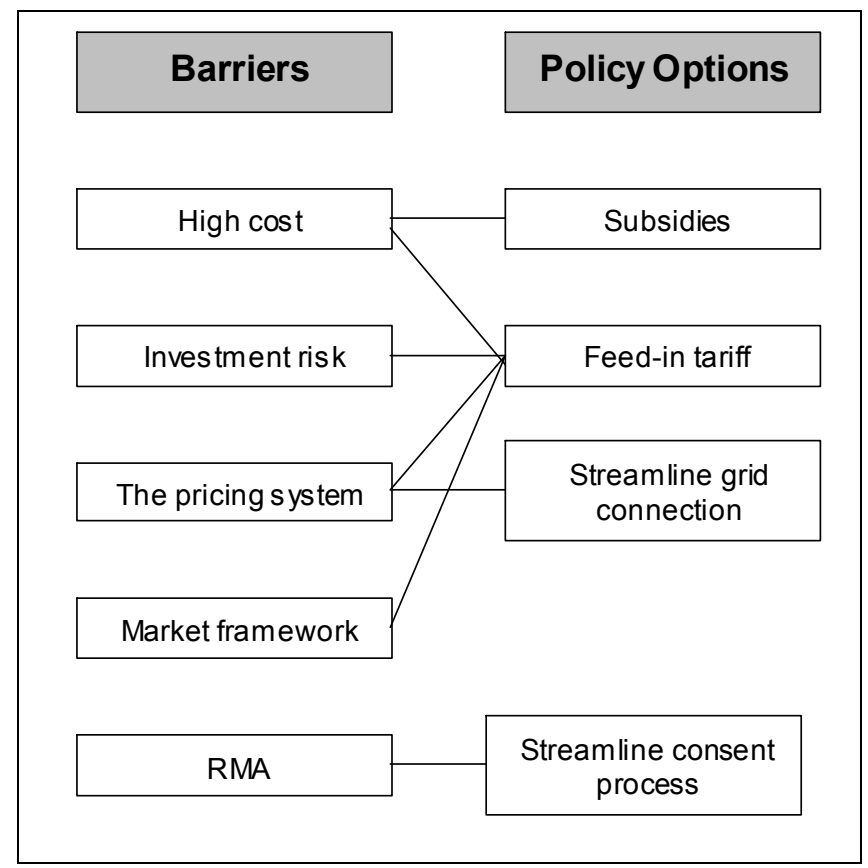

Figure 23: Matching the barriers facing SSW in New Zealand with various policy instruments

\section{Investment subsidies}

Offering cash up-front to lower the initial capital cost would go a long way to stimulate investment in SSW projects, especially if those developers include community groups and farmers. Despite the assurances of success that investment subsidies would be likely to provide, many stakeholders interviewed were opposed to the option, simply because they are opposed to subsidies as a matter of principle. Denmark first offered investment subsidies in 1979, and since then 30 other countries have introduced them. New Zealand is still debating the option in 2007. It could be time to turn the page on a 'purist position' and accept that the importance of building a renewables industry warrants such an interventionist measure. One option could be to offer a limited subsidy package to the industry, of say $\$ 30$ million, distributed in a democratic and contestable way so that new players are attracted to the industry.

\section{Streamlining the consent process}

Given the finding that rural survey respondents have a higher acceptance of SSW than large wind projects in their area, and some interest in community-owned wind, the consent process for community-owned SSW should prove relatively cheaper and easier than for large, corporate-owned wind farms. However, if it is found that the 
RMA process restricts such SSW in the same way it impedes larger developments, then the RMA process will need addressing.

One option is to classify SSW as a controlled activity under the RMA, whereby if a given SSW project meets specified standards, terms or conditions it would automatically be granted resource consent. This would be analogous to the EIA exemptions used overseas.

There are two ways that SSW could be classified as a controlled activity: either through a National Policy Statement or by encouraging local authorities to include it in a district plan change. Each approach has its own advantages and disadvantages. A National Policy Statement approach would be beneficial because it would likely be more effective and cost-efficient, and it would create a uniform standard nationally. The downside is that a 'one-rule-fits-all' approach might not work for all regions.

The advantages of encouraging district plan changes are that it would allow territorial authorities to create rules that are more appropriate to the local area, i.e. SSW project conditions that are appropriate in rural regions might not be appropriate in urban areas. Also, under section $77 \mathrm{~B}(2)(\mathrm{b})$ the consent authority has the power to specify in the plan matters over which it has reserved control. This might include sites of cultural significance to tangata whenua, or sites that have been set aside for other land uses. The disadvantages are that there wouldn't be national consistency, which developers are more likely to prefer. Further research could investigate what territorial authorities consider to be the best option.

\section{Feed-in tariff}

In my view, the FIT is the most suitable regulatory policy instrument to provide support for SSW in New Zealand. This is because the FIT will remove four of the critical barriers discussed above: investment risk, the pricing system and the market structure. I believe it could also remove the capital cost barrier, though this wasn't raised in the interviews.

In terms of lowering the initial capital cost investment subsidies are clearly the most direct option, but the FIT would also be beneficial in an indirect way. It is proven internationally that the security offered by the FIT makes it easier for independent 
developers to access finance. If New Zealand lending institutions follow suit, then the high cost of SSW projects will be less prohibitive to potential developers.

The FIT offers a set price over a specified time period, which removes the investment risk associated with selling electricity on the wholesale electricity market. Whereas the wholesale market is highly volatile, the FIT is fixed, making it considerably easier to predict future revenue streams. This is unlike the PRE, which offered little in terms of providing a stable and predictable return.

By setting a price for wind-generated electricity, the FIT helps correct market failures by creating a pricing system that better reflects the social and environmental benefits of distributed wind energy. Creating such a system would be consistent with the Electricity Commission's objective of ensuring that the full costs of producing and transporting each additional unit of electricity are signalled.

In relation to the vertically-integrated market structure, the FIT removes any difficulty a smaller investor may have in negotiating a fair purchase price, because the sale price is established in advance.

There is an additional reason why the FIT would be most suitable in the New Zealand context; the regional variability of spot prices. Figure 24 shows there is a high degree of regional variation in spot prices throughout the country.

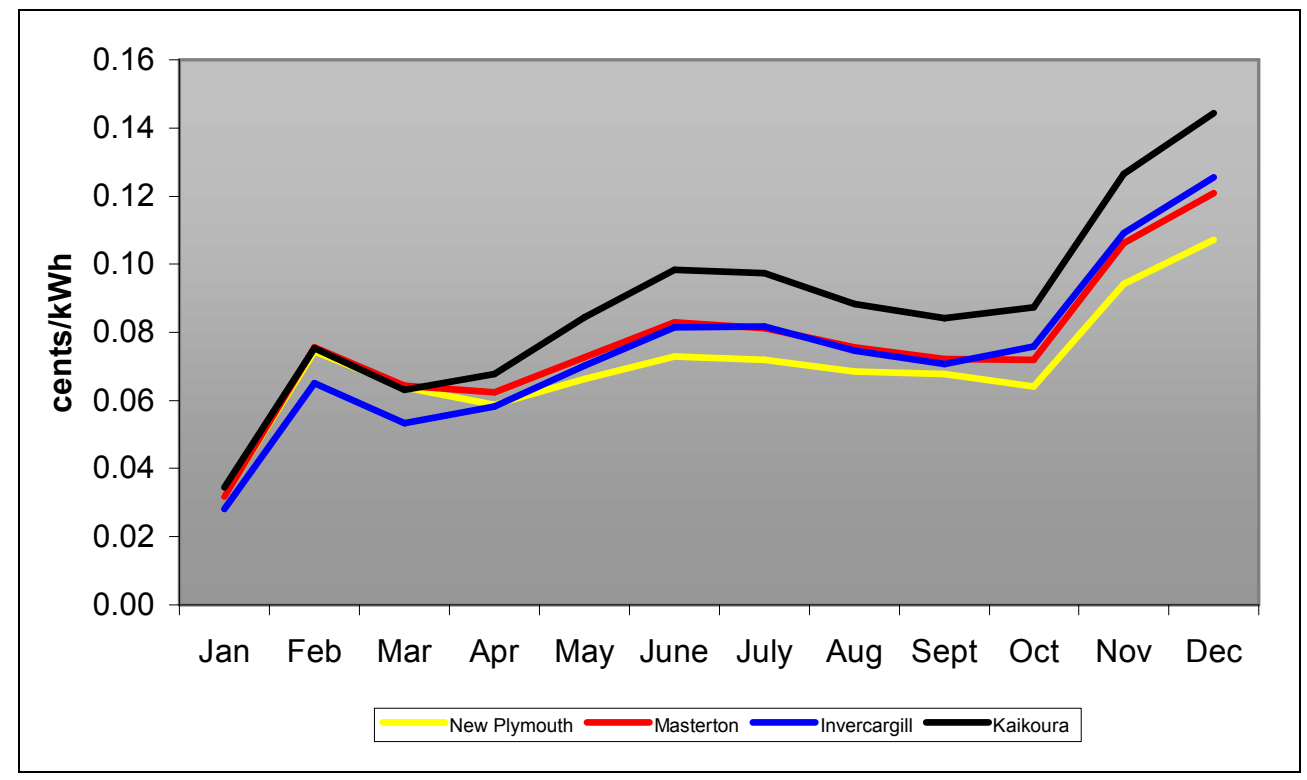

Figure 24: Average monthly spot prices at selected nodes - 2005 Source: M-Co 
The high regional variation of spot market prices means the economic viability of wind projects is also regionally variable (at least for those selling to the local wholesale market). Using the monthly prices shown in Figure 24, Table 13 below shows that a turbine operating in Kaikoura would generate \$12,662 more annual revenue per year than a turbine of equivalent size and capacity factor in New Plymouth. Over a 20 -year period, the NPV of total revenue is $25 \%$ higher for the Kaikoura turbine than the one in New Plymouth.

Table 13 Effects of regional variability of wholesale electricity pricing on wind project economics $^{11}$

\begin{tabular}{|c|c|c|c|c|}
\hline Spot market & $\begin{array}{c}\text { Average monthly spot } \\
\text { price for 2005 (\$/kWh) }\end{array}$ & $\begin{array}{c}\text { Annual revenue from } \\
\text { project (minus O \& M) }\end{array}$ & $\begin{array}{c}\text { Simple payback } \\
\text { period } \\
\text { (years/months) }\end{array}$ & $\begin{array}{c}\text { NPV of annual } \\
\text { revenue } \\
\text { (over 20 years) }\end{array}$ \\
\hline Masterton & 0.0765 & 48,996 & 6.1 & 530,720 \\
\hline New Plymouth & 0.0701 & 44,332 & 6.9 & 486,514 \\
\hline Kaikoura & 0.0877 & 56,994 & 5.3 & 608,221 \\
\hline Kaitaia & 0.0832 & 53,871 & 5.6 & 577,330 \\
\hline
\end{tabular}

This means that, at present, the economic viability of a given wind project is not only dependent on the local wind resource, but also the prices at the local spot market. Nodal pricing is said to be cost-efficient. But it has disadvantages in that projects may fail to be developed in regions with a low spot price, despite having a good wind resource. The feed-in tariff removes this problem by offering a fixed price to all regions.

In terms of grid connection, it would be advisable to follow the international trend and provide guaranteed grid access to independent developers (for a reasonable cost) as part of the FIT system.

Most commonly, the FIT is funded by a surcharge on the consumer price of electricity. However, given the rise in electricity prices in New Zealand in recent years (average retail prices rose 43.7\% between 1999 and 2006 (MED, 2007b), adding such a surcharge might not be perceived favourably among the public. One way around this problem could to be split the funding costs evenly between the government and the gentailers. In respect to the half that is paid for by the

\footnotetext{
${ }^{11}$ Annual revenue is calculated by multiplying the average monthly spot price for each region by the respective monthly output of the Brooklyn turbine during 2005. This is a hypothetical scenario, showing the revenue that the Brooklyn turbine would generate if it was located in these regions.
} 
gentailers, their contribution could be dependent on the amount of thermal generation they dispatch each month. For example, if a gentailer dispatched $40 \%$ of all thermalbased generation in a given month, it would bear $40 \%$ of the costs of funding the FIT over that time. Such a system would provide dual benefits: it would act as both an incentive to invest in wind (i.e. the FIT) and a disincentive to invest in thermal generation.

The Energy Minister David Parker recently gave the strongest indication yet that a 'cap and trade system' would be introduced to support renewables in New Zealand. It would be important to consider whether this system would support the development of SSW. Cap and trade systems are not used anywhere in the world as the primary support policy for wind energy, let alone SSW. A vast majority of the world's wind capacity (probably more than 95\%) has been built on either the FIT or quantity-based systems. It would be a more prudent approach to adopt internationally proven policies, rather than adopt an unproven system that lacks operational experience.

Cap and trade systems operate by making thermal generation more expensive. This will make wind cheaper in relative terms, but not necessarily in absolute terms. This will make SSW more viable for the existing generators, but it might do nothing to attract smaller, independent developers to the industry who will still face the same cost barrier. Moreover, the system will not remove two key barriers facing SSW in New Zealand; the unpredictability of selling to the wholesale market and the difficulty of negotiating an economic price with a retailer.

In the event that a cap and trade system is introduced, a policy framework could still be designed to cater for SSW. One way could be to set aside a specific amount of allowances for SSW, which could then be distributed among eligible projects. Also, other policy instruments such as the FIT could be used as complementary tools that operate within the cap and trade framework. However, this would have to be done in a way that avoids policy duplication.

There are of course disadvantages associated with SSW. From a policy making perspective it would be important to consider these. The most significant is the high cost. Although this is a major disadvantage, it still needs to be weighed against the potential benefits of SSW. Given the scale of these potential benefits, it can be 
argued that a strategic and comprehensive cost-benefit analysis would recognise that SSW is worthy of policy support.

In strictly economic terms, government support for SSW can be regarded not as an economic cost, but rather an investment that will provide returns in other areas. These returns include reducing the risk and cost associated with New Zealand's Kyoto deficit, reducing carbon emissions beyond Kyoto, increasing energy system resilience, industry development (creating skilled employment), improving rural landuse productivity and securing economic development (through providing greater long-term energy security).

If this support is provided, then SSW will play an increasingly prominent role in the future direction of New Zealand's wind industry. This direction could be towards an industry in which both SSW and large-scale wind farms are developed; an industry which experiences a more constant and sustainable rate of growth; and one which fully optimises the world class wind resource New Zealand has available. 


\section{CHAPTER 9: CONCLUSION}

This research has shown that SSW has the potential to alleviate four key characteristics limiting the growth of New Zealand's wind industry, and thus provide for a higher rate of industry growth. SSW also offers a number of potential cobenefits to the wider electricity sector.

But in order to capitalise on these benefits, there is arguably a need to move away from the present reliance on the market-based approach. New Zealand needs to create a regulatory framework in which SSW can compete on a level playing field with the traditional generation sources. International experience shows that the fastest growing wind industries are those in countries that adopt such a framework, illustrating that high rates of industry growth will not likely be achieved under competitive market conditions.

The introduction of appropriate policy changes would be consistent with government's overall strategic goals of improving the sustainability of New Zealand's electricity industry.

If these aspirations are translated into well-designed policies then SSW will begin to capture a market share that better reflects the various social, environmental and technical benefits it can provide. It appears that this will most likely be achieved under a policy framework that includes the FIT, investment subsides, and the classification of SSW as a controlled activity under the RMA. 


\section{AREAS FOR FURTHER RESEARCH}

- To assess the potential for using SSW in islanded and on-site power generation in New Zealand.

- To assess the ability of New Zealand's distribution lines to deliver and absorb distributed SSW. This would give an indication of the scale of the potential penetration of SSW in New Zealand.

- To replicate the rural landowner survey in other rural regions throughout New Zealand. If similar results are obtained it will verify the findings and conclusions made in this thesis.

- To replicate the rural landowner survey in urbanised regions throughout New Zealand. This will assess the potential for developing SSW in more populated areas, such as the Brooklyn turbine.

- To locate regions in New Zealand where there is a high correlation between wind speed profile and electricity demand. Installing SSW in these regions will optimise the potential for system benefits.

- To locate regions in New Zealand where there are both high wind speeds and transmission and distribution difficulties. Installing SSW in these regions will optimise the potential for distributed generation benefits.

- To survey regional and district councils throughout New Zealand on their views of classifying SSW as a controlled activity under the RMA.

- To compare the economic cost of SSW projects with large-scale wind farms in New Zealand. 


\section{REFERENCES}

ACG. (2006). The New Zealand gas industry in 2006: Review of its state and performance: Prepared by The Allen Consulting Group for the Gas Industry Company.

Akilade, A. (2006). Turbine shortage threatens wind farms. The Sunday Herald, Scotland: 8th October, 2006.

Ashby, M. (2004). Wind's up: Planning the future now: Connell Wagner, Wellington.

AusWEA. (2004). The compatibility of wind farming with traditional farming in Australia: Australian Wind Energy Association.

AusWEA. (2005). A progress report on the Australian wind energy industry: Australian Wind Energy Association.

AWEA. (2007). The American Wind Energy Association website: www.awea.org.

Bailey, D. (2006). Developers tripped up in booming market. Wind Power Monthly, 22 (9), pp 44-46.

Bailey, J., \& Morris, D. (2006). Renewable Electricty Mandates in Minnesota: Status and Impact. Minneapolis, MN: Institute for Local Self-Reliance.

Baines, J. (2005). Public opinion surveys across New Zealand - trends, comparisons and messages. Paper presented at the New Zealand Wind Energy Conference. 30th August, 2005, Wellington.

Bell, D., Gray, T., \& Haggett, C. (2005). The 'social gap' in wind farm siting decisions: Explanations and policy responses. Environmental Politics, 14(4), pp 460-477.

Berg, C. (2003). Minimising community opposition to wind farm developments in New Zealand: Opportunities in renewable energy planning: Master of Science, Victoria University, Wellington.

BMU. (2006). Environmental policy. Renewable energy sources in figures national and international development: Federal Ministry for the Environment, Nature Conservation and Nuclear Safety (BMU): Berlin, Germany.

Bolinger, M. A. (2001). Community wind power ownership schemes in Europe and their relevance to the United States. Lawrence Berkeley National Laboratory, California, USA Retrieved 12th May, 2006, from www.eetb.lbl.gov/ea/emp/reports/48357.pdf 
Bolinger, M. A. (2004). Making European-style community wind power development work in the United States. Berkeley, California, CA.: Lawrence Berkeley National Laboratory.

Buen, J. (2005). Danish and Norwegian wind industry: The relationship betwen policy instruments, innovation and diffusion. Energy Policy, 34(18), pp 3887-3897.

Butler, L., \& Neuhoff, K. (2004). Comparison of feed-in tariff, quota and auction mechanisms to support wind power development: Cambridge Working Papers in Economics 0503, Faculty of Economics (formerly DAE), Cambridge: University of Cambridge.

BWE. (2005). Minimum price system compared with the quota model - which system is more efficient? Osnabruck, Germany: Bundesverband WindEnergie, e.V. (German Wind Energy Association).

Cambell, D. (2007). Project update - Trustpower's wind developments. Paper presented at the The New Zealand Wind Energy Conference. 13th 14th March, 2007, Te Papa, Wellington.

Cameron, T. (2006). Energy3. Personal communication: Interview with Thomas Cameron, 30th November, 2006.

CanWEA. (2006). Canada Report to the International Energy Agency Wind Energy Agreement Executive Committee. Adelaide, Australia: Canadian Wind Energy Association.

CBC. (2005). Climate change: Review of policy and next steps. Cabinet Paper. 19th December, 2005: Cabinet Business Committee. Cabinet Reference: CBC Min (05) 20/10. Cabinet Office, Wellington.

Chabot, B. (2003). Why and how to invest in wind power in France. Paper presented at the HUSUMwind Conference: "Trends for future markets". 23rd - 27th September, 2003., Husum, Germany.

Clark, F. (2007a). New Zealand wind resource ready and waiting. New Zealand Wind Energy Association: Press Release, 21st March 2007 Retrieved 25th March, 2007, from www.scoop.co.nz/stories/P00703/S00245.htm

Clark, F. (2007b). Realising the potential - Wind Energy and the NZES. Paper presented at the The New Zealand Wind Energy Conference. 13th-14th March, 2007, Te Papa, Wellington.

Clement, D., Lehman, M., Hamrin, J., \& Wiser, R. (2005). International tax incentives for renewable energy: Lessons for public policy. Center for Resource Solutions. Prepared for the Energy Foundation China Sustainable Energy Program Retrieved 20th January, 2007, from www.resource-solutions.org/lib/librarypdfs/IntPolicy$\underline{\text { Renewable Tax Incentives.pdf }}$ 
Contact. (2007). Contact outlines $\$ 2$ billion in a new renewable generation programme: Contact Energy Ltd: Press Release, 23rd February, 2007.

Daniels, C. (2005). Grid the key to green power, says energy boss. New Zealand Herald: 15th February, 2005.

DTI. (2005). Community benefits from wind power: A study of UK practice and comparison with leading European countries - Report to the Renewables Advisory Board and the Department of Trade and Industry. 12th August, 2006, from www.cse.org.uk/pdf/pub1049.pdf

Dupuy, M. (2006). Electricty generation: Competition, market power and investment: New Zealand Treasury Policy Perspectives Paper 06/04.

DWIA. (2005). Danish Wind Industry Association Annual Report - 2005. The Danish Wind Industry Assocation Retrieved 10th January, 2007, from www.windpower.org/media(1034,1033)/Aarsberetning Annual report 2005.pdf

EC. (2004). Analysis of the state of competition and investment and entry barriers to New Zealand's wholesale and retail electricity markets. Wellington: Electricity Commission.

EC. (2007). Electricity Commission website: www.electricitycommission.govt.nz.

EECA. (2005). Renewable energy fact sheet 1: Wind energy. 12th November, 2006, from www.eeca.govt.nz/eeca-library/renewable-energy/wind/factsheet/wind-fact-sheet/05.pdf

EECA. (2006). Situation assessment report on the National Energy Efficiency and Conservation Strategy. Wellington.

EEG. (2005). Electricity from renewable energy systems in the EU-15 countries - A review of promotion strategies: Energy Economics Group.

EEG. (2006). Evaluation of different feed-in tariff design options - Best practice paper for the International Feed-In Corporation: Energy Economics Group and the Institute Systems and Innovation Research.

EER. (2006). Sharp growth in North American wind power despite turbine shortages: Emerging Energy Research: Press Release, 11th January, 2006.

EHMS. (2005). Availabilities and costs of renewables sources of energy. Wellington: Prepared for the Ministry of Economic Development by East Harbour Management Services. 
EIA. (2005). Policies to promote non-hydro renewable energy in the US and selected countries. Washington, DC: Energy Information Administration.

EREC. (2004). Energy sustainable communities: Experiences, success factors, opportunities in the EU25. Brussels: European Renewable Energy Council.

EWEA. (2005). Wind energy - The facts: An analysis of wind energy in the EU-25. Brussels: European Wind Energy Association.

EWEA. (2006a). The current status of the wind industry. Brussels, Belgium: The European Wind Energy Association.

EWEA. (2006b). Interview with Jeremy Rifkin: President, Foundation on Economic Trends. Wind Directions. The European Wind Energy Association: September 2005, 25 (6).

EWEA. (2007). European Wind Energy Association website: www.ewea.org.

Fisher, R. M. (2005). Wind energy in New Zealand: Regulatory and policy lessons to date. New Zealand Journal of Environmental Law, 9, 307333.

FWEA. (2007). The French Wind Energy Assocation website: www.fee.asso.fr

Galluzzo, T. (2005). Small packages, big benefits: Economic advantages of local wind projects. lowa: The lowa Policy Project.

Gipe, P. (2004). Community wind: The third way. Toronto: Ontario Sustainable Energy Association.

Gipe, P. (2006). Renewable Energy Policy Mechanisms. 9th September, 2006, from www. windworks.org/FeedLaws/RenewableEnergyPolicyMechanismsbyPaulGipe. $\underline{\text { pdf }}$

Gleisner, B., Barry, M., Webster, R., Lee, E., Fei, \& Mahummoud, S. (2005). Project WestWind: Conflict Resolution: Unpublished report.

GWEC/Greenpeace. (2004). Wind Force 12: A blueprint to achieve $12 \%$ of the world's electricty from wind power by 2020. Brussels: The Global Wind Energy Council and Greenpeace.

Hay, I. (2005). Qualitative research methods in human geography. Victoria, Australia: Oxford University Press.

HBWF. (2005). Hawkes Bay Wind Farm information sheet. Hawkes Bay Wind Farm Ltd Retrieved 12th January, 2007, from www.hawkesbaywindfarm.net.nz/downloads/april.pdf 
HDC. (2007). Environment Court declines wind farm application: Hastings District Council: Media Release. 17th April, 2007.

Heaps, B. (2006). Strata Energy Consultancy. Personal communication: Interview with Bill Heaps, 24th October, 2006.

Heaps, B., \& Hope, S. (2006). The importance of new entrants in the New Zealand electricty market. Paper presented at the 8th Annual New Zealand Energy Summit - 2006.

Hunt, D. (2006). Securing best outcomes for security of supply, price and the environment. Paper presented at the National Power New Zealand 2006. 1st - 3rd March, 2006, Hyatt Regency, Auckland.

Hyde, J. (2006). Industry gathers strength for next big surge. Wind Power Monthly magazine, 22 (3), pp 50-51.

Hyde, V. (2004). A wind weather build schedule. Wind Power Monthly magazine, 20 (5), pp 68.

Hyde, V. (2005). Market economics favour green choice. Wind Power Monthly magazine, 21 (6), pp 53-54.

ICN. (2004). Manufacturing opportunities from the New Zealand wind farm industry: A study prepared for the Industry Capability Network by Network Information Services Ltd and Wise Analysis Ltd.

IEA. (2002). IEA Wind Energy 2001 Annual Report. Paris, France: International Energy Agency.

IEA. (2004). Renewable energy: Market and policy trends in IEA countries. Paris, France: International Energy Association.

IEA. (2005). IEA Wind Energy Annual Report 2005. Paris, France: International Energy Agency.

IEA. (2006a). Global Renewable Energy Policies and Measures database, International Energy Agency. 17th May, 2006, from www.iea.org/textbase/pamsdb/grindex.aspx

IEA. (2006b). IEA Wind Energy Annual Report. Paris, France: International Energy Agency.

IWEA. (2007). The Irish Wind Energy Association: www.iwea.com.

IWPDM. (2006). Hydro in the mix in New Zealand. Water Power Magazine: Issued by International Water Power and Dam Construction Retrieved 10th March, 2007, from www.waterpowermagazine.com/story.asp?sectionCode $=166 \&$ storyCod $\underline{e=2039414}$ 
Jacobsson, S. L., V. (2006). The politics and policy of energy system transformation - explaining the German diffusion of renewable energy technology. Energy Policy, 34(3), 256-276.

Jenkins, A. (2006). New Zealand Electricity Networks Association. Personal Communication: Interview with Alan Jenkins, 22nd October, 2006.

Kammen, D., Kapadia, K., \& Fripp, M. (2004). Putting renewables to work: How many jobs can the clean energy industry generate? Berkeley, California CA: Report of the Renewable and Appropriate Energy Laboratory: University of California, Berkeley.

Khan, J. (2003). Wind power planning in three Swedish municipalities. Journal of Environmental Planning and Management, 46(4), 563-581.

Krohn, S. D., S. (1999). On public attitudes towards wind power. Renewable Energy, 16(1), 954-960.

Lee, T., Wren, B., \& Hickman, M. (1989). Public responses to the siting and operation of wind turbines. Wind Engineering, 13(4), 188-195.

Lewis, J., \& Wiser, R. (2005). A review of international experience with policies to promote wind power industry development: Prepared for the Energy Foundation China Sustainable Energy Program.

Loiter, J., \& Norberg-Bloom, V. (1999). Technology policy and renewable energy: Public roles in the development of new energy technologies. Energy Policy, 27(2), 85-97.

Massey, J. (2005). British investor grows porffolio. Wind Power Monthly, 21 (11), pp 39-40.

Matthes, R. (2005). Wind generation no panacea. New Zealand Herald. 20th June, 2005.

Matthes, R. (2006). Major Electricity Users Group. Personal Communication: Interview with Ralph Matheus, 24th October, 2006.

Mayston, B. (2006). Image of wind farms attacked. Otago Daily Times. 15th November, 2006.

McGovern, M. (2004). Moving towards market realities. Wind Power Monthly, 20 (5), pp 31-32.

MED. (2003). Facilitating distributed generation: A discussion paper. Wellington: Ministry of Economic Development.

MED. (2006). Draft New Zealand Energy Strategy to 2050: Powering our future. Wellington: Ministry of Economic Development. 
MED. (2007a). Discussion paper: Summary of changes to draft regulations for connection of distributed generation. Ministry of Economic

Development Retrieved 14th April, 2007, 2007, from

http://www.med.govt.nz/upload/45640/distributed-generation-2007discussion-paper.pdf

MED. (2007b). Ministry of Economic Development website: www.med.govt.nz.

MED/EECA. (2005). Wind Energy Integration in New Zealand. Wellington: Report prepared for the Ministry of Economic Development and the Energy Efficiency and Conservation Authority.

Menz, F. C. V., S. (2006). The effectiveness of different policy regimes for promoting wind power: Experiences from the States. Energy Policy, 34(14), 1786-1796.

Meridian. (2006). Options, choices, decisions: Understanding the options for making decision's about New Zealand's energy future. Wellington: Meridian Energy.

Meyer, N. (2004). Renewable energy policy in Denmark. Energy for Sustainable Development, 8(1), 25-36.

MfE. (2005). Review of climate change policies. Wellington: Ministry for the Environment.

MfE. (2006). Projected balance of emissions units during the first commitment period of the Kyoto Protocol. Ministry for the Environment Retrieved 22nd November, 2006, from www.climatechange.govt.nz/resources/reports/projected-balanceemissions-jun06/projected-balance-emissions-jun06.pdf

Milligan, M. (2004). Wind energy economics. In Encylopedia of Energy (Vol. 6, pp. 409-418): Elsevier Academic Press.

Mitchell, C. C., P. (2004). Renewable energy policy in the UK 1990-2003. Energy Policy, 32(17), 1935-1947.

MLURI. (2005). Perceptual studies of windfarms. The Macaulay Land Use Research Institute. 20th February, 2007, from www.macaulay.ac.uk/ccw/task-two/strategies.html

MOE. (2004). Gas exploration incentives: Office of the Minister of Energy. Cabinet Business Committee. 15th June, 2004.

MOE. (2006). Government Policy Statement on Electricity Governance. Wellington: Minister of Energy. October 2006.

Nielsen, K. H. (2002). Translating wind power policies: The construction of frames of meaning for wind technologies in Denmark, 1976-2002. 
Paper presented at the International Summer School for Renewable Energy Technology: 15-18 July, 2002, University of Salzburg.

NWCC. (2001). Distributed wind power assessment. Washington D.C:

National Wind Coordinating Committee. Prepared for the Distributed Wind Working Group.

NWEA. (2007). The Netherlands Wind Energy Association: www.nwea.nl.

NYSDPS. (2004). New Jersey renewable portfolio standard - Cost study report II, Volume A. Appendix A: Renewable resource costs and characteristics: New York State Department of Public Service, New York State Energy Research and Development Authority, Sustainable Energy Advantage, LLC and La Capra Associates.

NZCCO. (2007). New Zealand Climate Change Office website: www.climatechange.govt.nz/policy-initiatives/projects/index.html.

NZHOR. (2006). 2005/06 Financial review of Meridian Energy Ltd: New Zealand House of Representatives: Report of the Commerce Committee.

NZPA. (2004). Meridian taking another look at wind after Aqua canning. The New Zealand Herald. 2nd April, 2004.

NZPA. (2006). New power turbine planned for Auckland. The New Zealand Herald. 13th July, 2006.

NZPA. (2007a). Government favours carbon trading system. The New Zealand Herald. 25th April, 2007.

NZPA. (2007b). Trustpower to proceed with wind farm in Oz. The New Zealand Herald. 12th January, 2007.

NZWEA. (2005). Drawn-out approval for Awhitu wind farm raises questions about RMA: New Zealand Wind Energy Association: Press release, 23rd December, 2005.

NZWEA. (2006). Renewable energy target needs more wind power: New Zealand Wind Energy Association: Press release, 31st March, 2006.

NZWEA. (2007). New Zealand Wind Energy Association website: www.nzwea.org.nz.

OSEA. (2005). Powering Ontario communities: Proposed policy for projects up to $10 \mathrm{MW}$ : Prepared by the Ontario Sustainable Energy Assocation for the Ontario Ministry of Energy.

Parker, D. (2006). Wind's potential to meet New Zealand's energy needs. Paper presented at the The New Zealand Wind Energy Conference. 
13th March., Hon David Parker, Minister of Energy. Te Papa, Wellington.

PCE. (2006). Wind power, people, and place. Parliamentary Commissioner for the Environment Retrieved 16th December, 2006, from www.pce.govt.nz/reports/allreports/1 $877274 \quad 29$ 1.pdf

Pieprzyk, B. (2004). How do subsidies for fossil and nuclear energies inhibit the development of renewable energies? Paper presented at the The 3rd World Wind Energy Conference \& Renewable Energy Exhibition. 31st October - 4th November, 2004, Bejing, China.

Pirazzi, L. (2006). Report on the Italian Wind Industry. Paper presented at the International Energy Agency Wind Energy Agreement Executive Committee. Adelaide, Australia.

Predac. (2005). Guidelines and comparision of renewable energy experiences: Spatial planning of wind turbines. European Actions for Renewable Energies. 5th December, 2006, from www.cler.org/predac/IMG/pdf/Guide English WP 8.pdf

Pretli, D. (2003). Winds of change: Report prepared for Greenpeace New Zealand.

REN21. (2005). Renewables Global Status Report: 2005: Renewable Energy Policy Network.

REN21. (2006). Renewables Global Status Report: 2006 Update: Renewable Energy Policy Network.

Rhoads, H. W., W. (1998). NWCC's distributed wind research project. Washington DC: The National Wind Coordinating Committee.

Rickerson, W., \& Grace, R. (2007). The debate over fixed price incentives for renewable electricity in Europe and the United States: Fallout and future directions: Prepared for the Heinrich Boll Foundation.

Sawin, J. (2004). National policy instruments: Policy lessons for the advancement and diffusion of renewable energy technologies around the world. Bonn, Germany: Worldwatch Institute.

SDC. (2005). Wind power in the UK: A guide to the key issues surrounding onshore wind power development in the UK: Sustainable Development Commission, UK.

SEANZ. (2006). Stern Review: New Zealand MUST invest in renewable energy. Press Release: Sustainable Electricity Association of New Zealand. 
SEED. (2005). Community wind: An Oregon guidebook: Prepared for the Energy Trust of Oregon by Northwest Sustainable Energy for Economic Development.

SEI. (2003). Attitudes towards wind farms and wind energy in Ireland. 25th September, 2006, from www.irishenergy.ie/uploadedfiles/renewableenergy/attitudestowardswind.pdf

SEI. (2007). VRB ESS Energy storage and the development of dispatchable wind turbine output. Sustainable Energy Ireland Retrieved 14th April, 2007, 2007, from www.sei.ie/index.asp?loclD=1030\&doclD=-1

Shearer, I. (2006). Sustainable Electricity Association. Personal Communication: Interview with lan Shearer; 5th December, 2006.

Silverman, D. (2005). Doing qualitative research: 2nd edition. London, UK: SAGE publications.

SOPAC. (2007). Working procedures and agenda: Pacific Energy Ministers Meeting: 25-26th April, 2007: Rarotonga, Cook Islands.

Sorensen, H., Hansen, L., Hammarlund, K., \& Larsen, J. (2004). Experience with and strategies for public involvement in offshore wind projects. International Journal of Environment and Sustainable Development, 1(4), 326-336.

StatisticsNZ. (2006). Thermal generation reaches record March levels. Media release: Statistics New Zealand, 7th June, 2006.

Steeman, M. (2006a). Climate policy change of heart wins support. Manawatu Standard. 7th October, 2006.

Steeman, M. (2006b). Genesis wants wind farm stakes. The Dominion Post. 13th October, 2006.

Steeman, M. (2006c). Wind farm axed as turbine costs rise. The Dominion Post. 5th September, 2006.

Stenzel, T., Foxon, T., \& Gross, R. (2003). Review of renewable energy development in Europe and the US: A report for the DTI Renewables Innovation Review.

Stern, N. (2007). The economics of climate change: The Stern review: Cambridge University Press.

Strengers, Y. (2006). Time to strengthen market drivers for proven clean energy technologies. Paper presented at the The Australian Wind Energy Association Conference. 10th January, 2006. 
SUSTELNET. (2004). Regulation of distributed generation: A European policy paper on the integration of distributed generation in the internal electricity market: Sustainable Electricity Network.

SWEA. (2007). The Swedish Wind Energy Association: www.svenskvindkraft.org.

Tabureguci, D. (2005). FEA goes big time into renewable energy. June 5th, 2006, from www.islandsbusiness.com

Toke, D. (1999). Community ownership - The only way ahead for UK wind power? Ontario, Canada: Ontario Sustainable Energy Assocation.

Toke, D. (2005). Community wind power in Europe and in the UK. Wind Engineering, 29(3), 301-308.

Treasury. (2007). The Treasury website: www.treasury.govt.nz/kyotoliability/.

UMR. (2004). Omnibus Results. Auckland: Survey conducted by UMR Research Ltd for the Energy Efficiency and Conservation Authority.

Wang, Y. (2006). Renewable electricity in Sweden: An analysis of policy and regulations. Energy Policy, 34(10), 1209-1220.

Watts, C. (2005). An exploration of public opinion of wind farms situated close to a populated area: The Awhitu Wind Farm proposal near Auckland, New Zealand: Auckland University of Technology, Auckland.

Weinburg, C. (2007). Lessons from the Californian experience. Paper presented at the The New Zealand Wind Energy Association Conference. 13th-14th March, 2007, Te Papa, Wellington.

Wier, J. (2007). Makara wind farm in doubt. The Dominion Post. 29th March, 2007.

Williams, M. (2006). Parliamentary Commissioner for the Environment. Personal Communication: Interview with Morgan Williams. 20th November, 2006.

Wilson, A. (2006). New Zealand Wind Farm Developments (pp. Personal Communication: Interview with Alistair Wilson, 16th October, 2006).

Wolsink, M. (1989). Attitudes and expectancies about wind turbines and wind farms. Wind Engineering, 13(4), 196-206.

Wolsink, M., \& van de Wardt, J. W. (1989). Visual impact assessment: a review of Dutch research: EWEC, Glasgow.

WPM. (2005). Industry Summary. Wind Power Monthly magazine, 21 (10), pp 78. 
WPM. (2006). Best performers: Wind turbines compared. Wind Power Monthly magazine, 22 (7), pp 59.

WWEA. (2007). New world record in wind energy capacity: Press release, 29th January, 2007: The World Wind Energy Association.

Yates, A. (2006). New Zealand Wind Farm Group. Personal Communication: Interview with Al Yates. Conducted via email.

Zervos, A. (2005). Renewable energy sources, including financing. Paper presented at the European Energy and Transport Forum. 30th November, 2005. 


\section{APPENDIX A: LIST OF INDUSTRY STAKEHOLDERS INTERVIEWED}

I would like to thank the following people for taking the time and allowing me to interview them.

Catherine Beard Executive Director Greenhouse Policy Coalition

Ron Beatty Senior Advisor Retail Electricity Commission

Thomas Cameron Co-Director Energy ${ }^{3}$

Rob Davison Economic Services Division New Zealand Meat \& Wool

Alan Jenkins Chief Executive New Zealand Electricity Networks Association

Murray Kennedy Strategy and Asset Manager Wellington Regional Council

Bill Heaps Managing Director Strata Energy Consultancy

Brent Layton Director New Zealand Institute of Economic Research

Ralph Matthes Executive Director Major Electricity Users Group

Shelly Nixon Clearing and Settlements Manager The Marketplace Company

Sarah Patterson Manager, Trade Policy New Zealand Meat \& Wool

Darryl Renner Senior Advisor Electricity Commission

Alan Seay Spokesperson Meridian Energy

Ian Shearer Chief Executive Sustainable Electricity Association of New Zealand

Jim Weston

Wairarapa President Federated Farmers 
Morgan Williams Former Parliamentary Commissioner for the Environment

Alistair Wilson Director New Zealand Wind Farm Developments

Gareth Wilson Electricity Group Ministry of Economic Development

Al Yates Managing Director New Zealand Wind Farm Group 


\section{APPENDIX B: ETHICS APPLICATION AND APPROVAL FORMS}

\section{Participant Information Sheet for a Study on Small-Scale Wind in New Zealand}

Researcher: Martin Barry: School of Geography, Environment and Earth Sciences, Victoria University of Wellington.

I am a Masters student in Environmental Studies at Victoria University of Wellington. As part of this degree I am writing a thesis examining the potential of small-wind projects as part of New Zealand's wind industry. The University requires that ethics approval be obtained for research involving human participants. I am inviting various members of the New Zealand electricity and manufacturing sectors to participate in this study. Participants will be asked to give their views and opinions on the merits and disadvantages of small wind projects to the New Zealand wind industry, along with an identification of any barriers to its wider uptake.

Should any participants feel the need to withdraw from the research project, they may do so without question at any time before the data is analysed. Just let me know in time. Responses from the interviews will be collected on a confidential basis, but the intention is to quote participants in the study. Quotes will be checked with you before the thesis is finalised.

All material collected will be kept confidential, and only myself and my thesis supervisor, Dr Ralph Chapman, will see the interview transcripts which will be destroyed at the end of the research. The thesis will be submitted for marking to the School of Geography, Environment and Earth Sciences and deposited in the University Library.

If you have any questions or would like to receive further information about the project, please contact me at 044635233 ext 8393, barrymart@student.vuw.ac.nz, or my supervisor, Dr Ralph Chapman, at the School of Geography, Environment and Earth Sciences at Victoria University, PO Box 600, Wellington, phone (04) 4606153. 


\section{Consent to Participation in Research}

Project Title: Distributed Small-Scale Wind in New Zealand: Advantages, Barriers and Policy Support Instruments

I have been given and have understood an explanation of this research project. I have had an opportunity to ask questions and have them answered to my satisfaction.

I understand that I may withdraw myself (or any information I have provided) from this project (before data collection and analysis is complete) without having to give reasons or without penalty of any sort.

Please tick one of the following:

I am content to be identified and quoted in the thesis and accordingly I am signing the attached Waiver of Confidentiality form. I understand that the lead investigator will use his best endeavours to check any quotations with me before the thesis is completed

Or

I am content to be interviewed but do not wish to be identified and quoted in the thesis

Signed:

Name of participant

Date: 


\section{APPENDIX C: STAKEHOLDER INTERVIEW QUESTIONS}

The following questions formed the basis for discussion with industry stakeholders. Most interviews took between forty-five minutes and an hour.

Definition: Small-scale wind projects are developments with 3 or less utility scale turbines.

1. Do you believe small-scale wind in New Zealand is worthy of policy support? Are any of these benefits particularly relevant/significant for NZ?

2. What do you consider the most appropriate/effective support policies to be?

3. Do you believe small-scale wind will ever develop in New Zealand without policy support? I.e. Is the free market conducive to market entry?

4. What are some possible ways that support policies might be funded? E.g. Retail surcharge, public benefit fund

5. What do you consider to be the barriers facing small-scale wind?

6. Is community ownership - in particular farmer involvement - a worthy option for NZ? 


\section{APPENDIX D: RURAL SURVEY QUESTIONNAIRE}

My name is Martin Barry and I am writing a Masters thesis at Victoria University. My research is investigating views about small wind farms (1 or 2 turbines) in rural New Zealand, along with the willingness of farmers and rural landowners to invest in wind turbines themselves. This survey covers farmers and rural landowners in the Wairarapa and Taranaki regions.

The turbines in the photos shown are around $60 \mathrm{~m}$ tall, with a blade span of around $25 \mathrm{~m}$.

Please note that I am not associated with any energy company or wind farm developer.

1. Do you support/oppose wind power as a means of generating electricity in New Zealand?

1

Strongly support

2

Support
3

Indifferent
4

Oppose
5

Strongly oppose

2. Please imagine a new small-scale (2 turbine) wind farm placed in your district. How would you view the impact of such a wind farm? (See photo below).

1

Very Positive
2

Fairly Positive
3

Neutral
4

Fairly Negative
5

Very Negative

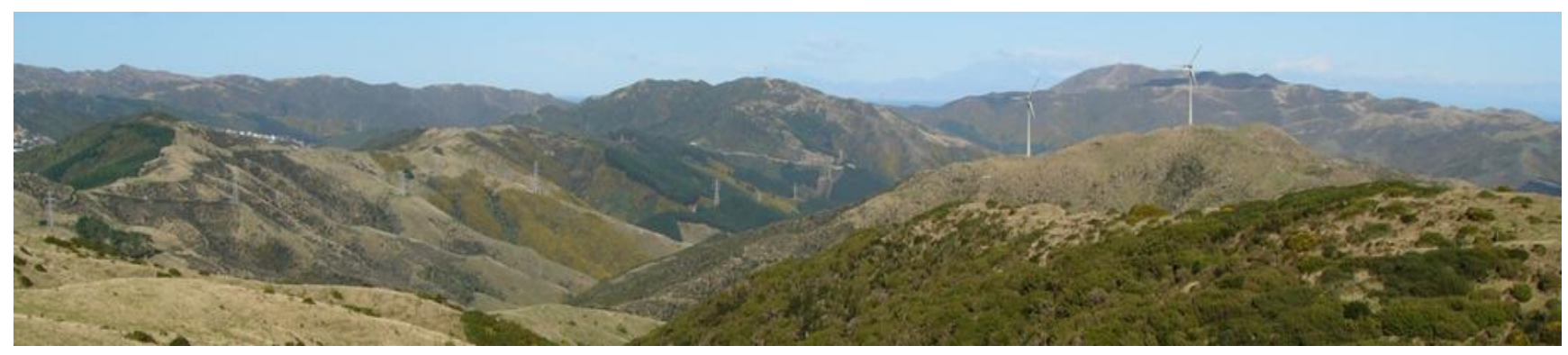

3. Now please imagine a larger wind farm (14 turbines) in your district. How would you view the impact of such a wind farm? (See photo below).

1

Very Positive
2

Fairly Positive
3

Neutral
4

Fairly Negative
5

Very Negative

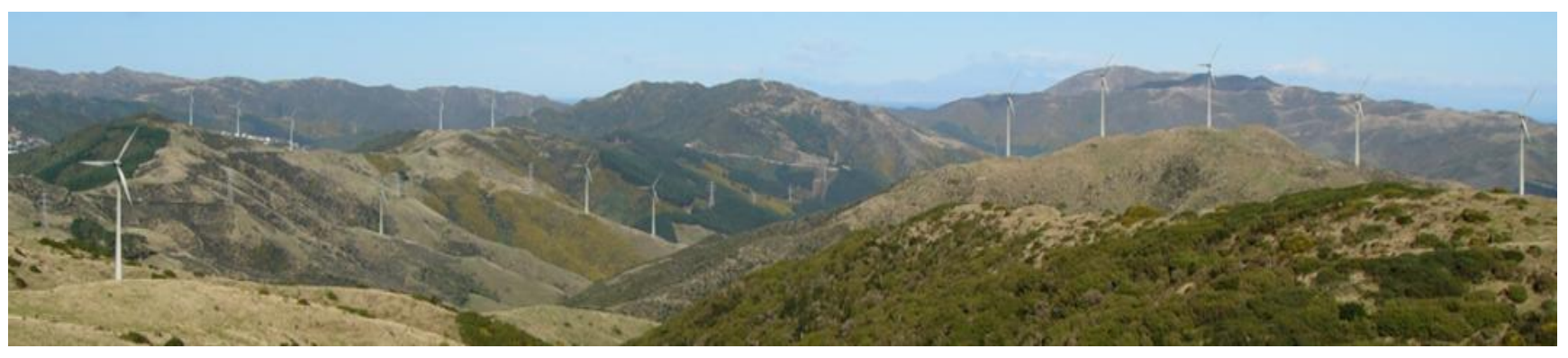


4. In Germany and Denmark community ownership of wind farms is widespread. For example, more than 1,000 wind turbines in Denmark are owned by farmers.

Is the idea of installing a wind turbine on your land appealing to you?
1
2
3
4
5

Very Interested Possibly Interested Not Sure/

Probably Definitely

Don't Know Not Interested Not Interested

5. Imagine the government provided financial assistance to ensure the return on a private wind turbine investment was comparable with other forms of investment, like government 10 -year bonds. Under these conditions would you be interested in investing in and installing a wind turbine on your land?
1
2
3
4
5

$\begin{array}{cccc}\text { Very Interested Possibly Interested } & \begin{array}{l}\text { Not Sure/ } \\ \text { Don't Know }\end{array} & \begin{array}{c}\text { Probably } \\ \text { Not Interested }\end{array} & \begin{array}{c}\text { Definitely } \\ \text { Not Interested }\end{array}\end{array}$

6. Do you perceive any barriers to installing a wind turbine on your farm? Please rank the following from 1 to 8 (with 1 being the greatest barrier to 8 the least). Write N/A next to any you don't consider to be a barrier.

Upfront cost

Getting access to the local electricity lines network

Finding a buyer for the electricity generated

Getting an adequate sale price for the electricity generated

Getting resource consent for installing the turbine

Obtaining adequate and reliable information (e.g. technical, legal, financial)

Long-term security of the investment

Adverse impact, e.g. visual, noise etc

Other, please specify... 